\title{
Computer-based nutrition education for general practice : development of a training program and effect assessment by standardized patients
}

Citation for published version (APA):

Maijburg, B. (2003). Computer-based nutrition education for general practice : development of a training program and effect assessment by standardized patients. [Doctoral Thesis, Maastricht University]. Datawyse / Universitaire Pers Maastricht. https://doi.org/10.26481/dis.20030625bm

Document status and date:

Published: 01/01/2003

DOI:

10.26481/dis.20030625bm

Document Version:

Publisher's PDF, also known as Version of record

Please check the document version of this publication:

- A submitted manuscript is the version of the article upon submission and before peer-review. There can be important differences between the submitted version and the official published version of record.

People interested in the research are advised to contact the author for the final version of the publication, or visit the DOI to the publisher's website.

- The final author version and the galley proof are versions of the publication after peer review.

- The final published version features the final layout of the paper including the volume, issue and page numbers.

Link to publication

\footnotetext{
General rights rights.

- You may freely distribute the URL identifying the publication in the public portal. please follow below link for the End User Agreement:

www.umlib.nl/taverne-license

Take down policy

If you believe that this document breaches copyright please contact us at:

repository@maastrichtuniversity.nl

providing details and we will investigate your claim.
}

Copyright and moral rights for the publications made accessible in the public portal are retained by the authors and/or other copyright owners and it is a condition of accessing publications that users recognise and abide by the legal requirements associated with these

- Users may download and print one copy of any publication from the public portal for the purpose of private study or research.

- You may not further distribute the material or use it for any profit-making activity or commercial gain

If the publication is distributed under the terms of Article 25fa of the Dutch Copyright Act, indicated by the "Taverne" license above, 
COMPUTER-BASED NUTRITION EDUCATION

FOR GENERAL PRACTICE 
The study presented in this thesis was performed at the Care and Public Health Research Institute (CAPHRI), which participates in the Netherlands School of Primary Care Research (accredited by the Royal Duth Academy of Sciences (KNAW)

Universilaire Pers Mastricht

ISBN $00-5278-377-2$

O Maiburg, Maastricht 2003

Layout and printing: Datawyse / Universitaire Pers Maastricht 


\section{COMPUTER-BASED NUTRITION EDUCATION FOR GENERAL PRACTICE}

DEVELOPMENT OF A TRAINING PROGRAM AND EFFECT ASSESSMENT BY STANDARDIZED PATIENTS

\section{PROEFSCHRIFT}

ter verkrijging van de graad van doctor aan de Universiteit Maastricht, op gezag van de Rector Magnificus, Prof. dr. A.C. Nieuwenhuijzen Kruseman volgens het besluit van het College van Decanen, in het openbaar te verdedigen op woensdag 25 juni 2003 om 14.00 uur door

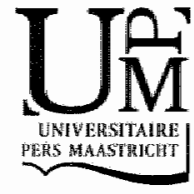




\section{PROMOTORES}

Proi. dr. J.W. wari Ree

Prof. dr. E.M.H. Mathus - Vliegen (Universiteit van Amsterdam)

CO-PROMOTOR

Dr. J).E. Rethans

\section{BEOORDELINGSCOMMISSIE}

Prof. dr. C.P.M. wan der Vleuten (voorzitter)

Prof. dr. I.F.M. Metsemakers

Dr. P. Ram

Prof. dr. ir. W.H.M. Saris

Prof. dr. C. van Weel (Katholieke Universiteit Nijmegen)

The study presented in this thesis was supported by research grants from the Dutch Sugar Bureau, the Dutch Dairy Foundation for Nutrition and Health, and the Dutch Meat Board. 


\section{CONTENTS}

CHAPTER ONE | INTRODUCTION

CHAPTER TWO THE NECTAR STUDY: DEVELOPMENT OF NUTRITION MODULES FOR GENERAL PRACTICE VOCATIONAL TRAINING; DETERMINANTS OF NUTRITION GUIDANCE PRACTICES OF GP TRAINEES

CHAPTER THREE | THE NEEDS OF GENERAL PRACTITIONERS FOR PRACTICE-ORIENTED NUTRITION EDUCATION;

A DELPHI STUDY AMONG DUTCH GENERAL PRACTITIONERS

CHAPTER FOUR | DEVELOPMENT OF A COMPUTER-BASED INSTRUCTION ON NUTRITION, SIMULATING CONSULTATIONS BY GENERAL PRACTUTIONERS

CHAPTER FIVE | FIELDING INCOGNITO STANDARDIZED PATIENTS AS "KNOWN" PATIENTS IN A CONTROLLED TRIAL IN GENERAL PRACTICE

CHAPTER SIX | CONTROLLED TRIAL OF EFFECT OF COMPUTER-BASED NUTRITION COURSE ON KNOWLEDGE AND PRACTICE OF GENERAL PRACTITIONER TRAINEES

CHAPTER SEVEN | PROGRESS OF PRACTICE BEHAVIOR IN GENERAL PRACTITIONER TRAINEES IN CONSULTATIONS WITH INCOGNITO STANDARDIZED PATIENTS WITH NUTRITION-RELATED COMPLAINTS; A CONTROLLED TRIAL OF THE EFFECT OF A COMPUTER-BASED NUTRITION TRAINING

CHAPTER EIGHT | GENERAL DISCUSSION

SUMMARY

APPENDIX

As an attachment to the back cover of this thesis the reader will find a cd-rom, composed by the author. It contains a presentation (in Dutch) of the computer-based instruction on nutrition (SIMGP Nutrition in General Practice) and a pdf-version of the thesis. 
CHAPTER ONE

INTRODUCTION 
This thesis discusses the development of a computer-based instruction on nutrition for Dutch general practitioner trainees and the assessment of its effectiveness. In the introduction to this thesis, I first try to substantiate the need for nutrition education, by discussing the role of nutrition in the vocational training and everyday practice of general practitioners (CPS). Secondly, I describe the rationale behind the decision to use computer-based instruction (CBI) as the preferred format for nutrition education. These sections then lead to the main objective and general research questions of the study. Next, this introduction discusses the specific objectives, methods and design of the development and assessment stages of the study.

The onder of the objectives in this introduction reflects the structure of the thesis. While the chapters of this thesis can be read individually, in a random sequence, reading them consecutively will provide a chronological overview of the process of development and assessment of the nutrition $\mathrm{CBI}$, although some overlap inevitably occurs between the chapters.

\section{NUTRITION IN THE VOCATIONAL TRAINING AND EVERYDAY PRACTICE OF GPS}

As early as 1983, the Dutch "Basic Job Description for the General Practitioner" designated the assessment of patients' nutritional status and eating habits, and the provision of mutrition guidance, in general as well as more specifically in cases of diabetes mellitus and hypertension, as a part of a GP'stask (1). The final report of the Dutch GP working party that designed the new curriculum for vocational training for general practice in 1986 - which was largely based on the "Basic Job Description" - even included 68. nutrition-related topics in the curriculum of GP trainees (2). A study on the medical education of Dutch GPS, published in 1989, revealed a comparable number of nutrition-related topics to be implemented in the vocational training of GPs (3). Yet, almost ten years later, the deficiency of nutrition education in both undergraduate and postgraduate medical education became apparent from a report by the Dutch Nutrition Foundation (4). This report mentioned the availability of only one course in nutrition, developed at the GP vocational training department of Utrecht University (5). Likewise, we were able to find only one national refresher course on nutrition for Dutch GPS at that time (6). Similar situations have also been reported in several other countries, and many attempts have been made to fill this gap in nutrition education $(7-16)$.

The role of the subject of nutrition in everyday GP practice in the Netherlands was investigated for the first time in 1988, in a study which tried to assess the frequency of questions about nutrition during office consultations by GPS (17). It resulted in a list of nutrition-related diseases, and the report discussed the content of nutrition education for GPs. It took until 1997 before more insight was provided into the delicate relation between GPS and nutrition guidance. It was found that patients expect a great deal from GPs in terms of nutrition guidance and that GPS are seen as the most important source of nutrition information (18). Futhermore, GPS often felt they lacked the necessary expertise to deal with patients' questions on nutrition, due to insufficient training on this 
subject 191. Furthermone, many Dutch practice guidelines for GPs, although dealing with subjects related to nutrition, pay no attention at all to nutritional advice on the subject $(20,21)$.

The discrepancy between the current very small share of nutrition education in the curriculum and the ubiquitous character of nutrition problems in everyday practice, as well as the disparity between patients' and GPS' views on nutrition guidance, have often been explained by the fact that nutrition has been generally regarded as a "soft" science (22). Secondly, the science of nutrition lacks applicability in everyday GP practice: it is. either high-level biochemistry or it is reduced to the level of tittlemtattle (MathusVliegen, 2002). It seems obvious, therefore, that there is a need for nutrition education in GP vocational training.

\section{COMPUTER-BASED INSTRUCTION AS THE DIDACTIC FORMAT OF CHOICE}

Most teachers in Dutch GP vocational training are experienced GPs, who are themselves not acquainted with nutrition topics (19). This fact induced us to search for a more or less teacher-independent format to confront trainees with patients with nutrition-related complaints and diseases, whereas the above-mentioned (Utrecht) nutrition course used a teacher-dependent method of small-group instruction as its teaching format. Furthermore, we wanted to use patient cases, as they offer excellent opportunities for contextual learning.

For these reasons, we explored the possibilities of computer simulations. We telt that adoption of this educational format would entail two further advantages: it would enhance the attraction of the topic of nutrition, which is often perceived as a rather dull subject, and it would mean the introduction of a new learning method in the vocational training of Dutch GPs.

In 1971, Harless gave a detailed description of the CASE system (23), which can be regarded as the precursor of many types of computerised patient simulations (24). In the 1990 s, the value of computer-based instruction (CBU became generally established and accepted: students who attended a CBI course learned as much as those who took the paper and pencil version, and in most cases, the CBI students needed less time to learn (25-27). In 1995, Friedman clearly outlined the choices to be made in the development of simulations, especially with regard to the structure of this kind of CBI (24). Reeves pointed out the pedagogical dimensions of CBI which have to be taken into account when developing computer-based education (28). At the same time, several authors mentioned the opportunities offered by computer technology for nutrition education $(29,30)$. A series of CD-ROMs on clinical nutrition was published by Zeisel's group (31), and other authors followed suit (32).

In the Netherlands, several initiatives have been taken to develop computer-based instruction for medical education. In addition to a neurology teaching program with computerised patient cases (33), two other programs using simulations had recently been developed when we started our study. One, the "dynamic patient simulator", was 
developed at Leiden, and mainly focussed on emergency medicine (34), while the other, "clinical simulations", on the subject of the locomotor system, originated at Maastricht (35). We decided to use the Maastricht "clinical simulations" as the starting point for our attempt to develop a computer simulation on the subject of nutrition for general practice.

\section{MAIN OBJECTIVE OF THE STUDY AND GENERAL RESEARCH QUESTIONS}

Based on the above considerations about the need for nutrition education in GP vocat:onal training, and our decision to use clinical simulations as the didactic format, we formulated the main objective of our study as follows: to enhance the knowledge, skills and attitude of Dutch GP trainees on the subject of nutrition by means of computer-based instruction. To achieve this main objective, we conducted a two-stage study. The first stage involved the development of a program simulating the nutrition aspects of general practice, while stage two assessed its effectiveness. Each stage of the study generated its own general research question:

1. What is the best way to develop a simulation of the nutrition aspects of general prac-

tice, taking into account the required standard educational components of course development?

2. To what extent does the newly developed simulation program improve the competence and performance of GP trainees?

We operationalised these general questions into several specific objectives, as described in the next two sections, which discuss the development and assessment of the CBI. We introduced the acronym NECTAR (Nutrition Education by Computerized Training and Research) for the study as a whole.

\section{THE DEVELOPMENT STAGE OF THE NECTAR STUDY: OBJECTIVES, METHODS AND DESIGN}

Opting for computer simulation as the didactic format of the nutrition course addressed onlly one of the educational components (i.e. choosing the didactic format) which should be taken into account in course development. After having examined various models of course construction $(36,37)$, we decided to study two important educational components in the development stage of our CBI: assessing the baseline situation (i.e. the existing range of knowledge, skills and attitudes) on the subject of nutrition among. GP trainees, and designing the educational content of a nutrition CBI.

As regards the assessment of the basel ine situation on the subject of nutrition among GP trainees, we were unable to retrieve useful information about this component from the semi-annual Dutch national knowledge test for GP trainees, nor was any previous research available on the skills or attitudes of trainees on the subject of nutrition. As we ultimately wanted to enhance the performance of trainees, we planned to assess the baseline situation in terms of determinants of nutrition guidance practices. Although 
these determinants have been previously assessed among practicing GPS $(38)$, we considered it too much of a simplification to extrapolate these findings to GP tratnees: These considerations generated the first specific objective of the NECTAR study:

To identify determinants of nutrition guidance practices of GP trainees in order to reveal educational directions for the development of the nutrition $\mathrm{CBI}$.

We addressed this objective in a cross-sectional study by sending a slightly changed version of the Wageningen GPs Nutritional Practices Questionnaire (39) to all Dutch trainees. The outcomes of this questionnaire study and its implications for education on nutrition are discussed in chapter two of this thesis.

The second purpose was to design the educational content of the nutrition CBI. The easiest way to accomplish this would have been to copy the directives given by several authors or authorities on this issue $(7-9,17)$. As these directives, however, had various practical drawbacks - being too comprehensive without ranking topics in terms of priority, or not reflecting the Dutch situation - we preferred to base the course content on the needs of practicing Dutch GPs for nutrition education. We formulated the objective of this element of our study as follows:

To draw up a concise priority list of nutrition topics reflecting the needs of Dutch GPS for nutrition education, geared to everyday practice, which can be used to decide on the main topics and educational content of computer-based instruction.

This second objective was met by performing a two-round Delphi study (40) among Dutch GPs, using newly developed, pilot-tested questionnaires. Chapter three of this thesis describes the Delphi study and its results, and its consequences for the program to be developed.

While the above studies, the outcome of which mainly dictated the content of the nutrition $\mathrm{CBI}$, were still in progress, we started to design our new simulation of GP consultations, taking into account the suggestions made on this subject by several prominent authors $(24,28,41)$. This led us to the third objective:

To describe the various stages of development of the nutrition CBI, the ultimate structure and content of the program, and the didactic principles incorporated in it.

In developing the simulation, we worked closely together with an educational technologist (A. Koehorst), who had also contributed to the development of the above-mentioned "clinical simulations" at Maastricht University. This part of the NECTAR study is presented in chapter four of this thesis. 


\section{THE ASSESSMENT STAGE OF THE NECTAR STUDY: OBJECTIVES, METHODS AND DESIGN}

In addition to an effectiveness assessment of the competence of trainees by means of a knowledge test at the "knows" level (42), we also opted for an assessment of their performance - defined as the way doctors actually handle their patients in their professional practice (43) - to address the "does" level of assessment $(42,44)$. The steps to be taken in the construction of a knowledge test intended to assess factual knowledge have been clearly described by several authors (45-47). Assessment of practice behaviour, however, requires a so-called direct method of performance assessment (48). Incognito standardized patients (SPs) visiting the GP's practice have been regarded as the "gold standard" in this type of evaluation (49-51).

Two issues regarding the use of SPs in practice have remained rather poorly documented so far. The first is the methodology of the deployment of incognito SPS as a measuring instrument in trials. The few available trials of this type have only marginally addressed this issue (51-53), in contrast to many cross-sectional studies (54-61). The second problem is that of SPs faking to be "known" patients (i.e. patients who have previously visited the same practice). As far as we know, such "known" patients have never been used before, as it is much simpler to introduce SPs as new patients $(55,61)$. However, we fielded our SPs as "known" patients in a controlled trial, since many of the practices involved in our study did not accept new patients. Because of these two rather special features of our SPS as measuring instruments, we formulated the following, fourth objective of the NECTAR study:

To establish the feasibility of introducing SPs as "known" patients into practices, to indicate the practice preparations required to do so, and to describe the various aspects of using $\mathrm{SP}_{5}$ in a triall (pretest/posttest design).

The development and deployment of our $S P$ s are described in chapter five of this thesis. In assessing the effectiveness of our newly developed CBI, we restricted ourselves to the following two objectives relating to competence and performance assessment, and representing the fifth and sixth objectives of the NECTAR study:

To determine the degree to which GP trainees' factual knowledge of nutrition improves as a result of the CBI (competence) and

To examine whether the nutrition $\mathrm{CBI}$ improves the adequacy of consultations performed by GP trainees in real practice with patients with nutrition-related complaints (performance).

We carried out a controlled trial to assess the effectiveness of our newly developed nutrition CBI. We used experimental groups (which attended the CBI during and in addition to their vocational training programme) and control groups (which merely took the regular vocational training programme), and applied a pretest/posttest format 
(testing before and after our educational intervention, i.e. the CBD. We used group randomisation of four trainee groups included in the trial to compose the experimental and control groups. Logistic reasons prevented us from allocating trainees to groups at random.

In order to achieve the fifth and sixth objectives, we submitted trainees to a 79-item written knowledge test and sent three incognito SPs to the GP practices where they worked during regular consultation hours, in the pretest as well as in the posttest. Chapter six addresses the overall effects of our nutrition CBI on the factual knowledge and practice behaviour of GP trainees, whereas chapter seven focuses on the content specificity of the various nutrition-related problems simulated by SPS, the consistency of consultations by trainees (in terms of nutrition-based consultation categories) and the content of nutritional advice given by trainees.

Finally, chapter eight discusses the findings reported in the various chapters and puts these into perspective. A summary concludes the thesis.

\section{REFERENCES}

1. Dutch National Association of General Practitioners. Basic job description for the general practitioner. Utrecht: Dutch National Association of General Practitioners; 1983.

2. Dutch College of General Practitioners. The construction of a new curriculum of wocational training for general practice in the Netherlands. Utrecht: Dutch College of General Practitioners: 1987.

3. Tan LHC. Tekorten in de opleiding van huisartsen (Deficiencies in medical education of general practitioners). Amsterdam: University of Amsterdam; 1989 (in Dutch).

4. Dutch Nutrition Foundation. Huisarts en voeding (General practitioner and nutrition). The Hague: Dutch Nutrition Foundation, 1997 (in Dutch).

5. Buijs $G$, Almekinders $F$, Stasse-Wolthuis $M$, Schadé $E$, Schretlen $E$, Steenmetz $Y$. Onderwijsprogramma Voeding (Nutrition course). Utrecht: Department of General Practice, University of Utrecht; 1988 (in Dutch).

6. Büller HA, Mathus-Vliegen EMH, van Staveren WA. Voedingsproblematiek per levenslase (Nutrition problems related to different stages of live). Amersfoort: Benecke Consultants; 1997 (in Dutch).

7. Report of the American Medical Student Association's Nutrition Curriculum Project. Essen. tials of nutrition education in medical schools: a national consensus. Am J Clin Nutr $1997,65(5): 1559-61$.

8. American Academy of Family Physicians. Nutrition: recommended curriculum guidelines for family practice residents. June 2000 . Internet: http://www aafp.org/x $16543 . \mathrm{xml}$ (accessed 19 February 2003).

9. The Group on Nutrition, Society of Teachers of Family Medicine. Physician's curriculum in clinical nutrition: primary care. 2nd ed, 2001. Internet: hitp//www.stfm.org/pdfs/ GrouponNutrition.pdf (accessed 18 February 2003).

10. Contento I, Balch GI, Bronner $\mathrm{YL}$, et al. The effectiveness of nutrition education and implications for nutrition education policy, programs, and research: a review of research. I Nutr Educ $1995 ; 27(6): 279-83$. 
11. Deen $\mathrm{D}$ Ir, Karp $\mathrm{R}$, Lowell B. A new approach to nutrition education for primary care physicians in the United States. I Gen Intern Med 1994,907):407-8.

12. Helman A. Nutrition and general practice: an Australian perspective. Am I Clin Nutr $1997 ; 65$ (6 Suppl): $1939 \mathrm{~s}-42 \mathrm{~s}$.

13. Michener JL. Nutrition, education, and family physicians. Arch Fam Med 1997;6(2):146-7.

14. Murphy PS. Effect of nutrition education on nutrition counseling practices of family physicians. Acad Med 1989;64(2):98-102.

15. Ritenbaugh $C K$, Thomson $C A$, Taren $D$, ef al. Nutrition curricullum in medical education: an integrated and comprehensive approach. Teach Learn Med 1996;8(2):102-10.

16. Young EA, Weser $\mathrm{E}$, McBride HM, Page CP, Littlefield JH. Dewelopment of core competencies in clinical nutrition. Am J Clin Nutr 1983;38(5):800-10.

17. van Dusseldorp $M$, Meeuws $H$, van Kessel $H$, Mendriks $L$, Chin L, Bakx C. Frequentie van voedingsviragen op het spreekuur van de huisarts (The frequency of questions about nutrition during office consultation). Ned Tijdschr Geneeskd 1988;132(51)2325-8 (in Dutch).

18. Hiddink $G$, Hautwast $J G_{x}$ van Woerkum $C M$, Fieren $C_{\text {, wan }}$ 't Hof MA. Consumers' expectations about nutrition guidance: the importance of primary care physicians. Am I Clin Nutr 1997;65(6 Suppl): 1974s-9s.

19. Hiddink GJ, Hautvast JG, van Woerkum CM, Fieren CJ, van 't Hof MA. Nutrition guidance by primary-care physicians: perceived barriers and low involvement. Eur I Clin Nutr $1995 ; 4$; $9(11): 842-51$.

20. Thomas S, Geijer RMM, van der Laan $\| R$, Wiersma $T$ (eds). NHG-Standaarden voor de huisarts (Practice guidelines for the general practitioner). Utrecht: Wetenschappelijke uitgeverij Bunge; 1996 (in Dutch).

21. van Binsbergen J), Drenthen AI. ICPC-code approach of nutritional questions in general practice: a look at the future. Eur J of Clin Nutr 1999;5315uppl 2):522-4.

22. Mathus-Vliegen EMI-H. Nutrition as the Cinderella of medical training. Pract East Mediterr Ed $1994 ; 5: 699$.

23. Harless WG, Drennon GG, Marxer J, Root JA, Miller GE. CASE: a computer-aided simulation of the clinical encounter. I Med Educ 1971;46(5):443-8.

24. Friedman CP. Anatomy of the clinical simulation. Acad Med 1995;70(3):205-9.

25. Cohen PA, Dacanay LS. Computer-based instruction and health professions education: a meta-analysis of outcomes. Eval Health Prof 1992;15(3):259-81.

26. Fletcher-Flinn $\mathrm{CM}_{4}$ Gravatt $\mathrm{B}$. The efficacy of computer assisted instruction (cai): a metaanalysis. J Ecluc Comput Res 1995;12(3);219-42.

27. Kulik CLC, Kullik IA. Effectiveness of computer-based instruction: an updated analysis. Comput Hum Behav 1991;7(1-2):75-94.

28. Reeves TC. Evaluating what really matters in computer-based education. November 1997. Internet: htp://wwweducationau.edu.au/archives/cp/reeves.htm laccessed 18 February 2003).

29. Beerman KA. Computer-based multimedia: new directions in teaching and learning. I Nutr Educ 1996:28(1):15-8.

30. Kolasa KM, Miller MG. New developments in nutrition education using computer technology J Nutr Educ 1996:28(1):7-14.

31. Kohlmeier $M$, Althouse $L$, Stritter $F$, Zeisel SH. Introducing cancer nutrition to medical students: effectiveness of computer-based instruction. Am J Clin Nutr 2000;71(4):873-7.

32. Kolasa KM, Jabe AC, Miller MG. Images of Cancer Prevention. Greenville: East Carolina University; 1996. 
33. Weverling Gl, 5tam I, ten Cate T], van Crevel H. Computerondersteund onderwis voor het leren oplossen van neurologische problemen: een gerandomiseerd onderwijskundig onderzoek (Computer-assisted education in problem-solving in neurology" a randomized educational study). Ned Tijdschr Geneeskd 1996, 140(8):440-3 (in Dutch).

34. Bloemendaal PM, Baalen wan JM, Vergeer MJP. The development of a Dynamic Patient Simulator. In: Eight International Ottawa Conference; Philadelphia; 1998.

35. Koehorst AM, Ronteltap CFM. An enviromment for the developiment and presentation of computerized cases to learn diagnostic reasoning. In: Scherpbier AAJA, van der Vleuten CPM, Rethans 1), van der Steeg AJW (eds). Advances in medical education. Dordrecht: Kluwer Acadenic Publishers; 1997:769-73.

36. Het model wan beknopte didaxologie (The model of concise didaxology). In: De Corte $\mathbb{F}_{\text {, }}$ Geerligs CT, Lagerweij NAI, Peters II, Vandenberghe $\mathbb{R}$ (eds). Beknopte didaxologive. Groningen: Wolters-Noordhoff; 1981:18-9 (in Dutch).

37. Gerligs $T$, Snellen-Ballendong HAM. Cursusconstructie (Course construction). In: Metz JCM, Scherpbier AJJA, van der Vleuten CPM (eds). Medisch onderwijs in de praktijk. Assen: Van Gorcum; 1995:283-98 (in Dutch).

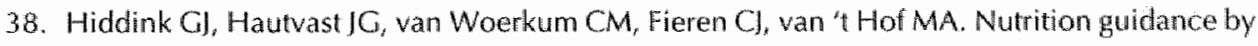
primary-care physicians: LISREL analysis improves understanding. Prev Med 1997;26(1): $29-36$.

39. Hiddink GJ. Determinants of nutrition guidance practices of primary-care physicians. Wageningen: Wageningen Agricultural University; 1996.

40. Delbecq AL, van de Ven AH, Gustatson DH. The Delphi technique. In: Group techniques for program planning. Glenwiew: Scott, Foresman and Company; 1975:83-107.

41. Lyon HC Jr, Healy JC, Bell JR, et all. PlanAlyzer an interactive computer assisted program to teach clinical problem solwing in diagnosing anemia and coronary artery disease. Acad Med 1992;67(12):821-8.

42. Miller GE. The assessment of clinical skills/competence/performance. Acad Med 1990;6519 Suppl):S63-7.

43. Rethans IJ, Norcini IJ, Barón-Maldonado $\mathrm{M}$, et al. The relationship between competence and performance: implications for assessing practice performance. Med Educ 2002:36:901-9.

44. Ram PM. Comprehensiwe assessment of general practitioners, Maastricht: Madastricht University; 1998.

45. Bordage $G$, Brailovsky C, Carretier H, Page G. Content walidation of key reatures on a national examination of clinical decision-making skills. Acad Med 1995;70(4):276-81.

46. Page $G$, Bordage $G$, Allen T. Developing key feature problems and examinations to assess clinical decision-making skills. Acad Med 1995;70(3): 194-201.

47. van leeuwen YD. Growth in knowledge of trainees in general practice. Maastricht: Maastricht University: 1995

48. Rethans J), Westin S, Hays R. Methods for quality assessment in general practice. Fam Pract $1996 ; 13(5): 468-76$.

49. Gorter SL, Rethans J1, Scherpbier AlJA, et al. How to introduce incognito standardized patients into outpatient clinics of specialists in rheumatology. Med Teach 2001;23:138-44.

50. Rethans IJ. Does competence predict performance? Maastricht: Mas astricht University; 1991.

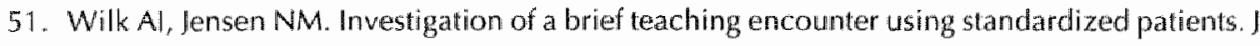
Gen Intern Med 2002;17(5):356-60. 
52. Cascheer LL. Klapow IC, Centor RM, al. An intervention to inciease physicians' use of adherencemenhancing strategies in managing hypercholesterollemic patients. Acad Med $1999 ; 74(12): 1334-9$.

53. Gerrity MS, Cole SA, Dietrich AI, Barrett JE. Improving the recognition and management of depression: is there a role for physician education? I Fam Pract 1999;48(12):949-57.

54. Brown IA, Abelson I, Woodward CA, Hutchison B, Noman G. Fielding standardized patients in primary care settings: lessons from a study using unannounced standardized patients to assess preventive care practices. Int ! Qual Health Care 1998; 10(3):199-206.

55. Carney PA, Dietrich AJ, Freeman DH, Mott LA. A standardized-patient assessment of a continuing medical education program to improve physicians' cancer-control clinical skills. Acad Med 1995;70(1):52-8.

56. Dolan NC, McGrae MC, Dermott M. Using unidentified standardized patients to evalluate housestaff delivery of preventive services. Teach Learn Med 1997;9(1):60-5.

57. Grad R, Tamblyn R, Mcleod PI, Snell L, Illescas A, Boudreau D. Does knowledge of drug prescribing predict drug management of standardized patients in office practice? Med Educ $1997 ; 31(2): 132-7$.

58. O'Hagan $\mathrm{Jl}$, Botting $\mathrm{CH}$, Davies $\mathrm{L}$. The use of a simulated patient to assess clinical practice in the management of a high risk asthmatic. NZ Med J 1989;102:252-4.

59. Russell NK, Boekeloo BO, Raf: IZ, Rabin DL. Using unannounced simulated patients to evaluate sexual risk assessment and risk reduction skills of practicing physicians. Acad Med $1991 ; 66$ (9 Suppl):S37-9.

60. Tamblyn RM, Grad R, Gayton D, Petrella L. Reid T, Groupo MDUR. Impact of inaccuracies in standardized patient portrayal and reporting on physician performance during blinded clinic visits. Teach Learn Med 1997;9(1):25-38.

61. Woodward CA, McConvey GA, Neufeld V, Norman GR, Walsh A. Measurement of physician performance by standardized patients. Refining techniques for undetected entry in physicians ${ }^{*}$ offices. Med Care 1985;23(8):1019-27. 
THE NECTAR STUDY: DEVELOPMENT OF NUTRITION MODULES FOR GENERAL PRACTICE VOCATIONAL TRAINING; DETERMINANTS OF NUTRITION GUIDANCE PRACTICES OF GP TRAINEES NECTAR study: development of nutrition modules for general practice vocational training; determinants of nutrition guidance practices of GP trainees. Eur J Clin Nutr 1999;53:S83-8. 


\section{ABSTRACT}

Objective to dentify determinants of nutrion guidance practices of general practitioner trainees (CP trainees), to investigate whether these determinants difter from those found by experienced generat practitoners, to reveal educational directions towards the development of computerbased instruction on nutrition.

Design Cross-sectional study by means of validated questionnaires.

Subjects All GP ranees in traning at the eight university deparments for wocational training in the Netherlands in September, $1998 \quad n=$ 9851.

Man outcome Reliability of determinants of nutrition gudance practices was measures calculated by means of Cronbach's alpha. The mechanism of action of deteminants was identified by means of linear structural relationship analysis (LSREL) using a model developed for Cips.

Results Crombach's alphas for factors ranged from 0.58-0.90. The empirical GP trainee data fitted with the corresponding GP model on the mechanism of action.

Conclusions The same predisposing factors, driving forces and barriers as found with GPS were identified with GP trainees, Comparing the GP and GP tranee models, only minor differences were found in the path coofliciens beween factors. Lack of nutrition training and education proved to be of great influence on the extent of nutrition information given. The CP tratnee model will be of use in developing computer-based instruction on mutrition. It is expected that GP may also benefit from this instruction. 


\section{INTRODUCTION}

General practitioners (GPs) are seen by patients as an important source of nutrition information (1). Lack of nutrition training and education among Dutch GPs has been assessed in previous investigations (2). This lack not only forms a barrier perceived by GPs, but also acts as a barrier to the extent of nutrition education and information given by GPs (3). As has been stated by the Dutch Nutrition Foundation, nutrition topics are rarely found in the basic medical education curricula as well as in the curricula of the University Departments for Vocational Training in the Netherlands (4). Experienced GPs in the field of nutrition education are rarely found in the faculties of Dutch voca* tional training departments. Because the role of nutrition in health and disease is obvious, it is stated more frequently that nutrition training and education of GPs is necessary and should be present in the curriculum of vocational training.

Based on our initiative to change this situation, in April 1997 the NECTAR study (Nutrition Education by Computerized Training and Research) was started at Maastricht University. The main objective of the NECTAR study is to enhance the knowledge, skills and attitudes of Dutch GP trainees in the field of nutrition by means of computer-based instruction on nutrition $(5,6)$. To achieve this, a computer-based instruction on nutrition has first to be developed (the development phase of the NECTAR study). Secondly, the effects of this instruction on nutrition will be assessed by means of a randomised controlled trial (the experiment phase of the NECTAR study).

Before jumping to the construction of educational materials (the computer-based instruction), two investigations were performed in the development phase of the NECTAR study to gather basic educational information. A Delphi procedure (7) among Dutch GPs was carried out to determine the content of the computer-based instruction on nutrition. This investigation will be reported on separately. The second investigation, a questionnaire conducted among all Dutch GP trainees, is presented in this paper.

Objectives of the questionnaire study in the development phase of the NECTAR study were:

- to identify determinants of nutrition guidance practices of GP trainees;

- to investigate whether these determinants differ from those found among experienced GPs.

We hypothesised that the GP model of the mechanism of action of determinants (predisposing factors, driving forces and barriers) found in previous studies (3), would also apply to GP trainees.

As the analysis of the questionnaire was expected to give direction towards the development of educational material (the computer-based instruction), we attempted to interpret this analysis from an educational point of view. Questions at the educational level are:

- do GP trainees wish for any form of nutrition education?

- what lessons can be learned from the identified determinants of nutrition guidance practices of GP trainees? 


\section{METHODS}

The study was designed as a cross-sectional study. The GP tranee questionnaire was. distributed among all GP trainees $(n=985)$ by the eight University Departments of Vocational Traming in the Netherlands in September 1998. In this way the total population of GP trainees (in all stages of their training) received the questionnaire, which was based on the Wageningen GPs Nutrition Practices Questionnaire. This GP questionnaire has been used and validated in cross-sectional and longitudinal investigations to determine the determinants of nutrition guidance practices of Dutch GPs (8, 9). To develop the GP trainee questionnaire, the originall GP questionnaire was slightly modified: terminology was adapted to suit GP trainees and two questions were added. One question concerned general impediments to nutrition guidance practices, while another question focused on the curriculum of the vocational training course.

After the initial personal letter and questionnaire, a follow-up letter was distributed by the departments two weeks later. After another two weeks, CP trainees were reminded by their GP trainers (10). The questionnaire could be completed anonymously.

As a first step in the analysis of the questionnaire, we computed determinants of nutrition guidance practices of GP trainees by using items from the questionnaire as pointed out by Hiddink (3) and measured reliability of these factors. Secondly, we used LISREL model analysis as the analysis of choice $(3,11)$ to obtain a GP trainee model of the mechanism of action of these determinants (12). The same nutrition guidance practices as tested in the GP study ("extent of nutrition education and information" and "noticing patients" overweight and guidance of treatment") were tested as dependent variables in this study (3). The variable "extent of nutrition education and information" was scored in one question on a 5-point Likert-type scale, ranging form "not at all" to "very intense". The variable "noticing patients" overweight and guidance of treatment" was operationalised in six items (Cronbach's alpha $=0.59$ ). One item addressed the percentage of patients in whom the GP trainee notices their weight. Five items were about guidance of treatment: three concerning the discussion of problems related to overweight and two concerning the extent of the advice.

\section{STATISTICS}

Factors were defined as sums of items, as pointed out by Hiddink (3), standardised for scale width. Gronbach's alpha was used as an indication of reliability of computed factors. Skewed distributions were normalised by square root transformation. Correlations were studied using Pearson's correlation test.

To identify the mechanism of action of determinants of the dependent variables, LISREL path analysis was used (Program version 8.14 ). When the conditions of low residuals, all t-values of effects $>2$, and an acceptable $Q$ plot of all standardised residuals were fulfilled, the LISREL solution was accepted. Chi-square, P-value, and adjusted goodness of fit index (AGFI) are presented to indicate the quality of the model. 


\section{RESULTS}

\section{RESPONSE}

Of all 985 GP trainees, 575 responded to the questionnaire: 215 males and 353 females (7 did not fill in sex). Fourteen GP tranees could not be reached for different reasons, so the net response rate was 59\%. The responding GP trainees were well distributed across the three years of the wocational training program, with a slight under-participation of second-year-trainees. The mean ( \pm s.d.) age of the participants was 31 ( \pm 3.5$) \mathrm{y}$. The mean practice list of their GP trainer was 2600 . The GP trainees saw 20 patients a day on average (range: 2 - 40 patients). The mean consultation-time was 13 min (range: 8 $38 \mathrm{~min})$.

The 575 respondents were well representative of the population of GP trainees according to sex, age (related to the data received form the National Bureau for General Practice Vocational Training) and year of vocational training (data received from the vocational training departments).

Because of the anonymous design of the questionnaire, it was impossible to contact non-responders. We therefore statistically computed trends in answering the questionnaire by correlating the GP trainee number (which reflects the moment of returning the questionnaire) with several questions and all factors derived from the questionnaire. With the exception of age (older GP trainees were more likely to return the questionnaire at a later moment), no significant trends were found in answers given.

\section{HEALTH PROMOTION PERCEPTION}

Of the G.P trainees, $72 \%$ claimed to be interested in the contribution of diet to health and $26 \%$ said they were "neutral" in this respect. Dutch GP trainees confirmed that they saw the provision of nutrition information (98\%) as a part of their task. However, they perceived their tasks in nutrition information to be more directed to secondary or tertiary prevention ( $87 / 96 \%$ positive answers) rather than to primary prevention (57\% positive answers).

In a two-item question, GP trainees were asked to score the importance of giving attention in the curriculum to general nutrition topics as well as to disease-related nutrition topics. The general nutrition topics were scored as important or very important by $75 \%$ of the GP trainees; and $89 \%$ of the GP trainees scored disease-related nutrition topics as an important or very important part of the curriculum.

When GP trainees were asked to fill in information on their experiences in practice, they reported an incidence of once or wice a day of patients who have a complaint related to nutrition. The number of patients who received nutrition education or information from the GP trainees was fewer than one a day on average. Of GP trainees, $76 \%$ reported that they regularly contact dieticians or refer patients to them. 


\section{DETERMINANTS OF NUTRITION GUIDANCE PRACTICES: \\ PREDISPOSING FACTORS, DRIVING FORCES AND PERCEIVED BARRIERS}

Table 1 shows the properties of determinants computed from the questionnaire. The fourteen determinants of nutrition guidance practices could be divided into predisposing factors, driving forces and perceived barriers. The four predisposing factors were revealed by the analysis of focus-group discussions and in-depth interviews with GPs in previous investigations (8). Driving forces were derived from questions regarding attitudes towards specific nutrition topics and general task perception. Perceived barriers were constructed from questions concerning impediments to nutrition information and education in general and in the case of overweight in particular. Of these 14 factors, six have a high Cronbach's alpha (> 0.70) and four have a moderate Cronbach's alpha $(0.58-0.65)$. The other four factors are based on one question.

\section{NUTRITION GUIDANCE PRACTICES "EXTENT OF NUTRITION EDUCATION AND INFORMATION" AND "NOTICING PATIENTS" OVERWEIGHT AND GUIDANCE OF TREATMENT" (DEPENDENT VARIABLES)}

In the Methods section we mention how the nutrition guidance practice "extent of nutrition education and information" was scored in the questionnaire. For analysing this practice as a dependent variable in a GP trainee model of determinants of nutrition guidance practices, 11 factors were used in the LISREL path analysis (Table 1). These factors contain the same set of predisposing factors, driving forces and perceived barriers as the GP model (3).

The hypothesis that the GP model for this dependent variable would also apply to GP trainees could be confirmed because the LISREL program provided a model with an excellent fit. The empirical GP trainee data fit with the GP model (Chi-square $\mathrm{di}=25=$ $35.7 ;$ P value $=0.08$ ); the $A G F I=0.97$. The percentage of explained variance in "extent of nutrition education and information" by the LISREL model is $25 \%$.

To obtain the GP trainee model (Figure 1), the same set of predisposing factors, driving forces and perceived barriers were used as in the GP model. Four main differences have been found in the mechanism of action of these factors (the path coefficients), being: the predisposing factor "interest in the effect of nutrition on health and disease" only acts via driving forces; the predisposing factor "perception of own ability to influence lifestyle and eating habits of patients with health problems" also acts on a barrier; the predisposing factor "perception of own ability to give dietary advice in the treatment and prevention of coronary heart disease" has no direct effect on the dependent variablle; the barriers "lack of time to treat overweight" and "lack of skills to treat overweight" also act via driving forces.

In Figure 2 the values of the highest path coefficients in the GP trainee model are shown. It reveals that the predisposing factor "perception of own ability to give dietary" 
Table 1 Computed determinants of nutrition guidlance practices of GP trainees, used in the LSREL path analysis of "extent of nutrition education and information" $(\mathrm{A})$ and of "noticing patients ovenveight and guidance of treatment" (B)

Description Item" Alpha ${ }^{2}$ Analysis

Predisposing factors

Interest in the effect of mutrition on health and disease Perception of role of behaviour and heredity on health Perception of own ability to give dietary advice in the treatment and prevention of coronary heart disease (= self-efficacy factor) Perception of own ability to influence lifestyle and eating habits of patients with thealth problems (- self-efficacy factor)

$\begin{array}{ccc}1 & - & A, B \\ 7 & .71 & A, B \\ 2 & .78 & A, B \\ & & \\ 2 & .90 & A, B \\ & & \\ 24 & .60 & A, B \\ 5 & .58 & A, B \\ 1 & - & A \\ 1 & - & B\end{array}$

Perceived barriers

Lack of time to treat overweight

Lack of skills to treat overweight

Lack of nutrition training and education

Lack of patient motivation to reduce overweight

$\begin{array}{lll}2 & .65 & \text { A, B } \\ 5 & .75 & \text { A, B } \\ 4 & .73 & \text { A } \\ 2 & .79 & \text { B }\end{array}$

Dependent variables

Extent of nutrition education and information

Noticing patients' overweight and guidance of treatment

1

A

6

59

$B$

1 Number of items constituting a factor; 2 Cronbach's alpha, an indication of reliability of factors.

advice in the treatment and prevention of coronary heart disease" and the barrier "lack of skills to treat overweight" firmly act through the barrier "lack of nutrition training and education". The barrier "lack of nutrition training and education" stands out because of the value of the path coefficient between this barrier and the outcome variable. This last value is obviously higher than the one found in the CP study (3).

The operational isation of the nutrition guidance practice "noticing patients' overweight and guidance of treatment" is mentioned in the Methods section. To analyse this practice as a dependent variable in a GP trainee model of determinants of nutrition guidance practices, 11 factors were used in the LISREL path analysis (Table 1). These factors contain the same set of predisposing factors, driving forces and perceived barriers as in the corresponding GP model. The hypothesis that the GP model for this dependent variable would also apply to GP trainees could be confirmed because the LISREL program provided a model with an excellent fit. The empirical GP trainee data fit with the GP 


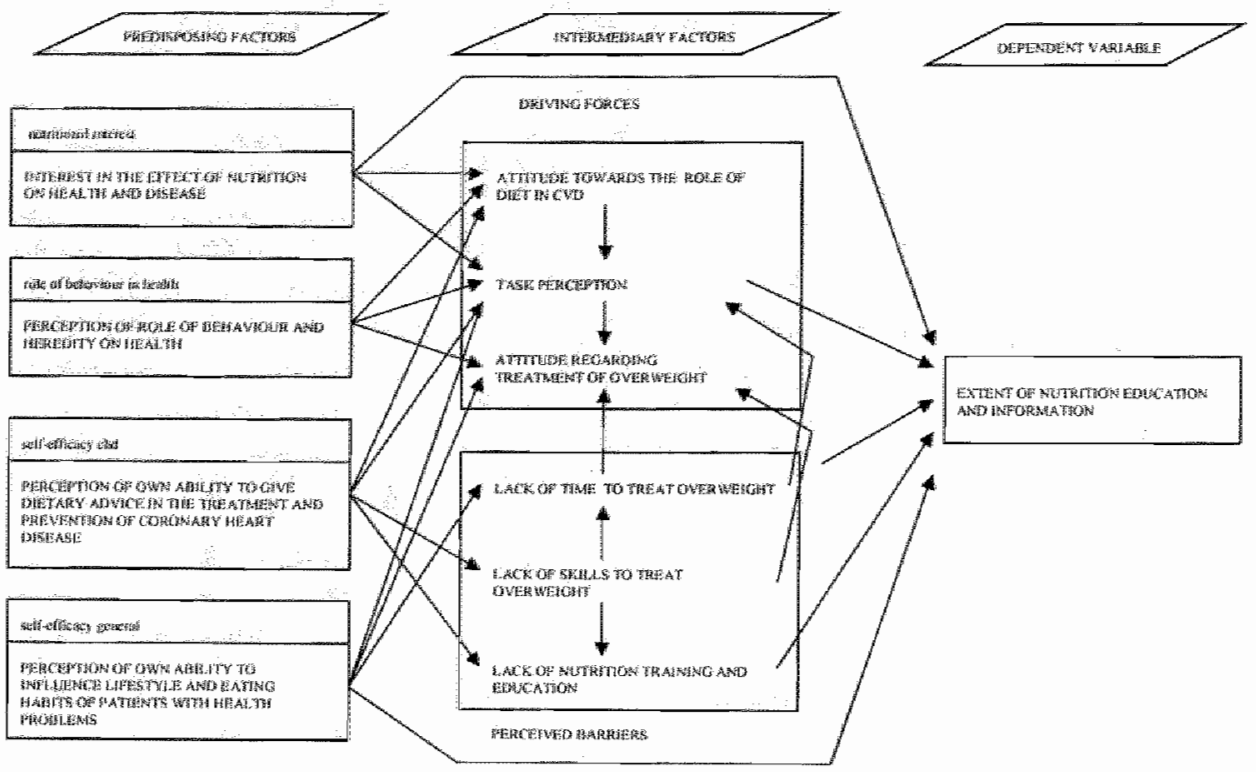

Figure 1. GP trainee model of mecluanism of action of determinants of "extent of nutrition education and information".
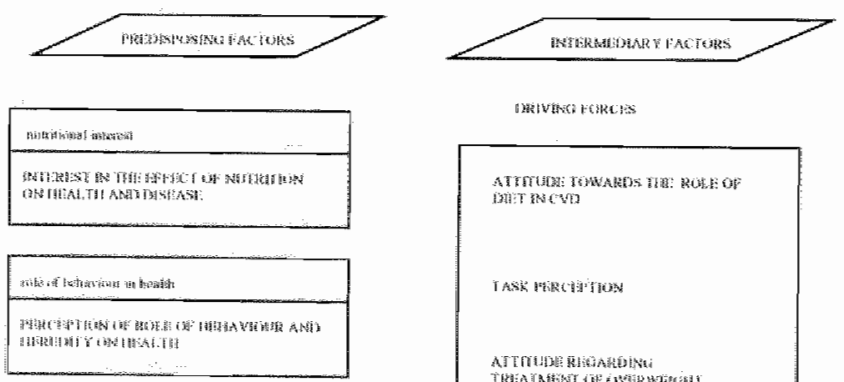

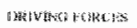
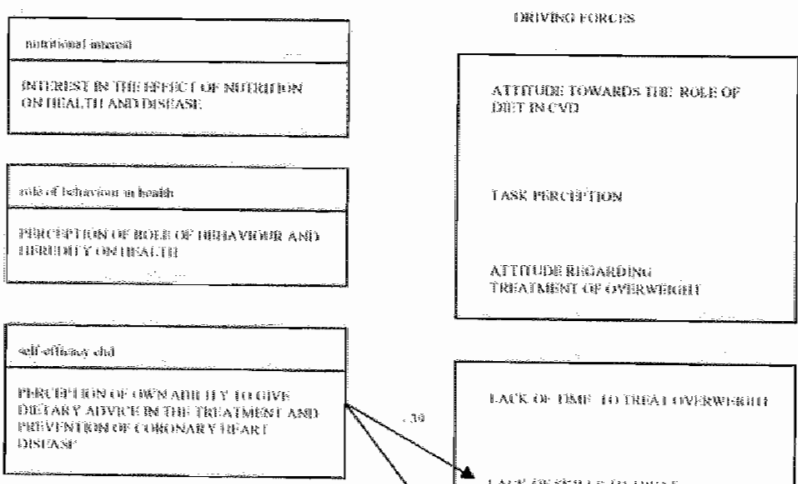

\section{wh whac kent}

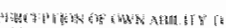

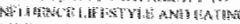

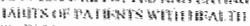

[t:

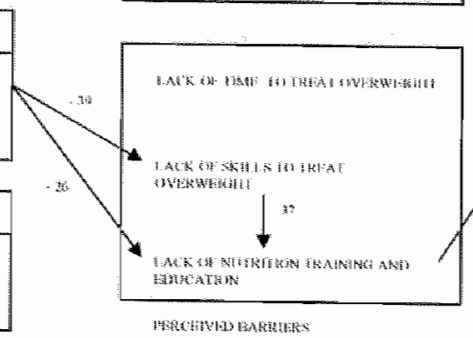

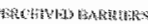

Figure 2. Highest path coefficients (vallues shown) in the GP trainee model of variable "extent of nutriton education and information". 


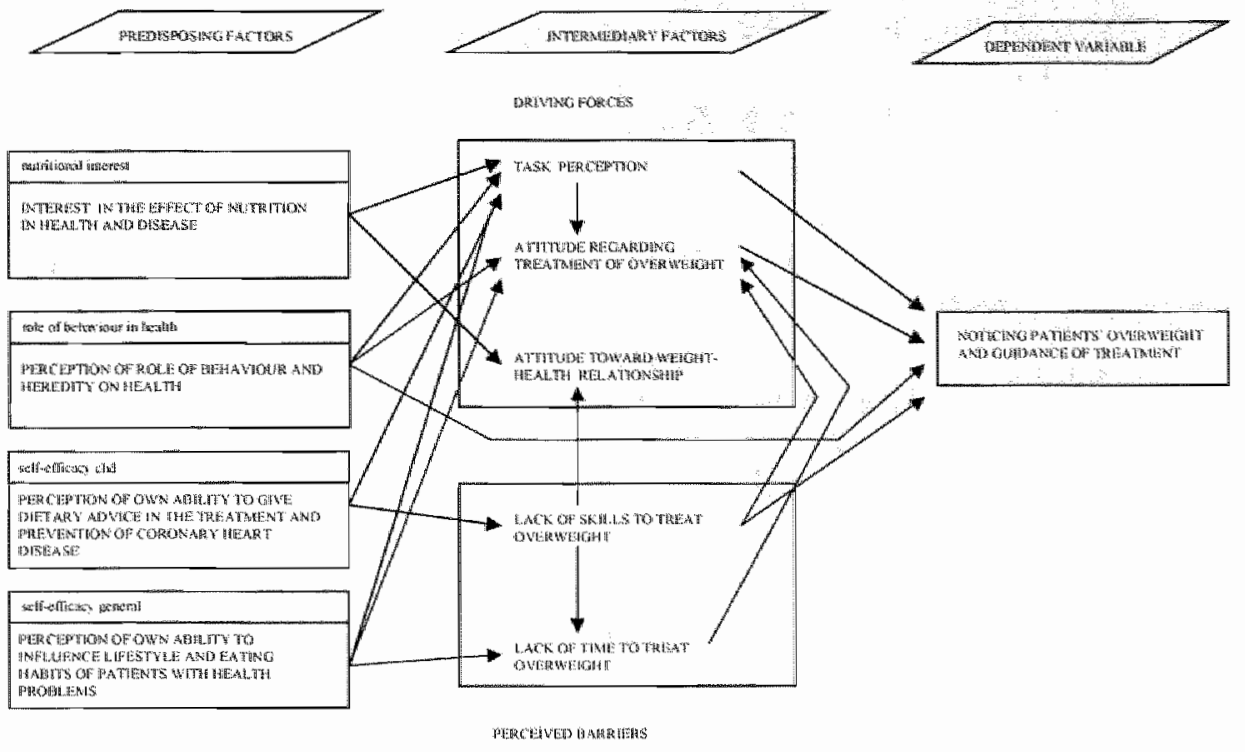

Figure 3. GP trainee model of mechanism of action of determinants of "noticing patients"overweight and guidance of treatment.

model (Chi-square $\left.\mathrm{df}_{21}=26.1 ; P_{\text {-value }}=0.20\right) ;$ the $\mathrm{AGFI}=0.98$. The percentage of explained variance in "noticing patients' overweight and guidance of treatment" by the LISREL model is $15 \%$.

To obtain the GP trainee model (Figure 3), the same set of predisposing factors, driving forces and perceived barriers as with the GP model were used. Attempts to build an even better model by inserting other factors in the GP model did not work. The three main differences found in the mechanism of action of these factors, are: the predisposing factor "perception of own ability to influence lifestyle and eating habits of patients with health problems" also acts on a barrier, the barrier "lack of skills to treat overweight" acts on several driving forces and, in addition, acts directly on the dependent variable.

\section{DISCUSSION}

The determinants of nutrition guidance practices of GP trainees were studied by means of a questionnaire which was distributed to all Dutch GP trainees. The response rate of $59 \%$ can be called rather high (2).

One of the educational questions we wanted to be answered by the acquired data was: do GP trainees actually wish for any form of nutrition education? The data on the interest of GP trainees in the issue of influence of nutrition on health in general, and 
those on the importance they attribute to nutrition topics in the curriculum of vocational training suppose that the answer must be positive.

It is obvious that we must take into account socially desirable answers in completing a questionnaire, but this effect will be minimised by the anonymous design of the study. When the curriculum is seen currentiy to fail to contribute to nutrition education of GP trainees, GP trainees certainly seem to be aware of this deficiency in the curriculum. As awareness is generally accepted as a first step necessary for change in behaviour (13), this step seems to have been taken.

When we can assume a willingness of $\mathrm{CP}$ trainees to pursue nutritional issues more rigorously in their practice, the next question is: what impedes them from doing so? What barriers do they encounter? The reported incidence of patients who have complaints related to nutrition is low related to the incidence reported by $G P_{S}$ and the Dutch Nutrition Foundation (2, 4). This is presumably due to trainees' insufficient skills in identifying nutrition issues in many problems presented by patients. This lack is likely to impede nutrition education and information given by GP trainees. From an educational point of view, it seems that it would be wise to insert the issue of the identification of nutrition topics with patients in the computer-based instruction on nutrition to be developed. Even when GP trainees do identify nutritional issues in the complaints of their patients, they seem to be incapable of handling or unwilling to handle these issues, according to the high referral rate to clieticians as reported in the questionnaires.

Four barriers perceived by GP trainees could be revealed by factor analysis (Table 1). These perceived barriers were used in the LISREL analysis to see whether they also act as a barrier. With the exception of the perceived barrier "lack of patient motivation" all barriers did act as a barrier. Concerning the perceived barriers "lack of nutrition training" and "lack of skills to treat overweight", our expectations were confirmed, because of the absence of nutrition topics in the curricula of both basic medical education and Dutch Vocational Training Departments. As GP trainees have more opportunities to take their time with their patients, it was surprising that the barrier "lack of time to treat overweight" acts as a barrier. It supposes that GP trainees experience nutrition education as time-consuming. For the computer-based instruction to be developed, this means that an easy-to-do strategy on nutritional matters should be used.

Like these barriers, the predisposing factors and driving forces revealed in previous studies among Dutch GPs (3) are all retrieved in the NECTAR study. Even more appealing is the fact that the mechanism of action of these CP trainee factors, determined by LISREL analysis, complies largely with the corresponding GP model of both nutrition guidance practices; differences are smail, compared with the total model. We inserted other factors in the GP model in an attempt to enhance the fit of the data, but this only worsened the fit of the data in this way. We can therefore state that GP trainees are very similar to experienced GPs as far as nutrition guidance is concerned. Because of this relationship between GPs and GP trainees, we conclude that computer-based instruction which affects the nutrition guidance practices of GP trainees will also be beneficial for experienced GPs. 
What have we learned from the elaborated GP trainee model so far from which elements can be used in constructing the computer-based instruction on nutrition? The outcome of the LISREL analysis primarily emphasises the need of nutrition training and education of GP trainees, because "lack of nutrition training and education" acts as a major barrier to the extent of nutrition education and information given by GP trainees. Furthermore, it shows which factors will or can be influenced by the computer-based instruction. In general, it is stated that the best possible outcome will be obtained by strengthening of predisposing factors and driving forces and minimising of barriers in the GP trainee model ( 8 ). The strongest path coefficients in the GP trainee model of the dependent variable "extent of nutrition education and information", concern the predisposing factor "perception of own ability to give dietary advice in the treatment and prevention of coronary heart disease" and the barriers "lack of skills to treat overweight" and "lack of nutrition training and education". This suggests that nutrition training and education of GP trainees on the subjects hypercholesterolemia and obesity is of great importance. Adding these nutrition subjects to the content of the computer-based instruction should result in minimising another barrier and strengthening the predisposing factor. On the whole, it is likely that "task perception" as a driving force will be strengthened through the completion of the computer-based instruction on nutrition. Thus, if the computer-based instruction does what it is expected to do, one could call it a multi-level approach from the point of view of the GP trainee model.

By using LISREL model analysis we were able to identify determinants of nutrition guidance practices of GP trainees. The same determinants as those found among GPs were retrieved in our study. The mechanism of action of these factors differed onlly slightly from the mechanism found in the GP model. These findings, in fact, make the model as developed for GPs more solid.

Many educational clues with relation to the development of the computer-based instruction on nutrition were revealed. The challenge of future research will be to prove that nutrition guidance practices of GP trainees (especially the extent of nutrition education and information) will be positively changed by completing the computer-based instruction on nutrition.

\section{REFERENCES}

1. Hiddink Gl, Hautvast JG, van Woerkum CM, Fieren Cl, van 't Hof MA. Consumers' expectations about nutrition guidance: the importance of primary care physicians. Am I Clin Nutr 1997;65(6 Suppl):19745-9s.

2. Hiddink Gl, Hautvast IG, van Woerkum CM, Fieren CJ, van ' 1 Hof MA. Nutrition guidance by primary-care physicians: perceived barriers and low involvement. Eur 1 Clin Nurr $1995 ; 49(11): 842-51$.

3. Hiddink Gl, Hautvast IG, van Woerkum CM, Fieren Cl, van 't Hof MA. Nultition guidance by primary-care physicians: LISREL analysis improves understanding. Prev Med 1997;26(1): $29-36$. 
4. Dutch Wutrition Foundation. Huisarts en voeding (General practitioner and nutrition). The Hague: Dutch Nutrition Foundation, 1997 (in Dutch).

5. Kolasa KM, Miller MG. New developments in nutrition education using computer technology. I Nutr Educ 1996;28(1):7-14.

6. Cohen PA, Dacanay LS. Computer-based instruction and health professions education: a meta-arallysis of outcomes. Eval Health Prof 1992,15(3):259-81.

7. Delbecq AL, wande Ven AH, Custafson DH. The Delphi technique. In: Group techniques for program planning. Gilenview: Scott, Foresman and Company; 1975:83-107.

8. Hiddink Gl, Determinants of nutrition guidance practices of primary-care physicians. Wageningen: Wageningen Agricultural University; 1996.

9. Hiddink Gl, Hautvast $\mathrm{IG}$, van Woerkum $\mathrm{CM}$, van 't Hof MA, Fieren $\mathrm{Cl}$. Cross-sectional and longitudinal analyses of nutrition guidance by primary care physicians. Eur J Clin Nutr $1999 ; 53$ ( Suppl 2):535-43.

10. Dillman DA. Mail and telephone surweys, The total design method. New York: Wiley; 1978.

11. Jöreskog KG, Sörbom D. LISREL VIl: a guide to the program and applications. 2 nd ed. Chicago: SPSS inc; 1989.

12. Green LW, Kreuter MW. Health promotion planning. An educational and environmentall approach. 2 nd ed. Mountain View: Mayfield Publishing Company; 1991.

13. Pathman DE, Konrad TR, Freed GL. Freeman VA, Koch GG. The awareness-tomadherence model of the steps to clinical guideline compliance. The case of pediatric vaccine recommendations. Med Care 1996;34(9):873-89. 
THE NEEDS OF GENERAL PRACTITIONERS FOR PRACTICE-ORIENTED NUTRITION EDUCATION; A DELPHI STUDY AMONG DUTCH GENERAL PRACTITIONERS

Submitted as: The needs of general practitioners for practice-oriented nutrition education; a Delphi study among Dutch general practitioners.

Bas HI Maiburg, Jan-Joost E Rethans and Jan W van Ree. 
ABSTRACT

Backeround Publshed guldelines and lists of topics in nutrition education for general pratifioners (GPs) are affected by practical drawbacks. which prevent them from being easily implemented in vocational training curricula.

Objective To draw up a concise prionty list of disease-related nutrition topics refecting the needs among Dutch general practitioners for nutrition education geared to everyday practice, which can be used to decide on the main topics and educational content of computer-based instruction.

Design Two-round Delphistudy, using pilot-tested questionnaires.

Setting General practice in the Netherlands.

Subjects 41 CPs who altended a national CME meeting on mutrition.

Main outcone

measures

Results Response in boty Delphi rounds was high 193 and $95 \%$. Anatysis of questionnaires in boh rounds yielded a priority list of disease-related nutrition topics, with the fourteen highest ranking topics idertical in both rounds. A fifteenth topic, only found in the second questionnaire, completed the priority list. A group of experts assessed this list as fully acceptable.

Conclusions It was possble to compile a priority list of disease-related nutrifion topics reflecting the needs of GPS for nutrition education. Based on the results of the Delph study, we generated the following list of five prionty topics: weight problems, diabetes mellus, hyerchotesterolemia, intestinal complaints and hypertension. This list of five and the summarised comments of respondents will detemine the main topics and educatonal content of computer-based instruction we are currendy developing. 


\section{INTRODUCTION}

The past decade has seen the publication of several guidelines for and lists of topics in nutrition education for general practitioners ( $G P S)$ or general practitioner trainees, to be implemented in the curriculum of GP vocational training (1-4). These guidelines are affected to a varying degree by practical drawbacks, which means they cannot be easily implemented in current vocational training curricula. Firstly, since there is - within the limited curriculum of GP vocational training - a particular need for a concise list of the main disease-related nutrition topics, the guidelines published so far are too comprehensive $(2,5)$. Secondly, the guidelines seem to be based on the opinions of expert clinicians and expert GPs with a clearly defined field of interest in nutrition, and so probably do not reflect the needs of general practitioners in everyday practice care (4). Thirdly, from a "national appropriateness" point of view, several publications do not refer to the Dutch situation, making them less useful for Dutch GPs (1).

In the Netherlands, the need for postgraduate nutrition education has re-emerged after recent research showed that patients: questions on nutrition and food tend to be preferentially addressed to GPs, who are seen by patients as the major and most reliable source of nutrition guidance (6). At the same time, however, it has been found that $\mathrm{CP}_{\mathrm{s}}$, as well as GP trainees, feel impeded by a lack of training and education in nutrition $(7$, 8). GP trainees have also indicated the necessity of introducing disease-related nutrition topics in the vocational training curriculum (8).

To overcome the above practical limitations of published guidellines, a project was initiated whose main goal was the compilation of a concise priority list of disease-related nutrition topics, reflecting the needs of Dutch general practitioners for nutrition education geared to everyday practice. It was believed that such a practice-oriented list would prove to be a useful starting point for implementing nutrition topics in vocational training curricula and for deciding on the educational content of a computer-based instruction on nutrition currently under development at the Department of GP Vocational Trai. ning of Maastricht University.

\section{METHODS}

Since we wanted to prepare a consensus list of the most important nutrition-related topics in general practice and find any disease-related nutrition topics that had so far been overlooked, a Delphi study among Dutch GPs seemed the preferred method (9). The Delphi method is generally accepted as a powerful means of reaching consensus and generating ideas among respondents. Briefly, the method involves sending a questionnaire to the respondents and analysing their response. This is then used to develop a new questionnaire and the cycle is repeated. Three methodological aspects are important in a Delphi study. Firstly, respondents are not aware of the identity of the other respondents, to ensure that their responses are independent. Secondly, participants 
respond individually to avoid group domination by certain individuals. Thirdly, mathematical voting procedures are used which permit the ranking of items. A two-round procedure was considered sufficient, since a comprehensive list of disease-related nutrition topics was already available (10). Our main Delphi question was: which disease-related nutrition topics are needed for a practice-oriented nutrition education for GPs? The procedure was carried out in the period from June to September, 1998. A panel of about thirty GP respondents was considered sufficient for our objective, i.e. generating topics for nutrition education. GPs were recruited by telephone from the list of participants to a national refresher course on nutrition (11). Since such nutrition courses are organised very rarely, the GPs were expected, from their attendance at this course, to be at least interested in the subject of nutrition in general, without being experts on a specific nutrition topic.

In the first Delphi round, respondents received a pilot-tested questionnaire comprising 77 nutrition topics. These topics were derived from a comprehensive list of disease-related nutrition topics in general practice compiled by the Dutch Nutrition Foundation (3) which, in turn, was based on the guidelines of the Dutch College of General Practitioners (12). The description of some topics was slightly modified to obtain a consistent list of diseases and complaints. Respondents. were asked to comment on all items in terms of acquaintance, importance and clarity, and to select the ten most important topics (top-10) for GP nutrition education. Although a comprehensive list of disease-related nutrition topics was used, respondents were invited to add their own topics. Participants to the study were twice reminded by telephone to complete the questionnaire. The questionnaires returned were analysed by summarising the comments on each item and scoring the topics selected by respondents (by awarding ten points to the top item in each top-10, nine points to the second item and so on to one point for the tenth item). The frequency with which each topic occurred in the respondents' top-10 lists was also assessed.

On the basis of the findings, a 39-item list was compiled for the second Delphi-round. Thirly-five items were retained from the first questionnaire by deleting those items that had been mentioned fewer than three times in the top-10 lists. Comments on all items to be deleted were analysed by the researcher before removal for any important observations which would justify retaining the items. Four new items mentioned by responclents were added. The second-round questionnaire was constructed by listing the 39 items, their scores and summarised comments from the first Delphi round. Respondents were again asked to comment on all items and to select their final top-10. If necessary, they were twice reminded by telephone to complete the questionnaire. The analysis of the second questionnaire was identical to that of the first. The 39 disease-related nutrition items were ranked by their sumscores and by the percentage of respondents who had mentioned each item.

The findings of the second Delphi round were finally presented to a small panel of experts including an experienced GP, a professor of general practice and a professor of 
clinical nutrition. They were asked to evaluate the face validity of the lanking of the topics in the list generated from the analysis of the second Delphi questionnaire.

\section{RESULTS}

\section{RESPONDENTS}

Fifty GPS who had attended a CME meeting on nutrition were eligible for inclusion in the study. Of these CPs, 41 agreed to participate in the Delphi study. Four CPs were unable to participate because of holidays during the study period or lack of experience in general practice. Only five GPs refused to take part. Among the 41 GPs thus recruited, seven were women. About half of the 41 GPs $(n=21)$ worked in an urban setting, the other half in a more rural setting.

\section{FIRST DELPHI ROUND}

Of the 41 respondents, $38(93 \%)$ returned the first questionnaire on time. These 38 GPs were to represent the panel of respondents for the second Delphi round. Table 1 shows the 14 highest-ranking items from the first questionnaire, together with their frequency of occurrence in the top-10 lists sent in by respondents (displayed as the percentage of respondents who mentioned the item). The "syndrome $X$ "item was not included in the list of items in the first questionnaire, but was mentioned by several respondents who felt it had to be added in the second questionnaire.

\section{SECOND DELPHI ROUND}

The response to the second questionnaire was $95 \%$ ( 36 of 38 respondents). The 15 items shown in Table 1 represent the 15 highest-ranking items from this 39-item questionnaire. These are shown together with their sumscores and the percentage of respondents who mentioned each item in their top- 10 list. Irrespective of the way items were ranked (by sumscore, percentage of respondents or both sumscore and percentage), the same cluster of 15 highest-ranking items emerged.

It should be noted that these 15 items correspond exactly to those found in the first Delphi round, except of course for "syndrome X". Furthermore, these 15 items (from the total of 39) represent $88 \%$ of all scores given to the items selected in the respondents' top-10 lists.

The comments on the thopics in both questionnaires could be assigned to the following five categories: social importance, incidence/prevalence, influence of nutritional change, cooperation with dieticians and item overlap. Respondents suggested combining the items "irritable bowel syndrome" and "chronic constipation/haemorrhoids/anal fissure" into one item: "intestinal complaints". 
Table 1 Highest-ranking nutrition items from two Delphi rounds, ranked by percentage of respondents who mentioned the item in their top-10 in second round fround 1: 77-item questionnaire, round 2: 39 -itern questionnaire)

\begin{tabular}{|c|c|c|c|}
\hline \multirow[b]{2}{*}{ Nutrition topic } & \multicolumn{2}{|c|}{ Round 2} & \multirow{2}{*}{$\begin{array}{l}\text { Round } 1 \\
\text { Respondents (\%) } \\
(n=38)\end{array}$} \\
\hline & $\begin{array}{c}\text { Respondents }(\%) \\
\quad n=36)\end{array}$ & Sumscore? & \\
\hline 1. Diabetes mellitus & 91 & 280 & 69 \\
\hline 2. Hypercholesterolemia & 91 & 259 & 71 \\
\hline 3. Obesity & 80 & 190 & 58 \\
\hline 4. Inritable bowel syndrome & 71 & 138 & 52 \\
\hline 5. Chron. constipation/haemorm/anal tissure & 69 & 91 & 52 \\
\hline 6. Eating disorders/loss of weight/overweight & 60 & 112 & 60 \\
\hline 7. Hypertension & 54 & 97 & 27 \\
\hline 8. Infant food allergy & 54 & 83 & 66 \\
\hline 9. Prevention (in generall) & 51 & 109 & 27 \\
\hline 10. Elderly people (in general) & 46 & 64 & 22 \\
\hline 11. Acute and chronic diarhoea & 43 & 63 & 33 \\
\hline 12. Syfadrome $x$ & 31 & 74 & - \\
\hline 13. Food allergy & 31 & 57 & 44 \\
\hline 14. Osteoporosis & 29 & 41 & 27 \\
\hline 15. Gastric complaints & 23 & 31 & 25 \\
\hline
\end{tabular}

1: scores derived from top-10 lists drawn up by respondents tno. 1 awarded ten points, no. 2: nine points and so on to one point for no. 10 ).

\section{MEETING OF EXPERTS}

The participants to the meeting of experts qualified the ranking of the nutrition-related topics that had emerged from the Delphi study as fully acceptable. They assessed the list of the 15 highest ranking nutrition-related topics as highly relevant to GPs in everyday care. They proposed the introduction of the item "weight problems" to replace the items "obesity" and "eating disorders/loss of weight/overweight".

\section{DISCUSSION}

The objective of this sludy was to develop a concise priority list of disease-related nutrithon topics reflecting the needs of GPs for nutrition education geared to everyday praclice. Alter the proposals made by respondents and experts for the integration of items had been implemented, we were able to compile a concise list of disease-related nutrition topics. It includes the following lop-5 of most important nutrition-related topics in general practice: weight problems, diabetes mellitus, hypercholesterolemia, intestinal complaints and hypertension. Although these topics can also be found in existing comprehensive guidelines for nutrition education $(1,2)$, the added advantage of the 
new list is the ranking of topics. The selection differs from the content of a previously developed Dutch nutrition course (4).

From the point of view of nutrition education, it is interesting that this top-5 covers the main categories of nutrients and energy equilibrium (carbohydrates in diabetes mellitus; fats in diabetes mellitus and hypercholesterolemia; fibres in intestinal complaints and diabetes mellitus; minerals in hypertension; energy in weight problems). Together with the summarised comments made by the respondents in our Delphi study, the top-5 list will be used as a basis for the content of a computer-based instruction on nutrition currently under development at Maastricht University.

We feel that the high participation rate among the GPs invited for this Delphi study and the high response rate in both rounds reflect the interest in and attention to nutritional matters among the participants. In our view, this kind of general interest and attention justifies giving serious consideration to the topics in the Delphi questionnaire. If we had opted for nutrition experts as respondents, this would not only have been difficult to achieve, because such experts are scarce among GPs, but would also entail the danger of focusing attention on their expert subjects. On the other hand, inviting interested GPs to participate, as we did, may have led to an underestimation of the importance of certain nutrition topics due to a lack of knowledge about nutrition among these GPs (13).

The question may be raised whether the respondents were biased in their selection of a top-10 of topics by their attendance at the CME meeting on nutrition. For example, the high ranking of the item "infant food allergy" in the first Delphi round could be attributed to this topic being one of the subjects at the CME meeting. In view of its score in the second Delphi round, any such effect seems to have waned over time, although it should be noted that respondents in this round were presented with a reduced pool of items from which they could select their final top- 10 .

The lists of highest-ranking items emerging from the two Delphi rounds included exactly the same disease-related nutrition topics. Since these items also represented approximately $90 \%$ of all scores, it may be concluded that there was a very high level of consistency in the respondents' choice of items: as a group they selected only a limited number of items for their top-10 lists. We therefore consider the results of this Delphi study to be reliable.

We also consider the results to be representative of the total group of 41 participants in the Delphi study, in view of the high response rate in both rounds. As mentioned in the methods section, the size of this panel of respondlents in a Delphi studly ensured that it was a powerful instrument for generating the nutrition topics we were looking for. Nevertheless, it is not possible to generalise the results of the present study to the total population of GPs. Although the sex ratio among respondents corresponds closely to the national figures (14) and the participating GPS were well distributed over urban and rural settings, the group of GPs included was recruited from among the limited number of GPs who attended the national CME meeting on nutrition. However, we feel that the results of the present study are likely to represent the opinion of those GPS who are interested in the subject of nutrition. 
In conclusion, we were able to compile the intended concise list of disease-related nutrition topics using the Delphi method. Because the list is prioritised, it provides a useful indication of the topics that should be successively implemented in GP training curricula.

We thank all 41 GPs for their contrbution wo this sudy.

\section{REFERENCES}

1. The Group on Nutrition, Society of Teachers of Family Medicine. Physician's curriculum in clinical nutrition: primary care. 2nd ed, 2001. Internet: http:/www. stfm.org/pdfs/Groupon Nutrition.pdf (accessed 18 February 2003).

2. American Academy of Family Physicians. Nutrition: recommended curriculum guidelines for family practice residents. June 2000. Internet: http://www.aafp.org/ $16543 \times \mathrm{m} /$ laccessed 19 February 2003).

3. Dutch Nutrition Foundation. Huisarts en woeding (General practitioner and nutrition). The Hague: Dutch Nutrition Foundation, 1997 (in Dutch).

4. Buijs G, Almekinders F, Stasse-Wolthuis M, Schadé E, Schretlen E, Steenmetz Y. Onderwijsprogramma Voeding (Nutrition course) Utrecht: Department of General Practice, Uniwersity of Utrecht, 1988 (in Dutch).

5. Mularski RA. Essentials of nutrition education in medical schools: a national consensus. Am I Clin Nutr 1997;65(5):1559-61.

6. Hiddink Gl, Hautwast JG, van Woerkum CM, Fieren $\mathrm{Cl}$, van 't Hof MA. Consumers' expectations about nutrition guidance: the importance of primary care physicians. Am I Clin Nutir 1997;65(6 Suppl): 1974s-9s.

7. Hiddink GI, Hautwast JG, van Woerkum CM, Fleren Cl, van "t Hof MA. Nutrition guidance by primary-Care physicians: LISREL analysis improves understanding. Prev Med 1997;26(1): 29-36.

8. Maiburg HI, Hiddink Gl, van 't Hof MA, Rethans Il, van Ree JW. The NECTAR study: development of nutrition modules for general practice vocational training; determimants of nutrition guidance practices of GP trainees. Eur \Clin Nutr 1999;53(Suppl 2):S83-8.

9. Dunn WR, Hamilton DD, Harden RM. Techniques of identifying competencies needed of doctors. Mad Teach 1985;7(1):15-25.

10. Delbecq All, van de Ven AH, Gustarson DH. The Delphi techniquen: In: Group techniques for program planning. Glenview: Scott Foresman Co., 1975:83-107.

11. Büller HA, Mathus-Vliegen EMH, van Staveren WA. Voedingsproblematiek per levensfase (Nutrition problems related to different stages of life). Amersfoort: Benecke Consultants, 1997 (in Dutch).

12. Thomas $S$, Geijer RMM, van der Laan IR, Wiersma T (eds.). NHG-Standaarden voor de huisarts (Practice Guidelines for the general practitioner). Utrecht: Wetenschappelijke uitgeverij Bunge, 1996 (in Dutch).

13. Comel M. Detection of problem drinkers in general practice. Maastricht: Maastricht University, 1994.

14. Hingstman L. Cijters uit de registratie van huisartsen (Figures from GP registration). Utrech: Netherlands Institute of Health Services Research, 1998 (in Dutch). 
DEVELOPMENT OF A COMPUTER-BASED INSTRUCTION ON NUTRITION, SIMULATING CONSULTATIONS BY GENERAL PRACTITIONERS

Submitted as: Development of a computer-based instruction on nutrition, simulating consultations by general practitioners.

Bas HJ Maiburg, André M Koehorst, Yvonne D van Leeuwen, Lisbeth MH MathusVliegen and Jan $W$ van Ree. 


\section{ABSTRACT}

Background General practitioners (GPs) and trainees are insufficienty prepared to give advice on matlers related to nutrition. We developed and assessed a computer simulation of GP consultafions or this subject and revealed distinct effects on competence and performance of trances during a controlled tral.

Objactive To describe the stages of development of computer-based instruction on mutrition, the ultimate structure and content of the program, and the didactic principles incorporated in it.

Development Together with a reference group of CPS, we developed a simulaHon consisting of a consulation and debriefing part, taking into account the directives for continuing medical education and many pedagogic dimensions of simulations. The structure of the computer consultation closely resembles that of a real GP consultation and is presented as individual screens per consultation phase in a menu-request format. Videos are used in the consultation and debrieting parts. We chose the Dutch food guide to delineate the main domain of the simulation, designed the general framework of items for the consultation phase screens and drafted nutritional background information for the items, assisted by an expert panel. Based on the literature and the panel faedback, we cleveloped 12 disease-related cases with lifelike videos of the consultation and assigned scores to all ifems, reflecting their importance.

Conclusion A multidisciplinary approach allowed us to develop a mullpotentid mutrition program with proven effectiveness. The program provides an attractive method to study nutrition. which seems to meat individual diferences in learning syle. Suggestions are made for turther exlension and improvement of the program. 


\section{INTRODUCTION}

Over the past five years, we have developed a new computer-based instruction on nutrition and have assessed its effectiveness among general practitioner trainees. A recently conducted controlled trial has shown that our computer-based instruction (CBI) provides a distinct improvement in both factual knowledge and practice behavior of trainees on the subject of nutrition (1).

In developing our nutrition program, we chose computer simulations as the didactic format, because of its teacher-independent nature. We expected this format to overcome the frequently cited problem of lack of faculty knowledgeable in the field of nutrition (2). We also preferred this innovative educational method because it would meet the demand for programs that allow self-tuition by trainees, which are becoming more and more prominent in GP vocational training. We were aware of the fact that a Dutch paper-and-pencil nutrition program, intended for (teacher-dependent) small-group instruction, had failed to become incorporated in GP vocational training curricula (3). On the basis of several meta-analyses on $C B I$, we expected computer simulations to be at least as effective as traditional learning and to provide a faster mode of learning than paper-and-pencil programs $(4,5)$. The need for a nutrition course had become apparent from previous research among general practitioners (GPs) and GP trainees, showing. that both groups perceive themselves to be deficient in providing nutrition guidance to their patients, largely due to a lack of nutrition education $(6,7)$.

Before we proceeded to design our nutrition CBI, we conducted two studies into two important elements of course development. Firstly, we assessed the baseline situation (i.e. the existing range of knowledge, skills and attitudes) on the subject of nutrition among GP trainees, by sending a questionnaire to all Dutch GP trainees. This inventory revealed that trainees were greatly interested in nutrition and that they preferred disease- and patient-related nutrition education (7). Secondly, we carried out a Delphi study among Dutch CPs, in order to decide on the content recuired for a nutrition CBI. This study yielded a top-five list of nutrition topics, reflecting the needs of Dutch CPs for nutrition education geared to everyday practice (Maiburg, Rethans, van Ree, 1998).

Using the above findings and starting from the available Maastricht "clinical simulations" - a CBI about the locomotor system, meant for undergraduate medical education (8) - we proceeded to design the new nutrition $\mathrm{CBI}$, a simulation of general practice called SIMGP Nutrition in General Practice. The objective of the present paper is to describe the various stages of development of the nutrition $\mathrm{CBI}$, the ultimate structure and content of the program, and the didactic principles incorporated in it.

\section{DEVELOPMENT}

We distinguished three stages in the development of the nutrition program: designing the non-content format of the simulation of GP consultations, defining the nutrition 
domain to be incorporated, and developing the individual cases for the program. The following sections describe the approach used and the outcome of each stage of development.

\section{SIMULATING GP CONSULTATIONS}

As mentioned above, the non-content part of the new nutrition CBI (SIMGP) was based on a program previously developed at Maastricht University by a team headed by Ronteltap (8). We redesigned the program for the purpose of continuing medical education (CME) of GPS and GP trainees, and for implementation through the World Wide Web. To meet the needs and expectations of these targets groups, we took the following precautions."

1. An expert in the field of GP vocational training contributed to the design of the general format of the simulation.

2. We carried out a comparative requirements analysis, using several existing interactive clinical systems, and a usability study, using a prototype version of the SIMGP program, among a group of practicing GPs who were interested in CME over the World Wide Web.

3. An evaluation session was held with three experts in the field of nutrition, the topic selected for the content of the program.

4. Feedback on a prototype program was obtained from many informal presentations to colleagues and interested parties.

Based on the outcome of the above actions, we finally constructed a simulation which is divided into two main phases, the consultation and the debriefing. The general structure of the SIMCP program is shown in Figure 1. The structure of the computer-simulated consultation closely resembles the general structure of a real GP consultation (9). This feature of the program offers opportunities for contextual learning and meets the demand for disease-and patient-related education ( 7 ).

In the SIMGP program, the GP or trainee starts the computer simulation by clicking on a patient presented in the waiting room screen. This action produces the patient record, containing a one-page synopsis of the patient's history. In order to enhance the level of reallism, this patient history is presented on an exact copy of a well-known rype of patient chart. Next, the exploration of the reason-for-encounter is shown on video (Figure 2a). We chose to volunteer the information for this part of the consultation (10), as it is extensively taught in other parts of the curriculum of GP trainees (9). However, this video promotes the contextual character of the simulation and serves as an anchoring point for the debriefing. After the reason-for-encounter video, the user actually starts to interact with the presented patient in separate screens for the individual components of the consultation: history taking, physical examination, laboratory testing and therapy (9). The user sellects actions by means of key words (items) which are visible on the screen (i.e. menu request for data) (10). For each action, the program can provide context-free background information in "pop-up" screens (Figure $2 \mathbf{b}$ ). This information is the same for a specific item throughout all consultations in a chosen 


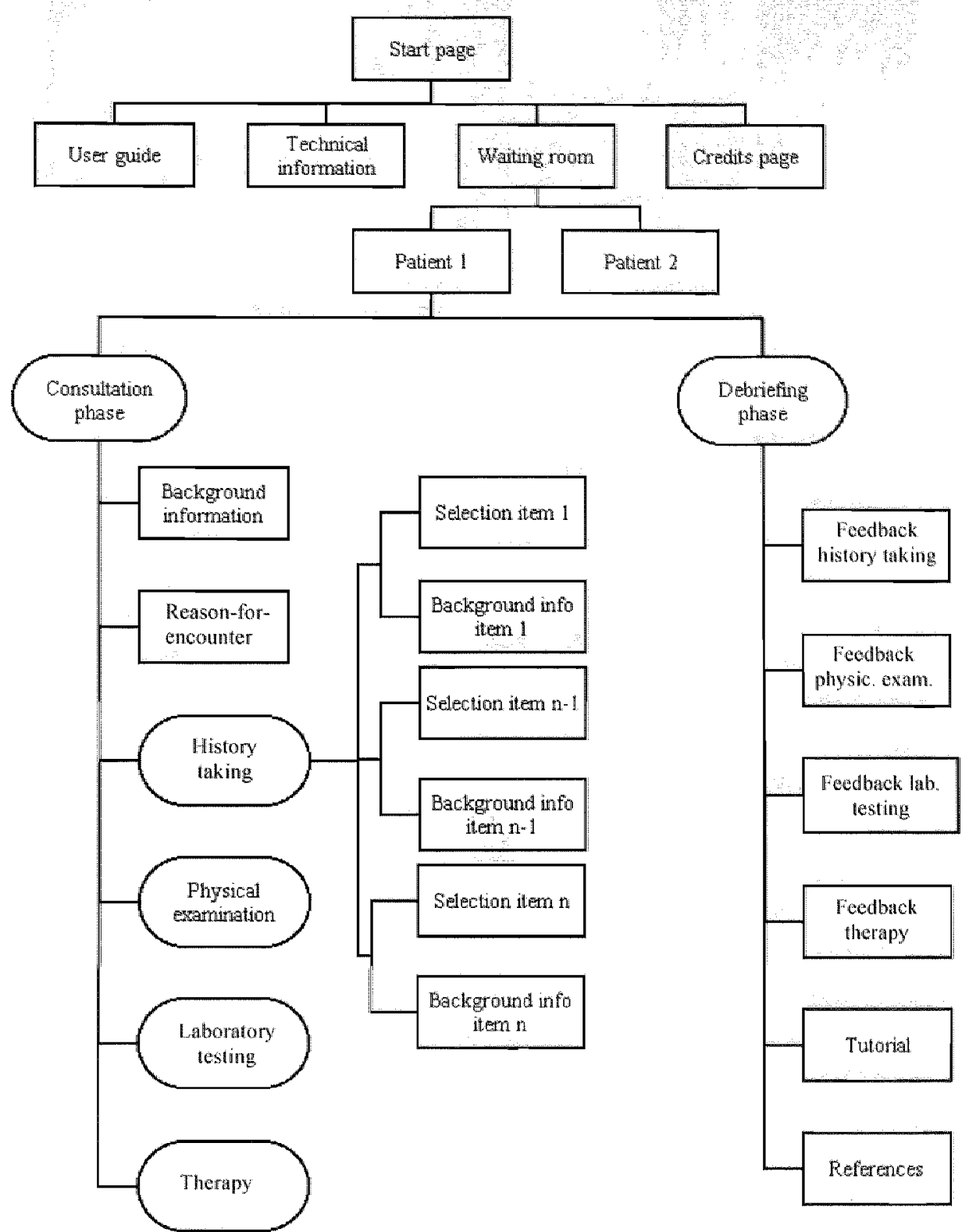

Figure 1. General structure of the Simulation of Ceneral Practice (SIMCP) program.

domain. In this way, we tried to induce reinforcement and recall of prior learning. As the user proceeds from one phase to the next, the program asks him/her to formulate a working hypothesis. We inserted these working hypothesis screens to simulate explicitly the GP's natural train of thought during consultations (9). 


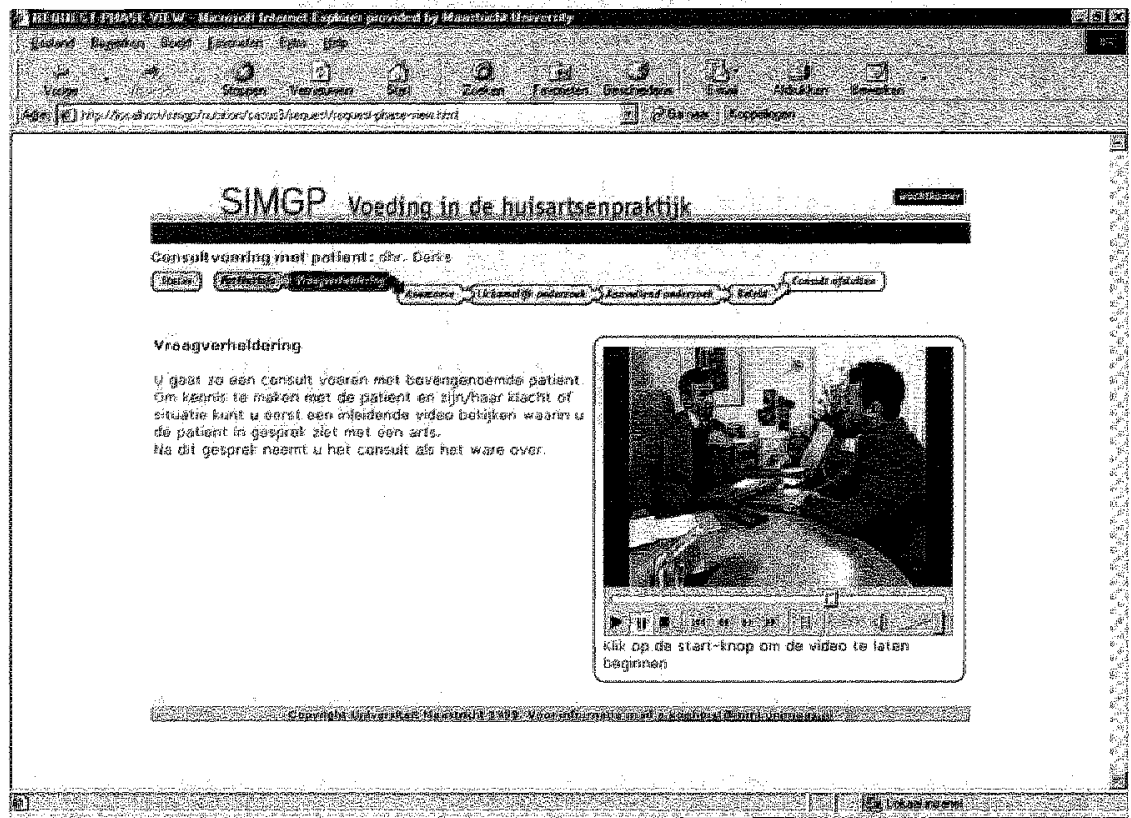

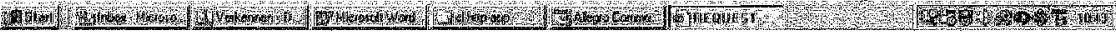

Figure 2A. Example of a "reason-for-encounter" screen in the SWMP Nutrition in General Practice program (screen text in Dutch).

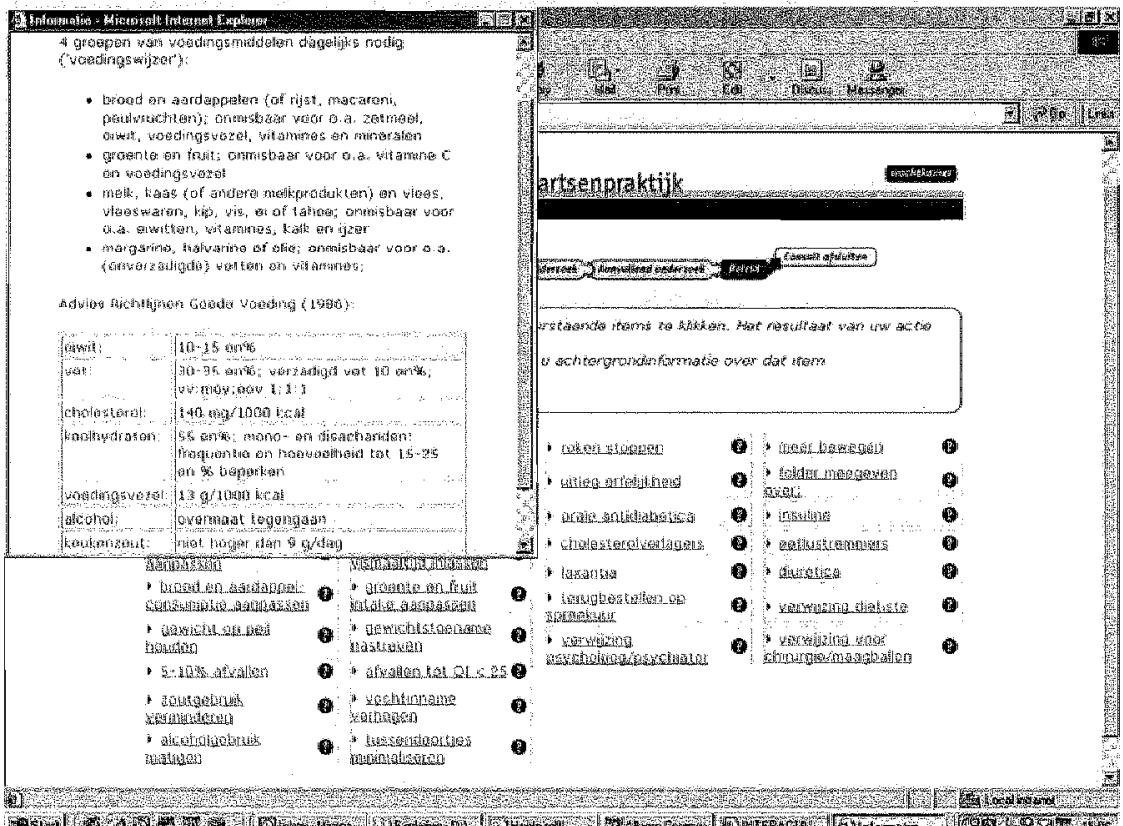

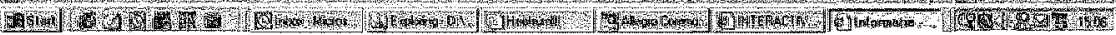

Figure 2B. Example of a "pop-up" screen showing background information on an item in the "therapy" screen (screen text in Dutch). 
During the debriefing phase, the program provides direct feedback on the performance for each consultation phase. The feedback consists of a comparison beiween the item choice and working hypothesis of the user and those of a GP expert, creating a form of peer review and feedback which have proved to be effective according to the literature on CME (11). Moreover, the feedback screens provide videos showing the GP expert at work. We expected these videos to serve as role-models for trainees - which has been recommended as an important element in nutrition education (12)- and to enhance the experiential value of the cases - which has been described as especially important in vocational training (13). In addition to the feedback screens, the user can produce a tutorial, a one-page summary of the case. The final page of the case contains a list of references.

The user is guided through the entire simulation by a linear navigation bar at the top of each screen. The presentation of the individual patients in the waiting room screen and the navigation bar provide "mapping" of the educational material (14). It is important to note that the users can tailor their route through the program to their pre-existing knowledge and skills. This facilitates a constructivist mode of learning (13).

\section{THE NUTRITION DOMAIN}

In the second stage of development of our nutrition $\mathrm{CBI}$, the main aspect of concern was the delineation of the domain of nutrition. After having consulted an expert panel, comprising an experienced GP, a professor of general practice and a professor of clinical nutrition, we chose the "Guidelines for a healthy diet" drawn up by the Dutch Nutrition Council (15) as the point of reference for the program. Together with the practice-oriented "Voedingswijzer" (a newly designed Dutch food guide derived from the guidelines), it presents a generally approved and accepted basis for nutrition education in the Netherlands (16).

Secondly, together with the expert panel, we converted elements of the Dutch food guide into a general framework of nutrition-related items to be incorporated in the individual screens of the SIMGP program. Each set of items per screen consisted of two types of item: obligatory items, which are imperative for a proper consultation, and superfluous items. For example, the history-taking screen included items about lifestyle (exercise, smoking) and diet history (food frequency, usual intake) which were assumed to be obligatory for almost all cases, and more specific disease-related items (polyuria, itching) which were assumed to be superfluous in many cases. The total set of items for the individual consultation categories is listed in Table 1.

Once the general framework of items had been defined, we drafted the background information for all items, in collaboration with the expert panel. The information was phrased at the level of novices in the field of nutrition (14), which is the level that emerged from our survey among trainees (7). Pasted together, the background information on the items comprised ten A4- size pages of concise texts about the nutritional aspects of the items. The background information on the history-taking item of "smoking", for instance, read: "appetite is influenced by smoking (appetite declines; 
Table 1 Total set of items for the individual consultation categones in the SIMCP Nutrition in General PraCtice program

\begin{tabular}{|c|c|c|c|}
\hline Hestory taking & $\begin{array}{l}\text { Physsical } \\
\text { examination }\end{array}$ & $\begin{array}{l}\text { Laboratory } \\
\text { evaluation }\end{array}$ & $\begin{array}{l}\text { Therapy } \\
\text { (nutrition guidance) }\end{array}$ \\
\hline Family history & Weight & Glucose & Complete food record \\
\hline Medication & Herght & Cholesteral & Add more variety of foods \\
\hline Supplements & Waist: circumference & Truglycerudes & Adjust percentage of fat \\
\hline Smoking & Hip circumference & FTH/TSH & Use semi-skimmed diary products \\
\hline Employment & Skin fold measurements & Liver enzymes: & Adjust meat intake \\
\hline Special diets & Xanthomas & Creatinine & Introduce fish meals. \\
\hline Weight loss or gain & Blood pressure & Cortisol & Adjust intake of bread and potatoes \\
\hline Diet history & Pulse & Hgh & Adjust intake of wegetables and fruit \\
\hline Sports/exercise & Heart & Albumin & Control weight \\
\hline Psychological stress & Lungs & Urine & Try to achiewe weight gain \\
\hline Fatigue & Abdomen & & Lose $5-10 \%$ of weight. \\
\hline Mobilitity & Peripherall pulsations & & Lose until BMI $<25 \mathrm{~kg} / \mathrm{m} 2$ \\
\hline Joint complaints & Reflexes & & Reduce use of salt \\
\hline Dyspnea & & & Augment intake of fluids \\
\hline Changes in sleeping pattern & & & Moderate alcohol intake \\
\hline Excessive sweating & & & Minimize snacks \\
\hline Polydipsia & & & Quit smoking \\
\hline Polyuria & & & Augment exercise \\
\hline Itching & & & Explanation of genetics \\
\hline Sexual function & & & Hand out leaflet on... \\
\hline Abdominal pain & & & Oral anti-diabetic medication \\
\hline Appetite changes & & & Insulin \\
\hline Nausea & & & Cholesterol-fowering medication \\
\hline Vomiting & & & Appetite-reducing medication \\
\hline Bowel changes & & & Laxatives \\
\hline Cardiac pain & & & Diuretics \\
\hline \multirow[t]{4}{*}{ Limited range of walking } & & & Order follow-up consultation \\
\hline & & & Referral to dietician \\
\hline & & & Referral to psychologist \\
\hline & & & Reierral to surgeon \\
\hline
\end{tabular}

smoking cessation causes a weight gain of about $5 \mathrm{~kg}$; it presents one of the risk factors for cardiovascular disease (promotes atherosclerosis and abdominal fat deposition)"

\section{DEVELOPMENT OF THE CASES}

After the activities described in the previous section had been completed, we were ready to develop the individual cases for the program. Based on two previously conducted studies (7; Maiburg, Rethans, van Ree, 1998), we selected the following five topics to be elaborated within the chosen nutrition domain: overweight and obesity, diabetes mellitus, hypercholesterolemia, hypertension, and intestinal problems. The 
Overweight and obesity cases

Normal-weighted shopkeeper wants to avoid becoming overweight

Overweight truck driver wants to start losing weight

Obese female nurse wants to exclude endocrine cause of obesity

Accountant with metabolic syndrome worries about physical condition

Diabetes mellitus cases

New onset diabetic teacher discusses food record

Diabetic housewife queries her diet (Mediterranean diet, fisth-oil, special diabetic toods?

Cardionascular disease cases

Computer programmer worries about raised serum cholesterol found during routine annual examination

Account manager worries about lifestyle and myocardial infarction of older brother

Hypertension cases

Hypertensive instrance adviser, suffering from headache, wants to prevent stroke

Registrar with brittle hypertension and raised weight discusses food record

Intestinal problems cases

Housewife with constipation, varying across years, wants sound nutrition advice

Secretary with regular abdominal complaints (IBS) queries origin and treatment of complaints

following procedures were used to ensure that the materials to be developed met high quality standards.

1. Case development was backed up by recent literature.

2. Cases were peer-reviewed by recognized experts in the field of nutrition (the expert panel).

3. The video for the program was shot by a professional crew.

4. A GP expert in the field of nutrition played the role of the general practitioner, while professional actors played the roles of patients.

5. The video was shot on location in a genuine GP surgery.

Up to now, we have written 12 cases, derived from the five topics referred to above. Table 2 lists the reasons-for-encounter for these cases. We completed the framework of items for each case and assigned a score to each item, which could be positive (expert's choice), negative (not preferred by expert) or neutral (not wrong, but making consultation less efficient). In addition to the completion of the framework of items, we developed a patient record for each case, containing notes of previous consultations, examinations, laboratory tests and prescriptions. We wrote a one-page tutorial for each case, presenting a summary of important elements (clues) of the consultation and offering some new, additional background information on the subject. Finally, we converted the case items into a script to be used for the video clips. The script was based on the items labeled "positive", as these reflect the expert's approach to the case. 
This paper describes the development of our new nutrition $C B I$, based on a simulation of general practice, which has proved to induce a substantial improvement in factual knowledge and practice behavior among GP trainees (1). In terms of Davis' classification, we have developed a program that presents a somcalled multipotential intervention, i.e. a combination of "predisposing factors" (e.g. the nutrition knowledge base), "enabling factors" (e.g. expert videos of consultations) and "reinforcing factors" (e.g. feedback on cases). We opted for this approach because such interventions generally yield the greatest change in GP performance (17). We applied a large number of didactic principles and educational elements in the consecutive stages of development. It remains unclear which elements account for the effects we found, and which elements could have been left out. In order to unravel the relative importance of the various elements, other types of research will have to been carried out than the controlled trial we conducted to assess the effectiveness of the program as a whole (18, 19). However, Lyon pointed at indiwidual learner differences: some GP trainees are more visually oriented, while others are verbally oriented $(20 \%$. Our CBI as a wholle seems to meet both types of orientation.

The above description of the development of our simulation indicates that this kind of development requires a multidisciplinary approach. In addition to the authors of the present paper, a group of interested GPs, a GP expert on nutrition, a nutritionist, a professional video crew, a group of actors and many colleagues and interested parties (who gave feedback during presentations of the prototype programi) contributed to its development.

Several aspects of the continuing development of the CBI deserve further consideration. The first is whether SIMCP programs could be developed for other domains. It has been claimed that novice stage domains are the best candidates for use in multimedia applications, since such applications offer a conceptual framework for handling problems in a particular domain (14). This statement is supported by our finding that trainees who used the CBI on nutrition - a novice stage domain for trainees - readily proceeded to a higher level of knowledge and skills (1). Hence, we have to identify various novice-stage domains for trainees. Secondly, we will continue to improve the current version of the program. The possibility of returning to a preceding phase in the consultation to correct one's choice of items, and hiding the teedback page (which contains the items that present the expert consultation) until the case has been concluded, are two desirable ameliorations. Furthermore, we consider adding hyperlinks to extend the knowledge base of the nutrition CBH. To assess the Impact of these changes it will be necessary to conduct $\mathrm{CB} /$-to-CBI studies, comparing the effect of programs with and without such features (18). Thirdly, it will be interesting to investigate whether specific built-in features of the program achieve their intended effect. For example, do the working hypothesis screens which open when proceeding from one consultation phase 
to the next induce reflection on the case, and does the background information on items account for the improvement in factual knowledge?

In any case, the enthusiasm with which the trainees used the nutrition CBI allows us to assume that we have managed to provide trainees with an attractive method to study the important topic of nutrition, which is generally perceived as a rather dull subject. Furthermore, we are sufficiently encouraged by the remarkable effectiveness of the nutrition $C B I$ to continue our efforts to provide effective $C B I$ programs. In the end, we hope to achieve that potential users will decide that CBI should become an essential part of the curriculum of GP vocational training.

\section{REFERENCES}

1. Maiburg HI, Rethans J), Schuwirth LW, Mathus-Vliegen EM, van Ree IW. Controlled trial of effect of computer-based nutrition course on knowledge and practice of general practitioner trainees. Am J Clin Nutr 2003;77(suppl): 1019s-24s.

2. The Group on Nutrition, Society of Teachers of Family Medicine. Physician's curriculum in clinical nutrition: primary Care. 2nd ed, 2001. Intemet: htp./mww.stm.org/pdfs/Croupon Nutrition.pdf (accessed 18 February 2003).

3. Dutch Nutrition Foundation. Huisarts en voeding (General practitioner and nutrition). The Hague: Dutch Nutrition Foundation, 1997 (in Dutch).

4. Cohen PA, Dacanay LS. Computer-based instruction and health professions eclucation: a meta-analysis of outcomes. Eval Health Prof 1992;15(3):259-81.

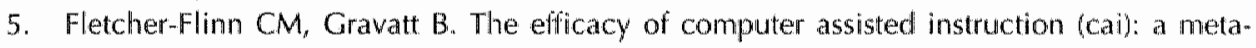
analysis. J Educ Comput Res 1995;12(3):219-42.

6. Hiddink $\mathrm{Gl}$. Hautvast $\mathrm{J}, \mathrm{G}$, wan Woerkum $\mathrm{CM}$, Fieren $\mathrm{Cl}$, wan "t Hof $M$ A. Nutrition guidance by primary-care physicians: LISREL analysis improves understanding. Prev Med 1997;26(1): $29-36$.

7. Maiburg HI, Hiddink G), van "L Hof MA, Rethans IJ, van Ree IW. The NECTAR study: development of nutrition modules for general practice vocational training; determimants of nutrition guidance practices of CP Irainees. Eur J Clin Nutr 1999;53(5uppl 2):583-8.

8. Koehorst AM, Ronteltap CFM. An enwironment for the development and presentation of computerized cases to learn diagnostic reasoning. In: Scherpbier AAIA, van der Vleuten CPM, Rethans J), wan der Steeg AFW (eds). Advances in medical education. Dordrecht: Kluwer Academic Publishers; 1997:769-73.

9. Dutch National Association of Generall Practitioners. Basic job description for the general practitioner. Utrecht: Dutch National Association of General Practitioners; 1983.

10. Friedman CP. Anatomy of the clinical simulation. Acad Med 1995;70(3):205-9.

11. Wensing $M$, Grol R. Single and combined strategies for implementing changes in primary care: a literature review. Int J Qual Health Care 1994;6(2):115-32.

12. Halsted $\mathrm{CH}$. Clinical nutrition education - relevance and role models. Am J Clin Nutr 1998;67:192-6.

13. Reeves TC. Evaluating what really matters in computer-based education. November 1997. Internet: http//www.educationau.eduau/archives/cp/reeves.htm (accessed 18 February 2003). 
14. Atkins MJ, O'Halloran C. Evaluating multimedia applications for medical education, AMEE Medical Education Guide No. 6. Med Teach 1995;172):149-60.

15. Nutrition Council. Guidelines for a healthy diet. The Hague: Nutrition Council; 1986.

16. The Netherlands Nutrition Centre. De Voedingswijzer. Toelichting en achtergronden. Criteria woor voedingsmiddelen (The food guide. Explanation and backgrounds. Criteria for food components). The Hague: The Netherlands Nutrition Centre; 1997 (in Dutch).

17. Davis DA, Thomson $M A$, Oxman $A D$, Haynes RB. Changing physician performance. $A$ systematic review of the effect of continuing medical education strategies. JAMA 1995;274(9): $700-5$.

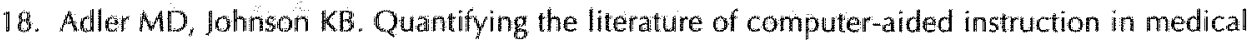
education. Acad Med 2000,75(10): 1025-8.

19. Friedman $C P$. The research we should be doing. Acad Med 1994;6961:455-7.

20. Lyon $H C$, Jr, Healy $J C_{\text {, }}$ Bell $I R$, et al. PlanAlyzer, an interactive computer-assisted program to teach clinical problem solving in diagnosing anemia and coronary artery disease. Acad Med $1992 ; 67(12): 821-8$. 


\section{FIELDING INCOGNITO STANDARDIZED} PATIENTS AS "KNOWN" PATIENTS IN A CONTROLLED TRIAL IN GENERAL PRACTICE

Submitted as: Fielding incognito standardized patients as "known" patients in a controlled trial in general practice.

Bas HJ Maiburg, Jan-Joost E Rethans, Ingrid M van Erk, Lisbeth MH Mathus-Vliegen and Jan $W$ van Ree. 


\section{ABSTRACT}

Backgound Incognito standardized patients (SPS) have only been used to represent new patients so far. The few frials with incognito SPS prowide few detals on the method used for fielding them.

Objective To establish the teasibllty of introducing SPS as "known" patients (i.e. having previously visted the practice) into prachices, to indicate the required practice preparations, and to describe the various aspects of using SPs in a pretest postest design.

Method We used incognito SPs as "known" patients in a controlled trial to assess practice behaviou of 49 trainees. SPS received a wo-day training in role-playing and completing checklists. We compiled comprehensive practice information folders of each practice to be visited. Real personal data and laked medical data of SPs were inserted in the file system of each practice to be visited Apart from $S P$ roles with slightly different reasons-for-encounter and different $S P_{S}$, the same training protocol, checklists and practice information folders were used in the posttest.

Results SPS carred out 287 visits in 50 practices. All practices prepared the patient records for the SP visits in a fairly authentic practice style. Trainees detected the SP in 74 visits. Main reasons for detection were imperfections of patient records and aspects of SP roles or role-playing.

Conclusion Fielding incognito SP visits as "known" patients was feasible but labour-intensive. Preparing the SP patien records and familiarising SPs with the interior of practices represented new elements in the use of SPS. The pretestpostest format made their use more efficient instead of complicating it. 


\section{INTRODUCTION}

Standardized patients (SPS), being laymen taught to portray patients in a standardized and consistent way, are widely used for both educational and research purposes 111. The training format of SPS and the preparation of SP encounters largely depends on the purpose to be achieved, and is greatly influenced by the setting in which these encounters are supposed to take place. Many studies using SPs have been carried out in non-practice settings (2-11), with medical students as well as physicians meeting SPs in a laboratory setting to assess skills and attitudes or to evaluate the effect of educational programmes. Such SP sessions have usually been observed or videotaped and rated by trained observers. As students and physicians in these studies were aware of being observed and assessed, they were likely to perform in a different way than they do in everyday practice (12).

The use of incognito SPs in the outpatient or practice setting arose from the objective to assess the performance of physicians, performance being defined as measuring what doctors do in actual professional practice (without being aware they are being assessed) (13-24). Several studies have shown that the use of incognito SPS has distinct advantages over chart audits and general practitioner's self reports to reveal performance $(13$, 25). Various authors have described the methodology of introducing incognito SPs into outpatient clinics or practices of general practitioners (GPS), which involves training for standardized role portrayal, training to complete checklists in a reliable way $(13,18)$, and preparation for entry into practice settings without being suspected or detected as a SP (15).

However, the reviewed literature about incognito SPs revealed two limitations to the fielding of incognito SPs. First, SPs were always introduced as new patients, visiting the clinic or practice for the first time. Although the feasibility of introducing SPS as new patients has been well ascertained, and the accuracy of SPs in standardized portrayal and in recording the content of their visits has also been well documented $(26,27)$, the introduction of such SPs is limited to those clinics or practices that actually accept new patients. Secondly, the great majority of the reviewed studies used a cross-sectional design $(13-20,23,28)$. The few studies with a pretest/posttest design provided a rather limited description of the fielding of SPS $(21,22,24)$.

We carried out a study using incognito SPs pretending to be "known" patients (i.e. having previously visited the GP's practice) and applied a pretest/posttest study format (29). We assumed that these features would require some adaptations to the current methods of fielding incognito SPs, including thorough local preparation of practices and providing the SPs with comprehensive information about these practices to achieve the "known" patient status, different (though comparable) SP roles and SPs, and different practice preparation to cope with the pretest/posttest format. The present paper describes the methods used. Our objectives were to establish the feasibility of introducing SPS als "known" patients into practices, indicate the practice preparations required to do so, and describe the various aspects of using SPs in a pretest/posttest design. 


\section{METHODS}

Our SPS were used as a measuring instrument in a controlled triall to assess the practice behaviour of $49 \mathrm{GP}$ trainees. The trial intended to assess the effectiveness of a newly developed computer-based instruction (CBI) on nutrition in the period July 2000 to July 2001 (29). In the pretest as well as the posttest of the trial, we sent three incognito SPs to the practices where the participating trainees worked. Several aspects of the preparations of the SP visits had to be considered, including standardized patient selection and training, role and checklist development, practice preparations and detection management.

\section{STANDARDIZED PATIENT SELECTION AND TRAINING}

We placed advertisements in two local newspapers and used telephone interviews (including personal data, general health status, weight and height) to select 30 of the 100 subjects who responded. During a meeting at our department we provided the 30 applicants with information about the study and held personal interviews, discussing level of education, motivation and relevant medical history (e.g. skin lesions which should be mentioned in the patient record). We paid special attention to language (and dialect) use and social skills. We made our definitive selection for future SPs by matching the data gathered from the applicants with the planned SP roles.

We trained three SPS for each of the three roles in the pre-and posttest: one to visit the practices in the northern region and one for those in the southern region (because these regions have different dialects), and one spare SP. One full day was spent on role rehearsal and practice with real GPS. Training focused particularly on the use of introductory phrases according to the script and on helping them avoid giving away clues as to their role. On the second day, SPs again practiced with real GPS, but now they also were trained in filling in the checklist they would have to complete immediately after a consultation during the trial. Their checklist scores were compared with those of the SP trainer, the supposed "gold standard". We aimed to achieve an accuracy among SPS of at least $85 \%$ of the SP trainer's score. At the end of the training, we explaned the use of the comprehensive information folders we had provided on each practice to be visited, which are described in detail in the Practice preparation section below. Furthermore, we provided each $S P$ with a calamity letter, containing information about the project, to be handed over to the trainee in case of unintended physical examination or treatment (18). We considered 25 trainee visits to be the maximum for each SP. Halfway through their visits, SPS underwent one day of remedial training to ensure that they remained true to their script and to evaluate the way they had completed their checklists. We used a different group of SPS in the pre- and posttests, not only for logistical reasons (the number of visits) but also because SPS who were detected in the pretest could not be used in the posttest. We used the same training protocol in the pre-and posttests. The researcher was on call during the entire trial to answer questions from SPs about their roles and visits. 
SPS were paid training hours and practice visits (11.30 euros per hour/vist, travelling costs 10.27 euros per kilometre) and part of the travelling time (11.30 euros per hour). After the conclusion of each part of the trial, we organized a debriefing meeting with the current group of SPs.

\section{ROLE AND CHECKLIST DEVELOPMENT}

In order to fully cover the content of the computer-based instruction (CBI) on nutrition, we combined the topics of the CBI to some extent, as we considered three SP roles to be feasible and reliable. In determining the final content of $S P$ roles, we aimed to reach consensus among the same expert panel which had contributed to the content of the CBI. The roles involved reasons-for-encounter which did not differ from those commonly found in a GP practice. The pre-and posttest roles involved slightly different reasons-for-encounter, to avoid prompt recognition of roles in the posttest. However, the medicall content of the roles and the required medical interventions were identical. The expert panel also determined the content of the SP checklists to be used. Checklist items were derived from items in the CBI, which in turn were based on a process of key-feature analysis (30). Most items included a short explanatory note about how to score, to make scoring of the items more unambiguous. Because the medicall content of roles remained the same, it was possible to use the same checklists in the pre-and posttests, except for three skipped items on general history taking in one of the roles. The number of items per checklist varied between 35 and 42 .

\section{PRACTICE PREPARATION}

Since many practices in which trainees worked did not accept new patients, we decided to introduce our SPS as "known" patients (i.e. pretending that they were already registered at, and had previously visited, the practice). Using this type of incognito SPs meant we had to carry out two types of practice preparations.

First, we started a process of extensive practice mapping, after having acquired informed consent of the GP trainer in whose practice trainees worked (one trainee per GP). We obviously wanted to enable SPs to behave as genuine patients of the practice concerned, even though they had actually never visited it before. Therefore, photographs of the exterior and interior of the practices were taken, ground plans were outlined and routes to practices delineated. Consultation hours, practice routines (e.g. the appointment system) and telephone numbers were acquired from practice flyers and interwiews with practice assistants. All these materials were collected to constitute a comprehensive information folder for each practice to be visited.

Secondly, we planned to insert faked patient records for our SPs in the file systems of each of the 49 practices to be visited, in order to fake previous consultations with the GP trainer. We used a two-step method, taking advantage of the fact that GP trainers were informed about the project. In the first instance, we sent general information about future SPS to all GP trainers, asking them to provide us with an appropriate mock 
address for each SP. We then sent the definitive patient records for SPs, containing their real personal data, medical history and type of insurance, together with the mock address and faked previous consultations. The direct links between the $\mathrm{GPs}^{\prime}$ and pharmacists' computer systems prohibited the use of prescriptions in the patients' medical history. The use of family lists linked to each genuine patient record induced us to add such a list to the faked SP records as well.

We asked GP trainers to enter these data into the practice file system in their own style (and handwriting, if applicable), indicating which data were minimally required. We emphasized that they should not add new medical data to the information sent, as SPs

54 would be unaware of these data. Before SPs started to make consultation appointments with trainees, we called all practices by telephone to ensure that they had managed to produce patient records for all SPs concerned. We took particular care to ensure the correct mention of (faked) recent physical examination and laboratory findings, in order to prevent SPs undergoing such examinations.

After the pretest had been concluded, we sent general information about visiting SPs to all practices involved, to enable them to remove the SP records. We entered faked SP records in the posttest using a one-step method, as we were able to re-use the mock addresses from the pretest phase. The practice information folders were prepared for re-use in the posttest by merely changing the name of the SP concerned. After the conclusion of the posttest, another SP record cleaning letter was sent to all practices.

\section{DETECTION MANAGEMENT}

Before the study started, trainees received a detection form, to be sent to the researcher whenever they felt to have been visited by a SP. The form included the SP's name and date of birth, reason-for-encounter and reason for detection. We also asked trainees to indicate the moment of detection (i.e. before, during or after the consultation), and whether the detection had influenced the way they treated the patient. We urged them not to discuss (presumably) detected SPS with their trainee colleagues during their weekly vocational training day at our department.

\section{RESULTS}

\section{STANDARDIZED PATIENT EXPERIENCES}

At the end of the training sessions, SPs had reached an accuracy in recall of the consultations of $94 \%$ in the pretest and $95 \%$ in the posttest. The corresponding figures during remedial training were 93 and $95 \%$, respectively.

Of the total of 294 planned visits, the SPs carried out 287 . The seven missing visits were caused by trainee drop-out. Each SP managed to get appointments within the limited time of the pre- and posttest phase (each phase comprising two months), while planning a varying number of visits per day ( 1 to 2 , exceptionally 3 to 4$)$. With a single exception, 
$S P$ s visited the practices during regular consultation hours. One SP cancelled her participation in the project at the start of the training session for one of the SP roles. The spare $S P$ instantly took the place which fell vacant.

$S P$ s reported no major difficulties with completing their checklists. The space provided for individual observations was often used to comment on the GP trainee's general skills and attitude and to express concern about possible detection. Unexpectedly, as recent physical examination and laboratory findings were part of their faked medical records, some SPs underwent rectal examination or blood sampling. During the debriefing sessions, SPs mentioned that the careful way trainees handled these situations prevented them from using the calamity letter at these moments. SPs expressed some concern about the poor quality of route maps provided in the practice information folders.

The total costs of the SP project amounted to 16,400 euros.

\section{INTRODUCTION OF INCOGNITO STANDARDIZED PATIENTS INTO PRACTICE}

After a thorough explanation about the project and the expected burden on the practices, GP trainers readily consented to the project. The trainers generally seemed rather curious to see how things would go and were even excited about participation in the project. We did not encounter any reluctance among GP trainers when we visited their practices during our "mapping" tours.

All 50 practices (one trainee moved to a different practice during the trial) managed to prepare the patient records required for the three SPS in the pre- and posttest in time; these records contained the minimally required data. The authenticity of data in the $5 \mathrm{P}$ records, in terms of normal practice style, varied. In some practices, the GP trainers themselves wrote the journal notes (based on our data), whereas in some other practices the practice assistant completed the SP record using the standard text sent by us. Sometimes GPs or assistants added telephone or insurance numbers to the records to improve authenticity. During the entire project, there was only one documented visit during which the patient record could not be retrieved because the prepared patient record had been incorrectly filed.

\section{DETECTION OF STANDARDIZED PATIENTS VISITS}

Trainees reported 77 visits of presumed SPs, of which 74 were correct detections (26\% of all visits). Twenty-seven detections took place in the pretest, 47 in the posttest. Three reports regarded genuine patients. We received 59 fully completed detection forms on SPs. Fifteen correct detections were mentioned in e-mails or short notes.

The main reasons for detection according to these forms were elements of $S P$ roles or $S P$ role-playing and patient record issues, or combinations of these. Because the subject of the $\mathrm{CBI}$ was nutrition, patients with complaints or questions related to nutrition were readily suspected. In the posttest, trainees of the experimental group were familiar with 
the topics included in the $\mathrm{CBI}$, making these topics even more suspect. The room for improvement of the regular food intake in several roles was also mentioned as a reason for detection. In addition, SPs who were persistent in their questions about nutrition and who easily prompted clues raised suspicion. Patient record issues comprised uncommon journal notes and prescriptions and the absence of telephone or insurance numbers. Some unique causes of detection were the identification of a non-existing (mock) address, the urban appearance of a SP in one of the rural practices and the dialect of the SP.

The majority of correct detections ( $88 \%$ ) occurred during the consultation. Twenty-six trainees $(44 \%)$ mentioned that the presumption of being visited by a SP had changed the way they handled the patient. Of these trainees, 14 indicated that they tended to perform better from the moment they suspected being visited by a SP, while the others indicated to be more or less confused, making them omit elements of the consultation. Some trainees eagerly searched for SPs visiting them, as was demonstrated by the excited way they reported presumed SPs. One trainee voluntarily admitted that presumed or detected SPs had been discussed among trainees during vocational training days at our department.

\section{DISCUSSION}

This paper reports on the methods we used in fielding SPs as "known" patients (i.e. pretending that they were already registered at, and had previously visited, the practice) in a controlled trial, which was carried out to assess progress in trainees' practice behaviour induced by a newly developed $\mathrm{CBI}$ on nutrition. We had assumed that our decision to use "known" patients and field incognito SPs in a trial would require some adjustments to current methods of incognito SP use, as these methods had so far been limited to the use of SPS as new patients and were incompletely described in the few previous trials with incognito SPs. We started with the selection of new SPs and ended up with almost 300 visits carried out by SPs.

Our decision to use SPs pretending to be "known" patients forced us to introduce a new aspect in organizing the incognito SP visits, that is, simulating what had previously happened to these patients in the practices. This was done by inserting complete SP patient records in the practice filing system. As the trainees worked in their GP trainers' practices, we were able to involve the GP trainers in the organization of this part of the project. GP trainers and their practice-assistants did a great job in preparing all the required SP records, including faked data of previous consultations. We regard this part of the preparation of SP visits as the most innovative element of using SPS as "known" patients. It also turned out, however, to be the most labour-intensive part. In addition, patient record issues were mentioned as one of the reasons for detection. We think it would have been unfeasible for the researchers to personally check the entire set of prepared patient records for proper practice style and medical content. 
Another aspect of using "known" patients regarded the SPS' simulated familiarity with the local practice situation. SPs had to be provided with the necessary information about practices to allow them to act like genuine patients. The comprehensive practice information folders, also used in previous studies (31), complied with this requirement. A new component introduced into these folders was information on the interior of the practices, since the SPS - as "known" patients - ought to be familiar with these aspects as well.

Using incognito SPs in a pretest/posttest design required several additional measures to be taken in the posttest phase to avoid detection of SPs. The risk of detection could be increased by recognition of the patients" reason-for-encounter and complaints (i.e. the SP role), and of the SP as such. Although the use of different groups of SPS and (slightly) different reasons-for-encounter seemed an obvious choice, the development of more SP roles in particular had some serious limitations. Since each role ought to be applicable to each practice, roles (and practice preparations) not only had to meet the standards of general health care supplied by Dutch CPs, but also had to take into account all kinds of local exceptions. For example, blood samples from diabetics might be taken at the GP practice or at hospital laboratories, and be entered into the patient records in various ways. This means that it is important to be extremely well informed about the health system in which SPs will be fielded, with all its local exceptions.

On the other hand, the pretest/posttest format turned out to be rather efficient. We were able to simply copy the pretest training protocol and re-use the SP checklists and practice information folders. Even entering patient records into the practice file systems was simplified in the posttest phase. Furthermore, researchers became more experienced during the trial. On the whole, we think that the synergistic effects in a pretest/postlest format outweigh the additional measures to be taken for such a design.

The overall detection rate of SPs $(26 \%)$ was somewhat higher than that found in cross-sectional studies, mainly as a result of the detections in the posttest. The few trials using incognito SPs in a pretest/posttest design so far did not supply SP detection rates. We had clearly underestimated the eagerness of some trainees to unmask SPS and the excitement the project caused among trainees. A longer delay between the announcement and the actual start of the SP project, in both the pre- and posttests, would probably have reduced the trainees' alertness. However, the whole project (pretest, intervention and posttest) had to be carried out within a period of one year, as trainees only remained in the same practice for one year. Furthermore, we realized that the weekly return to the institute for a day of vocational training represented a perfect opportunity for some trainees to exchange information about SPs, a situation that can hardly be controlled.

We wondered whether we could have reduced the number of unmaskings due to the $\mathrm{SPS}^{\prime}$ role or role-playing. Reducing the room for improvement in their regular food intake, one of the reasons for detection, would have limited the opportunities for trainees to show what they had learned from the nutrition CBI. As we had somewhat overestimated the number of patients with nutrition-related complaints normally seen 
by trainees in daily practice, the SP roles on nutrition became more conspicuous than expected. We therefore assume that more training of SPs would not have resulted in markedly fewer $S P$ s being unmasked. After all, at the end of the remedial training days, SPs performed their roles in a fairly optimal way (also in terms of the completion of their checklists).

\section{CONCLUSION}

We feel that extensive preparation of incognito SPs to perform as "known" patients, including $S P$ training, role and checklist development and practice preparation, is feasible but labour-intensive. Using SPs in studies with a pre- and posttest format produces synergistic rather than complicating effects. Although our study did not examine the relation between the methods of fiel ding incognito SPS and the assessment of practice effects of the educational program, the favourable results of our trial (29) at least suggest that incognito SPs represent an appropriate tool to assess these effects.

\section{REFERENCES}

1. van der Vleuten CPM, Swanson DB. Assessment of clinical skills with standardized patients: state of the art. Teach Learn Med 1990;2:58-76.

2. Walsh RA, Sanson Fisher RW, Low A, Roche AM. Teaching medical students alcohol intervention skills: results of a controlled trial. Med Educ 1999;33(8):559-65.

3. Campbell $E$, Weeks $C$, Walsh $R$, Sanson Fisher R. Training medical students in HIV/AIDS test counselling: results of a randomized trial. Med Educ 1996;30(2):134-41.

4. Sachdeva AK, Wolfíson PI, Blair PG, Gillum DR, Gracely EJ, Friedman M. Impact of a standardized patient intervention to teach breast and abdominal examination skills to third-year medical students at two institutions. Am J Surg 1997;173(4):320-5.

5. Kinnersley P, Pill R. Potential of using simulated patients to study the performance of general practitioners. Br J Gen Pract 1993:43:297-300.

6. Ramsey PG, Curtis IR, Paauw DS, Carline ID, Wenrich MD. History-taking and preventive medicine skills among primary care physicians: an assessment using standlardized patients. Am I Med 1998; 104(2):152-8.

7. Stillman P, Swanson D, Regan MB, et al. Assessment of clinical skills of residents utilizing standardized patients. A follow-up study and recommendations for application. Ann Intern Med 1991;114(5):393-401.

8. Davis $\mathrm{P}$, Kvern $\mathrm{B}$, Donen $\mathrm{N}$, Andrews $\mathrm{E}$, Nixon $\mathrm{O}$. Evaluation of a problem-based learning workshop using pre and posttest objective structured clinical examinations and standardized patients. J Contin Educ Health Prof 2000;20(3):164-70.

9. Kokotailo PK, Langhough R, Neary El, Matson SC, Fleming MF. Improving pediatric residents' alcohol and other drug use clinical skills: use of an experiential curriculum. Pediatrics 1995:96:99-104.

10. Lockyer I, el Guebaly N, Simpson E, Gromoff B, Toews J, Juschka B. Standardized patients as a measure of change in the ability of family physicians to detect and manage alcohol abuse. Acad Med 1996;71(1 Suppl):51-3. 


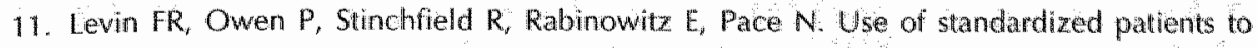
evaluate the physictans in residence program: a substance abuse training approach. I Addict Dis 1999; 18(2):39-50.

12. Rethars J] Norcini J], Barón Maldonado $M$, et al. The relationship between competence and performance: implications for assessing practice perfornance. Med Educ 2002;36:901-9.

13. Tamblyn RM, Grad R, Gayton D, Petrella L, Reid T, Groupo MDUR. Impact of inaccuracies in standardized patient portrayal and reporting on physician performance during binded clinic visits. Teach Learn Med 1997;9(1):25-38.

14. Dolan NC, McGrae MC, Dermott M. Using unidentified standardized patients to evaluate housestaff delivery of preventive services. Teach Learn Med 1997;901):60-5.

15. Woodward CA, McConvey GA, Neufelid V, Norman GR, Walsh A. Measurement of physician performance by standardized patients. Refining techniques for undetected entry in physicians' offices. Med Care 1985;23(8):1019-27.

16. Grad R. Tamblyn R, Mcleod P), Snell L, Illescas A, Boudreau D. Does knowledge of dirug prescribing predict drug management of standardized patients in office practice? Med Educ 1997;31(2):132-7.

17. Brown JA, Abelson 1, Woodward CA, Hutchison B, Norman G. Fielding standardized patients in primary care settings: lessons from a study using unannounced standardized patients to assess preventive care practices. Int I Qual Health Care 1998;10(3):199-206.

18. Gorter SL, Rethans J, Scherpbier AlJA, et al. How to introduce incognito standardized patients into outpatient clinics of specialists in rheumatology. Med Teach 2001;23:138-44.

19. Russell NK, Boekeloo BO, Rafi $\mathbb{Z}$, Rabin DL. Using unannounced simulated patients to evaluate sexual risk assessment and risk reduction skills of practicing physicians. Acad Med $1991 ; 66(9$ Suppli:S37-9.

20. Carney PA, Dietrich Al, Freeman DH, Mott LA. A standardized-patient assessment of a continuing medical education program to improve physicians' cancer-control clinical skills. Acad Med 1995;70(1):52-8.

21. Casebeer LL, Klapow JC, Centor RM, et al. An intervention to increase physiciants use of adherence-enhancing strategies in managing hypercholesterolemic patients. Acad Med 1999;74(12):1334-9.

22. Gerrity MS, Cole SA, Dietrich AJ, Barrett JE. Improving the recognition and management of depression: is there a role for physician education? I Fam Pract 1999;48(12):949-57.

23. O'Hagan II, Botting CH. Davies L.J. The use of a simulated patient to assess clinical practice in the management of a high risk asthmatic. NZ Med I 1989;102:252-4.

24. Wilk Al, lensen NM. Investigation of a brief teaching encounter using standardized patients. I Gen Intern Med 2002;17(5):356-60.

25. Luck I, Peabody IW, Dressethaus TR, Lee M, Glassman P. How well does chart abstraction measure quality? A prospective comparison of standardized patients with the medicall record. Am J Med 2000;108(B):642-9.

26. Vu VN, Barrows $H S$. Use of standardized patients in clinical assessments: recent dewelopments and measurement findings. Educ Res 1994:23(3):23-30.

27. Rethans J1, wan Bowen CPA. Simulated patients in general practice: a different look at the consultation. BM! 1987;294:809-12.

28. Glassman PA, Luck $\mathbb{~}$, O'Gara EM, Peabody JW. Using standardized patients to measure quality: evidence from the literature and a prospective study. It Comm / Qual Improv $2000 ; 26(11): 644-53$. 
29. Maburg HI, Rethans J), Schuwirth LW, Mathus-Wiegen EM, van Ree JW. Controlled trial of effect of computer-based nutrition course on knowledge and practice of general practitioner tranees. Am I Clin Nutr 2003;77(suppl:1019s-24s.

30. Page $G_{1}$ Bordage $G$, Allen T. Developing key-feature problems and examinations to assess clinical decision making skills. Acad Med 1995;70(3):194-201.

31. Rethans Jj; Drop $\mathbb{R}_{\text {, Sturmans }} F_{\text {, }}$ van der Vleuten $C$. A method for introducing standardized (simulated) patients into general practice consultations. Br I Gen Pract 1991;41(344):94-6. 
CONTROLLED TRIAL OF EFFECT OF COMPUTER-BASED NUTRITION COURSE ON KNOWLEDGE AND PRACTICE OF GENERAL PRACTITIONER TRAINEES

Published as: Maiburg HJ, Rethans JJ, Schuwirth LW, Mathus-Vliegen EM, van Ree JW. Controlled trial of effect of computer-based nutrition course on knowledge and practice of general practitioner trainees. Am J Clin Nutr 2003;77(suppl): 1019s-245. 


\section{ABSTRACT}

Background Nutrition education is not an integral part of either undergraduate or postgraduate medical education. Computer-based instruction on nutrition might be an attractive and appropriate tool to fill this gap.

Objective The study objective was to assess the degree to which computerbased instruction on nutrition improves factual knowledge and practice behavior of general practitioner (GP) trainees.

Design We carried out a controlled experimental study, using a 79-item knowledge test and 3 incognito standardized patients ${ }^{\prime}$ visits in a pre- and posttest design with 49 first-year GP trainees. The experimental group $(n=25)$ received an average of 6 hours of a newly-developed computer-based instruction on nutrition. The control subjects $(n=24)$ took the standard vocational training program.

Results The percentage of correct answers on the knowledge test increased from $30 \%$ at pretest to $42 \%$ at postest in the experimental group, and from $36 \%$ to $37 \%$ in the control group. Analysis of covariance, with the pretest scores as covariate, showed a significant experimental versus control group difference at posttest: $9.2 \%(P=0.002$ ). The mean percentage of correctly performed ttems during the 3 standardized patients' visits (assessed by checklists) showed an increase in the experimental group from $20 \%$ at pretest $1036 \%$ at postest, whereas the control group changed from $20 \%$ to $22 \%$. Analysis of covariance, with the pretest scores as covariate, revealed a significant group difference at posttest: $13.7^{\%}(P<0.001)$.

Conclusion The computer-based instruction proved its effectivenes both by increasing faclual knowledge and by substantially entancing GP trainees' practice behavior on the subject of nutrition. 


\section{INTRODUCTION}

In the Netherlands, general practitioners (GPs) and GP trainees often feel they lack the expertise necessary to deal with patients' questions on nutrition, because of insufficient education on this subject in both undergraduate and postgraduate medical courses (1). This phenomenon has also been reported in many other countries, and many attempts have been initiated to fill this gap in nutrition education (2-10). Recent research shows that GPs and GP trainees are interested in nutrition in general and welcome diseasemellated nutrition education $(11,12)$. lt also found that patients have great expectations of GPS with regard to nutrition guidance (13). These findings motivated us to develop a new medical education program on nutrition. We chose computer based instruction $(\mathrm{CBl})$ to overcome certain flaws of previously developed educational programs (1). As CBI enables. GP trainees to complete the program without a teacher, this method should avoid the major problem of faculty at vocational training departments not being acquainted with nutrition topics themselves (14). Moreover, CBI was developed as an Internet program, allowing easy updating and distribution of updates. As CBI is not currently used in the curriculum of GP vocational training in the Netherlands, opting for CBI also meant opting for innovation.

Although the value of CBI has been generally established and accepted $(15,16)$, we still had to prove the effectiveness of the newly-developed CBI on nutrition. This assessment formed part of the NECTAR (Nutrition Education by Computerized Training and Research) study, whose main objective is to enhance the knowledge, skills and attiludes. of Dutch GP trainees on the subject of nutrition.

In terms of the effect of the nutrition $C B I$ as an educational tool, we were interested in the improvement of both knowledge (competence) and performance of CP trainees (17. 18). Competence-based assessment measures what doctors can do in controlled representations of professional practice, whereas performance-based assessment measures what doctors actually do in their professional practice. Our first objective was to determine the degree to which GP trainees" factual knowledge of nutrition would improve as a result of the CBH. Second, we wanted to examine whether the nutrition CBI improved the adequacy of consultations performed by GP trainees in real praclice with patients with nutrition-related complaints.

The first objective refers to the "knows" level of facts and figures, as distinguished by Miller (19, 20). Many assessments of the value of educational tools are restricted to this level. The second question refers to the "does" or "performance" level, which implies transter of knowledge and skills into daily practice. 


\section{SUBJECTS AND METHODS}

\section{DESIGN}

The study used a pretest/posttest design in which GP trainees' knowledge and practice behavior were assessed before and after an educational intervention. Subjects were divided into an experimental group (using a newly-developed CBI) and a control group (taking the regular program). Both pretest and posttest used a 79 -item knowledge test and 3 visits by incognito standardized patients as measuring instruments. Standardized patients' vists in the posttest were carried out an average of 1 mo after the conclusion of the intervention. The experiment took place from July 2000 to July 2001 . The study was performed in accord with the Helsinki Declaration of 1975 as revised in 1983 (35th World Medical Assembly, Venice, Italy, October 1983)

\section{SUBJECTS}

We included all 49 GP trainees who started their GP vocational training program in 2000 at Mastricht University. The selection committee of the Department of Vocational Training, in which the researchers were not represented, allocated these trainees to 4 groups. Two groups were to constitute the experimental group $(n=25)$, with the other 2 groups being control subjects $(n=24)$. Together with the selection committee, we stratified the admitted GP trainees according to their sex and the university where they had completed their undergraduate medical program (Maastricht ws elsewhere). Afterwards, the selection committee reallocated some GP trainees, mainly for logistic reasons beyond the scope of our study.

At the start of their vocationall training, GP trainees received information about the design of the study and the way they would be informed about its progress and results. During the same session, they completed a questionnaire on background variables (mainly focusing on previous experience with the subject of nutrition), providing us with information about the composition of the research groups. Participation in the experiment was obligatory.

All GP trainees worked in different practices with their own GP trainer fone trainee per wainer). Therefore, we also asked their GP trainers to fill out a questionnaire assessing their own attitude about nutrition, as GPs and as GP trainers. We argued that differences in the way GP trainers handle nutrition-related problems in practice, as well as differences in the numbers of patients with these problems seen by the GP trainers, might well influence GP trainees and thus to a degree confound the effect of the CBI.

\section{INTERVENTION}

The GP trainees in the experimental group received a newly-developed CBI, involving a simulation of a GP consultation consisting of 12 interactive streaming-video patient cases presenting with complaints related to nutrition (i.e. food pyramid, obesity, diabetes mellitus, hypercholesterolemia, hypertension, irritable bowel syndrome, and 
Tablle 1 Teaching objectives of computer-based instruction on nutrition

\section{Overweight and obesity}

Adequate assessment of overweight

Assessment and value of waist circumference and watst-to hip ratio

Instant assessment of $\mathrm{BMI}\left(\mathrm{in} \mathrm{kg} / \mathrm{m}^{2}\right)>30$

Broad oultine of energy equilibrium

Exclusion of endocrine etiology of obesity

Recognition of the metabolic syndrome

Indication of need for weight management in overweight patients

Nutrition guidance according to the food pyramid

Nutrition guidance in overweight patients (BMI $\left.25.0-29.9 \mathrm{~kg} / \mathrm{m}^{2}\right)$

Indication and prescription of medication for obesity

Nutrition guidance in patients with obesity (BMI $30.0-34.9 \mathrm{~kg} / \mathrm{m}^{2}$ )

Indication of surgical treatment of obesity

Nutrition guidance in patients with the metabolic syndrome

Diabetes mellitus

Value and role of fiber-rich carbohydrates, fats, Mediterranean diet, fish oil xnd special diabetic or dietelic foods

Estimate of nutritional compliance of diabetic patients

Nutrition guidance in diabetic patients

Cardiovascular disease

Origin of saturated fatty acids in daily foods

Value and role of unsaturated tatty acids and phytosterols

Influence of coffee and alcohol

Nutrition guidance in patients with hypercholesterolemia

Hypertension

Origin of salt in daily foods

Salt sensitivity of blood pressure

Role of alcohol

Relation with obesity

Nutrition guidance in (obese) patients with hypertension

Intestinal problems

Value and role of voluminous breakfast containing adequate amounts of fat and food fibers in

patients with constipation

Nutrition guidance in patients with constipation

Value and role of various food fibers in patients with irritable bowel syndrome

Nutrition guidance in patients with irritable bowel syndrome

constipation). The teaching objectives of the $\mathrm{CB}$ are shown in Table 1. The $\mathrm{CP}^{\mathrm{P}}$ trainees ran the program during their weekly vocational training days at the institute. We scheduled the CBI sessions at 2- 10 -week intervals, with a maximum of 5 sessions, each session taking $1.5 \mathrm{~h}$. After a plenary instruction session by the researcher, the GP trainees went through the CBI at their own pace during these sessions, each GP trainee being provided with a personal computer. The actual learning process with the CBI took an average of 6 hours. The control group took the regular vocational training program, 


\section{Diabetes mellitus}

The notion that people suffering from diabetes mellitus should eat less carbohyctrate depending on fat as a nutrient is out of date. The European Asscociation for the Study of Diabetes has issued guide lines indicating the ideal composition of nutrition for diabetics.

List below the current guidelines (in energy percents) for carbohydrates and fats in diabetic nutrition.

Carbohydrate:

en\%

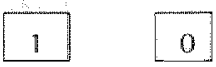

\section{Diabetes mellitus/Overweight}

During the consultation, the general practitioner trainee:

yes no ?

Explained the need tor a $5-10 \%$ weight reduction
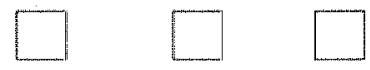

Emphasized the necessity of physical exercise
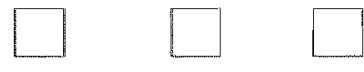

Figure 2. Part or stanclardized patient checklisit.

in which nutrition topics are sparsely incorporated and are subordinated to medical diagnosis and treatment.

\section{INSTRUMENTS: THE KNOWLEDGE TEST}

We developed a 79-item knowledge test with open-ended questions, which was to be used in both the pre- and the posttest. The level at which we tried to design the questions was the "knows" level - that is, straightrorward facts and figures about nutrition. We chose this format to prevent any "giving away" of the right answers, which multiple choice questions are likely to do (21). The general format of the questions is shown in Figure 1.

We ensured the content vallidity of the knowledge test by assessing the domain and making a blueprint (indicating the required chapters and the percentage of items for 
each chapter) for the test. We were careful to derive test items from the content of the CBI, which was based on a process of key-feature analysis by several inutrition experts $(22,23)$. An expert on knowledge testing revised the textual quality of the questions. Earlier studies had shown that the number of items to be used was sufficient to obtain good reliability in knowledge tests covering the broad GP domain (24).

We performed a pilot of the knowledge test in a GP trainee group not included in our study to assess the level of difficulty of the test and to avoid ceiling effects, as we planned to use the same test twice. The GP trainees took the test under exam conditions. The researcher graded all tests following a predefined grading protocol, being blinded for group allocation. The test score consisted of the number of correctly answered items (incorrect answers and items not answered scoring zero), converted to percentages.

\section{INSTRUMENTS: INCOGNITO STANDARDIZED PATIENTS}

To assess the practice behavior of GP trainees with regard to problems on the subject of nutrition, we decided to use incognito standardized patients (SPS). SPS are nonphysicians taught to portray patients in a standardized and consistent way. Such incognito SPs visit GP trainees as regular patients during daily practice and complete a checklist on the consultation afterwards, thus assessing the "performance" level of the trainee $(25,26)$. We trained 14 newly acquired SPs, who matched the intended roles. Their instruction included standardized role-playing, reliable completion of checklists and remedial training halfway through the planned visits. The total training time amounted to 16 hours per role.

The content of the 3 SP roles in the pre- and posttest (intestinal problems, cardiovascular disease/hypertension and overweight/diabetes mellitus) covered the entire domain of nutrition as incorporated in the CBI. We developed the SP checklists with the experts who had contributed to the content of the CBI. The total number of checklist items in the pretest was 118; in the posttest it was 115. Scoring categories for SPs includied "performed correctly" (- yes), "not performed/performed incorrectly" ( $=$ no) and "dubiously performed", as shown in Figure 2. SPs completed the checklists immediately after leaving the GP practice. In the case of a follow-up consultation, SPs used the same copy of the checklist again. The score for each case consisted of the number of correctly performed items (incorrectly, dubiously or not performed items scoring zero), converted to percentage scores. We computed the total SP test score as the mean of the 3 checklist scores.

To ensure that $\mathrm{SP}$ s would remain incognito, we provided each GP practice that: was to be visited by SPS with medical context information on each of the SPs. In addition, we provided the SPs with comprehensive information on each of the practices they were to visit $(27,28)$. We used different groups of SPs in the prem and posttest. SPS were blinded for the group allocation (experimental vs control group) of the GP trainees. The GP trainees received a so-called SP detection form, to be sent to the researcher in case they thought they had identified an SP. 
To evaluate differences in baseline variables between research groups, we used an independent samples $t$ test for age, Mann-Whitney tests for (skew-distributed) numeric variables and ordinal variables from the GP trainers' questionnaires, and chi-square tests for data on sex and the university of undergraduate medical studies. To assess whether differences in knowledge fest and SP test scores between experimental and control groups in the posttest were significant, taking into account the differences in the pretest, we carried out a linear regression analysis (analysis of covariance) (29). We also used the linear regression analysis to elicit and correct for confounding variables. To compute the significance of differences in knowledge test and SP test scores between the pre- and posttests, we performed paired samples $t$ tests for both experimental and control groups.

Depending on the variable level, we used Pearson $r$ or Spearman's $\rho$ for correlations. We computed the reliability of the instruments as Cronbach's $\alpha$. For the knowledge test, we entered the scores on all test items to compute Cronbach's $\alpha$; for the SP test, we entered the percentage scores of the 3 cases.

Two-sided $P$-values equal to or $<0.05$ were considered significant. We carried out all analyses in SPSS for Windows 9.0 (SPSS Inc., Chicago, IL) (30).

\section{RESULTS}

Characteristics of experimental and control groups are reported in Table 2. The groups showed no significant differences for age, sex or the university of their undergraduate medical studies. Previous theoretical and practice experience on the subject of nutrition did not differ between the 2 groups.

All GP trainees included in the study took part in the pretest (knowledge test and SP test). One GP trainee in the experimental group was visited by only $2 \mathrm{SPs}$, as he moved to another surgery during the pretest phase. One GP trainee in the control group, as well as one in the experimental group, abandoned the training program during the posttest phase, for reasons not related to the experiment.

\section{KNOWLEDGE TEST}

The resuits of the knowledge test, including total scores and scores per chapter are shown in Table 3.

The relative improvement in the total score of the experimental group between the preand posttests amounted to $40.3 \%$. Assessment per chapter revealed relative improvement rates in the experimental group of $54.4 \%$ for food pyramid, $67.7 \%$ for overweight and obesity, 67.8 for diabetes mellitus, $9.9 \%$ for cardiovascular disease, $29.4 \%$ for intestinal problems and $37.3 \%$ for hypertension. Analysis of covariance, performed to correct for differences between the experimental and control groups in the pretest 
Table 2 Characteristics of general practitioner (GP) trainees and their CP trainers in control and expen: mental groups ${ }^{\top}$

\begin{tabular}{|c|c|c|c|}
\hline & $\begin{array}{c}\text { Control } \\
n=8 M, 16 . F)^{2}\end{array}$ & $\begin{array}{c}\text { Experimental } \\
\left(n=11 \mathrm{M}, 14 \mathrm{~F}^{2}\right.\end{array}$ & P-value \\
\hline \multicolumn{4}{|l|}{ GP trainees } \\
\hline Age & $29.2 \pm 3.1^{3}$ & $30.6 \pm 4.0$ & $0.169^{4}$ \\
\hline Maastricht graduates $(n)$ & 16 & 12 & $0.187^{5}$ \\
\hline Relevant nutrition experience ( $n$ ) & 2 & 2 & $0.966^{\text {th }}$ \\
\hline \multicolumn{4}{|l|}{ GP trainers } \\
\hline Relewant nutrition experience $(n)$ & 4 & 3 & $0.641^{5}$ \\
\hline GP trainee teaching on nutrition/mo & $6.0 \pm 7.1$ & $7.3 \pm 9.8$ & $0.902^{6}$ \\
\hline Nutrition-related patient cases $(\mathrm{n} / \mathrm{mo})$ & $27.3 \pm 30.0$ & $32.9 \pm 27: 1$ & $0.425^{6}$ \\
\hline Providing mutrition guidance (times/mo) & $16.6 \pm 15.0$ & $28.9 \pm 26.0$ & $0.204^{6}$ \\
\hline $\begin{array}{l}\text { Perceived importance of nutrition in } \\
\text { GP training }\end{array}$ & Normal-high & High & $0.0006^{6}$ \\
\hline Use of obesity brochure & Never-some & Sorne-regullar & $0.007^{6}$ \\
\hline
\end{tabular}

1: One trainee per trainer; $2: M / F$ distribution pertains to GP trainees; $3: \bar{x} \pm S D ; 4:$ unpaired samples l test;

5: Pearson Chi-Square; 6: Mann-Whitney Test.

scores, showed a significant experimental versus control group difference at posttest of $9.2 \%(P=0.002)$. Relative to the mean pretest score, this implied an improvement of $28.0 \%$ in the experimental group. Pretest reliability of the knowledge test was .70, whereas posttest reliability amounted to .83 (experimental group .84 ; control group .80 ).

\section{INCOGNITO SPS}

Of the $2.94 \mathrm{SP}$ visits planned, 287 were actually carried out (98\%). The 7 missing visits were due to dropout by GP trainees, as mentioned above. Five of the 287 visits resulted in a follow-up consultation within several days, mainly to discuss a requested food record.

The results of the SPs' pre- and posttest scores are displayed in Table 4. Based on all visits, the SP scores for the experimental group between the pre- and posttest showed a relative improvement of $79.6 \%$. For the sake of consistency in our method of analysis, we once again used analysis of covariance to compute experimental versus control group differences on the posttest, although the pretest scores hardly differed. This anal$y$ sis showed a significant difference of $13.7 \%(P<0.001)$ between the groups at posttest. Relative to the mean pretest score, this implied an improvement of $68.2 \%$ in the experimental group. Reliability of the SP pretest was 67 , and that of the posttest .72 (experimental group .45; control group .71).

In addition to several visits by genuine patients, GP trainees correctly reported 74 visits of presumed SPs $(26 \%)$. During the pretest, the control group unmasked 16 visits of SPs, against 11 in the experimental group. The numbers of detected visits in the posttest were 15 and 32, respectively. As remaining incognito is an important feature of SPs in terms 
Table 3 Percentitage of correct answers in 79-item knowledge test before and after educational intervention for control and experimental groups of general practitioner trainees in the Nutrition Education by Computerized Traing and Research (NECTAR) study"

\begin{tabular}{|c|c|c|c|}
\hline & Before intervention & After intervention & $P-v a l u e^{2}$ \\
\hline \multicolumn{4}{|l|}{ Total score } \\
\hline Control & $35.7 \pm 8.4^{4}$ & $37.3 \pm 10.4$ & 0.168 \\
\hline Experimental"s & $30.0 \pm 7.0$ & $42.1 \pm 11.8$ & $<0.001$ \\
\hline \multicolumn{4}{|l|}{ Sicore per chapter } \\
\hline \multicolumn{4}{|c|}{ Food pyramid $(k=9)$} \\
\hline Control & 38.9 & 43.5 & 0.149 \\
\hline Experimental & 35.1 & 54.2 & $<0.001$ \\
\hline \multicolumn{4}{|c|}{ Overweightrobesity $(k=20)$} \\
\hline Control & 33.8 & 39.8 & 0.005 \\
\hline Experimental & 25.4 & 42.6 & $<0.001$ \\
\hline \multicolumn{4}{|c|}{ Diabetes mellitus $(k=12)$} \\
\hline Control & 22.2 & 22.5 & 0.852 \\
\hline Experimental & 17.7 & 29.7 & 0.006 \\
\hline \multicolumn{4}{|c|}{ Cardiovascular disease $(k=12)$} \\
\hline Control & 56.6 & 52.2 & 0.296 \\
\hline Experimental & 50.7 & 55.7 & 0.192 \\
\hline \multicolumn{4}{|c|}{ Intestinal problems $(k=14)$} \\
\hline Control & 37.5 & 36.3 & 0.784 \\
\hline Experimental & 32.0 & 41.4 & 0.006 \\
\hline \multicolumn{4}{|c|}{ Hypertension $(k=12)$} \\
\hline Control & 26.7 & 29.3 & 0.328 \\
\hline Experimental & 23.3 & 32.0 & 0.015 \\
\hline
\end{tabular}

1: The educational intervention consisted of computer-based instruction on mutrition; 2 ; paired samples $l$ test; $3: n=24$ before intervention; $n=23$ after intervention; $4: \bar{x} \pm S D ; 5: n=25$ both before and after intervention; $k$, number of items.

Table 4 Percentage of correctly performed ilems during the 3 standardized patients' visits before and after educational intervention for control and experimental groups of general practitioner trainees in the Nutrition Education by Computerized Training and Research (NECTAR) study

\begin{tabular}{|c|c|c|c|}
\hline & $\begin{array}{l}\text { Before intervention } \\
\qquad(k=118)\end{array}$ & $\begin{array}{l}\text { Alter intervention } \\
\qquad(k=115)\end{array}$ & $P$-value 2 \\
\hline \multicolumn{4}{|c|}{ All visits $(n=287)$} \\
\hline Control & $20.1 \pm 5.2^{4}$ & $22.4 \pm 8.0$ & 0.140 \\
\hline Experimental" & $20.1 \pm 8.8$ & $36.1 \pm 9.2$ & $<0.001$ \\
\hline \multicolumn{4}{|c|}{ Undetected visits $(n=213$ ) } \\
\hline Control & $19.1 \pm 6.3$ & $20.8 \pm 6.9$ & 0.150 \\
\hline Experimental" & $18.4 \pm 4.3$ & $33.0 \pm 11.4$ & $<0.001$ \\
\hline
\end{tabular}

1: The educational intervention consisted of computer-based instruction on nutrition; $k$, number of standardized patients checklistitems; 2 : paired samples ttest; $3: n=24$ before intervention; $n=23$ after intetvention; $4: x+5 D ; 5: n=25$ before intervention; $n=24$ after intervention; $6: n=21$ before intervention, $n$ $=20$ after intervention; $7: n=23$ before intervention, $n=18$ after intervention. 
of validity, we subsequently computed the scores of undetected wisits, which are also shown in Table 4 . This resulted in a relative improvement of the SP score of the expertmental group of $79.3 \%$. Analysis of covariance showed a significant experimental versus control group difference of $12.8 \%(P<0.001)$ at posttest, inplying $268.4 \%$ improvement in the experiment group relative to the mean pretest score.

\section{CONFOUNDING VARIABLES}

Analyzing for confounding variables, we found 2 items on the GP trainers' questionnaires on which the trainers of GP trainees in the experimental group had scored significantly higher than the trainers of the control group GP trainees (Table 2). The first item, "perceived importance of nutrition in GP training" did not significantly correlate with posttest scores on the knowledge test $(r=-0.186 ; P=0.204)$ or the SP posttest score $(r=$ $0.244 ; P=0.099$ ). "Use of obesity brochure" showed significant correlations with neither the knowledge test $(r=0.180 ; P=0.221)$ nor the SP test $(r=0.223 ; P=0.115)$.

We also found a significant difference of $5.8 \%(P=0.001)$ in 5 P pretest scores between male and female GP trainees and a significant difference of $4.4 \%(P=0.024)$ between GP trainees who had graduated from Mastricht University and those who had graduated from other institutions. Introducing sex and the university of undergraduate medical studies into the analysis of covariance showed that these variables were not confounding, as they hardly caused any change in the experimental versus control group difference on the SP posttest (31).

\section{DISCUSSION}

We carried out a controlled experiment with the objective of evaluating the degree to which our CBI on nutrition was able to change knowledge and practice behavior of GP trainees. At both the "knows" level and the "performance" level (19), the findings revealed differences between the group of CP trainees who had received the CBI and the trainees who had taken the standard vocational training program, the former showing considerably greater improvement.

The results of the knowledge test are encouraging, although it must be acknowledged that the questions in this test concentrated on straightforward facts. Facts and figures about nutrition are provided in the CBI in "pop up" screens, which can be activated on demand during the session, and in concluding tutorials. It is debatable how eagerly GP trainees searched for these elements in the CBI. Some GP trainees in the experimental group stated their disappointment on being questioned on facts and figures in the posttest, as they had not paid much attention to these elements in the CBI in their search for practical tools. A semiannual Dutch national knowledge test for GP trainees provides some comparative material on the development of GP trainees" knowledge about nutrition, as induced by the CBI (24). This national knowledge test, covering the total GP domain, shows an average growth in knowledge among all first-year CP trainees that is. 
quite similar to the growth in knowledge about nutrition we found in our experimental group GP trainees. This suggesis that knowledge about nutrition in our control group GP trainees fell short of their knowiedge about the total GP domain.

The results of the performance test taken by our GP trainees are remarkable for more than one reason. First, we succeeded in establishing an improvement in consultation behavior, using incognito SPs as an instrument. Although several studies have been conducted using $S P_{S}$ in practice, effects on practice behavior were rather ambiguous $(32,33)$. Second, the practice behavior itself was found to improve, indicating that the nutrition $C B 1$ is suitable for achieving this relatively ambitious target. We attribute this outcome to the concept of the CBI being a simulation of CP consultations. As GP trainees seem to be focused on the acquisition of tools for daily practice, the program provides them with not only written guidelines for nutrition history-taking and nutrition guidance, but also video clips of GP experts as role models for good nutrition practice. The SPs' pretest scores, as a measure of current practice behavior on the subject of nutrition, confirmed our expectations. These expectations were based on previous research among GPS and GP trainees, indicating a lack of nutrition education and a lack of sufficient consultation time as important barriers to performing nutrition guidance (12). The CBI seerned to remove both barriers. Clearly it offers sound nutrition education. Furthermore, our results suggest that GP trainees overcome the barrier of the lack of sufficient consultation time as soon as they have acquired the necessary practice skill of nutrition history-taking and nutrition guidance.

The question may be raised whether the absolute level of practice behavior achieved after our intervention is relevant for daily practice. Some idea of this can be obtained by comparing the scores of our GP trainees, whose mean score was $36 \%$, with those of experienced GPs found in previous studies with SPs, showing mean scores of $55 \%(17$, 34). Of course, we have to take into account that these studies belonged to a different domain. Nevertheless, our findings show that the CBI did help GP trainees to make considerable progress towards reaching experience levels found among practicing GPs. Whereas GPs likely take several consultations to deal with patients' complaints thoroughly (35), the vast majority of the SPS' visits turned out to be one consultation only, a situation partly accounted for by the limited time available in the study. This means that the results of our study have to be categorized as short-term and based on one consultation.

With regard to the composition of the experimental and control groups, we conclude that we have managed to achieve adequate similarity in terms of characteristics and SP pretest scores. However, we have to take into account the relatively small number of subjects included, causing rather wide confidence intervals.

We wondered whether our study assessed the real performance of our GP trainees, as the detection rate of SPS was somewhat higher than that found in other SP studies (36). However, the scores found in the analysis of only undetected visits hardly differed from those based on all visits. The effect on practice behavior, within the experimental group as well as between the experimental and control groups, was firmly sustained in the 
subgroup of undetected visits. As GP trainees were visited by SPs in their own consultation rooms, during regular consultation hours, we may conclude that our assessment of GP trainees in practice, based on all visits, very closely reflects daily practice performance.

Finally, to return to the educational starting point of the study, the merits of the nutrition CBI in the education of GP trainees on the subject of nutrition are obvious. What is noteworthy is not only the effects of the program, as discussed above, but also the fact that the GP trainees used this program without any teacher intervention. The CBI permits self-directed learning by GP trainees, a learning method that is one of the basic elements of a new curriculum to be implemented in Dutch GP vocational training. Furthermore, as models of nutrition guidance do not differ between GPS and GP trainees (12), it should also be possible to use the CBI for refresher courses for practicing GPs. In terms of intrinsic motivation, similar or even better effects might be anticipated, given that GPs may voluntarily choose to attend the program, whereas GP trainees had the program imposed on them.

For many years, teachers and trainers have entertained great hopes for using information and computer technology for educational purposes. We hope our study will contribute to speeding up the changes in the educational landscape.

We thank Amold D. Mt. Kester of the Department of Methodology and Statistics at Matastricht University for his advice on the analysis of this study.

\section{REFERENCES}

1. Dutch Nutrition Foundation. Huisarts en voeding (General practitioner and nutrition). The Hague: Dutch Nutrition Foundation, 1997 (in Dutch).

2. Deen D J $r$, Karp $R$, Lowell $B$. A new approach to nutrition education for primary care physicians in the United States. Gen Untern Med 1994;9:407-8.

3. American Academy of Family Physicians. Nutrition: recommended curriculum guidel ines for family practice residents. June 2000. Internet: htp:/www atafp.org/edu/guide/rep $275 \mathrm{html}$ (accessed 24 july 2002).

4. The Group on Nutrition, Society of Teachers of Family Medicine. Physician's curriculum in clinical nutrition: primary care. 2 nd ed, 2001. Internet: http://www.stim.org/pdis/Croupon Nutrition.pdf laccessed 31 July 2002).

5. Kohlmeier $M$, Althouse L, Stritter $F$, Zeisel $S H$. Introducing cancer nutrition to medical students: effectiveness of computer-based instruction. Am / Clin Nutr 2000;71:873-7.

6. Michener JL. Nutrition, education, and family physicians. Arch Fam Med 1997;6:146-7.

7. Report of the American Medical Student Assoctation's Nutrition Curriculum Project. Essenthals of nutrition education in medical schools: a national consensus. Am I Clin Nutr 1997;65:1559-61.

8. Murphy PS. Effect of nutrition education on nutrition counseling practices of family physicians. Acad Med 1989:64:98-102.

9. Ritenbaugh $C K$, Thomson $C A$, Taren D, et al. Nutrition curriculum in medical education: an integrated and comprehensive approach. Teach Learn Med 1996:8:102-10. 
10. Young EA. Weser E, McBride HM, Page CP, Littlefield JH. Development of core competencies in clinical nutrition. Am / Clin Nutr 1983;38:800-10.

11. Hiddink $\mathrm{Gl}$, Hautvast $G$, van Woerkum $C M$, Fieren $C J$, van 't Hof MA. Nutrition guidance by promary-Care physicians: LISREL analysis improves understanding. Prev Med 1997;26:29-36.

12. Maiburg HI, Hiddink GI, van "t Hof MA, Rethans JJ, wan Ree JW. The NECTAR study: development of nutrition modules for general practice vocational training; determinants of nutrition guidance practices of GP trainees. Eur | Clin Nutr 1999;53:583-8.

13. Hiddink $\mathrm{GJ}$, Hautwast $\mathrm{IG}$, van Woerkum $\mathrm{CM}$, Fieren $\mathrm{C}$, van 't Hof MA. Consumers' expectations about nutrition guidance: the importance of primary care physicians. Am I Clin Nutr $1997 ; 65: 19745-9 \mathrm{~s}$

14. Kolasa KM, Miller MG. New developments in nutrition education using computer technology. I Nutr Educ 1996;28:7-14.

15. Cohen PA, Dacanay LS. Computer-based instruction and health professions education: a meta-analysis of outcomes. Evall Health Prof 1992;15:259-81.

16. Kulik CLC, Kulik IA. Effectiveness of computer-based instruction: an updated analysis. Compur Hum Behav 1991;7:75-94.

17. Rethans II, Sturmans F, Drop R, van der Vleuten C, Hobus P. Does competence of general practitioners predict their performance? Comparison between examination setting and actual practice. BMI 1991;303:1377-80.

18. Rethans J), Norcini J, Barón-Malldonado $M$, et al. The relationship between competence and performance: implications lor assessing practice performance. Med Educ 2002;36:901-9.

19. Miller GE. The assessment of clinical skills/competence/performance. Acad Med $1990 ; 65: \$ 63-7$.

20. Ram PM. Comprehensive assessment of general practitioners. Maastricht: Maastricht University, 1998.

21. Veloski IJ, Rabinowitz HK, Robeson MR, Young PR. Patients don't present with five choices: an altemative to multiple-choice tests in assessing physicians' competence. Acad Med $1999 ; 74: 539-46$.

22. Bordage $G$, Brailovsky $C$, Carnetier $H$, Page $G$. Content validation of key features on a national examination of clinical decision-making skills. Acad Med 1995;70:276-81.

23. Bage $\mathrm{G}$, Bordage $\mathrm{G}$, Allen $\bar{T}$. Developing key-feature problems and examinations to assess clinical decisionmaking skills. Acad Med 1995;70:194-201.

24. van Leeuwen $\mathrm{YD}$. Growh in knowledge of trainees in general practice. Maastricht: Maastricht University, 1995.

25. Rethans IJ, Westin S, Hays $\mathbb{R}$. Methods for quality assessment in general practice. Fan Pract $1996 ; 13: 468-76$.

26. Vu VN, Barrows HS. Use of standardized patients in clinical assessments: recent developments and measurement findings. Educ Res 1994;23:23-30.

27. Gorter SI., Rethans J, Scherpbier AJIA, et al. How to introduce incognito standardized patients into outpatient clinics of specialists in rheumatology. Med Teach 2001;23:138-44.

28. Rethans II, Drop $R$, Sturmans, $F$, van der Vleuten $C$. A method for introducing standardized (simulated) patients into general practice consultations. Br J Gen Pract 1991;41:94-6

29. Vickers Al, Altman DG. Statistics notes: analysing controlled trials with baseline and follow up measurements. BMJ 2001;323:1123-4.

30. Huizingh KRE Inleiding SPSS 9.0 voor Windows en data entry (Introduction to SPSS 9.0 for Windows and data entryy. Schoonhoven: Academic Service, 2000 (in Dutch). 
31. Maldonado G. Greenland S. Simulation study of confounder-selection strategies. Am J Epidemiol 1993; $138: 923-36$.

32. Casebeer $\mathrm{LL}$, Klapow $\mathrm{IC}$, Centor RM, et al. An interwention to increase physicians use of adherence-enthancing strategies in managing hypercholesterolemic patients. Acad Med 1999:74:1334-9.

33. Gerrity MS, Cole SA, Dietrich AJ, Barrett JE. Improving the recognition and management of depression: is there a role for physician education? I Fam Pract 1999;48:949-57.

34. Lockver J, el Guebaly N, Simpson E, Gromoff B, Toews J, Juschka B. Standardized patients as a measure of change in the ability of family physicians to detect and manage alcohol abuse. Acad Med 1996;71:51-3.

35. van Weel C. Nutritional guidance in general practice - a conceptual framework. Eur I Clin Nutr 1999;53(supp) ):S108-11.

36. Rethans JI. Needs assessment in continuing medical education through standardized patients. I Contin Educ Health Prof 1998;18:172-8. 
PROGRESS OF PRACTICE BEHAVIOR IN GENERAL PRACTITIONER TRAINEES IN CONSULTATIONS WITH INCOGNITO STANDARDIZED PATIENTS WITH NUTRITION-RELATED COMPLAINTS; A CONTROLLED TRIAL OF THE EFFECT OF A COMPUTER-BASED NUTRITION TRAINING

Submitted as: Progress of practice behavior in general practitioner trainees in consultations with incognito standardized patients with nutrition-related complaints; a controlled trial of the effect of a computer-based nutrition training. Bas HJ Maiburg, Jan-foost E Rethans, Lambert WT Schuwirth, Lisbeth MH MathusVliegen and Jan $W$ van Ree. 


\section{ABSTRACT}

Background A newly developed computer-based instruction on nutriton has shown substantal overall effects on GP tranee practice behavior. The present sudy concentrated on nutritional aspects of the consulations by the trainces.

Objective To assess the improvement in handing warious nutrition-related cases, the adequacy of nutrition-based consultation categories and the content of the nutritional advice given.

Design Controlled trial, using 3 incognito standardized patients visits in a pre- and posttest format with 49 firstyear GP tranees. The experimental group on $=25$ ) received computer-based instruction on mutrition. The controls $(n=24)$ attended the standard vocational thining program.

Results Gi wanees in the experimental group significantly improved between pre- and postlest on all cases and consultation categores. Analysis of covariance, with the pretest scores as covariate, revealed a significant experimental versus control group difference at posttest for all cases (intestinal problems $11.3 \%$. $P$ $=0.001$; cardiovascular disease/hypertension $12.0 \%, P=0.003$; overweighv diabetes mellitus $13.1 \%, P<0.001$ ) and consultation categories (general history taking $3.1 \%, P=0.005$; diel history taking $18.6 \%, P=0.001$; physical examination $13.9 \%, P$ $=0.002$; nutrition guidance $14.3 \%, P<0.001$. Posttest revealed a significant inter-case correlation of scores on all cases and a significant correlation beween diet history laking and nutrition guidance scores. Retevant ditterences between soups in the content of nutritional advice were found.

Conclusions Effects of computer-based instruction appeared to be case-independent. It provided GP trainees with a consistent method of handling nutrition-ralated medical problems. Nutritional advice given by CP trainees improved most obviously tor the fat-intake issue. 


\section{INTRODUCTION}

General practitioners ( $C_{5}$ ) play an important role in delivering the message of healthy nutrition to patients, who perceive GIPs as a reliable source of nutrition information (1). Many GPS, as well as GP trainees, feel obstructed in the execution of this task by a perceived deficiency in nutrition knowledge and skills $(2,3)$. The mutrition guidance domain that GPs should be able to cover during daily practice can be found in the various national guidelines on nutrition issued by nutrition authorities and national colleges of general practitioners $(4,5)$. Overweight and obesity, cardiowascular disease and diabetes mellitus are among the most important topics, based on incidence, morbidity and the frequency of patients' questions on these issues. In the Netherlands, the topic of intestinal problems is also prominent, according to GPs (Maiburg, Rethans, van Ree, 1998).

The NECTAR (Nutrition Education by Computerized Training and Research) study, carried out at Maastricht University, aimed at enhancing the knowledge and skills of GP trainees on all of these nutrition topics. Given the established and accepted educational value of computer-based instruction (CBI) in general $(6-8)$, we tried to achieve this objective by constructing such a CBI. A previous study demonstrated the overall effectiveness of our CBI with respect to factual knowledge and practice behavior among GP trainees (9). The program induced marked improvements in practice behavior among GP trainees who followed the computer-based nutrition course, whereas few studies had so far showed such performance effects $(10,11)$. The above study assessed the effect of the CBI on practice behavior by having GP trainees visited by 3 incognito standardized patients with different nutrition-related medical problems, during their regular consultation hours $(12,13)$.

In the present study we concentrated on the nutritional aspects of these daily practice consultations. First, from the point of view of content-specificity (14), one would expect different degrees of improwement for the various medical problems presented to GP trainees. Our first objective was to assess whether the 3 cases contributed equally to the overall effect, irrespective of their nutrition content. Next, we wanted to address several questions about the achievements of GP trainees in their consultations. Did the CBI affect all categories of their consultations (i.e. general history taking, diet hislory taking, physical examination and nutrition guidancel or only their nutritional recommendations? Did the trainees merely apply a fixed protocol for nutrition guidance, as a sort of inflexible routine, or did they tailor their recommendations to patients' regular food intake (15)? These questions yielded the 2 following objectives for the present study: to examine how consistently the adequacy of nutrition-based consultation categories improwed and how diet history taking was related to the nutrition guidance provided by the GP trainees. Finally, since the beneficial effects of many nutritional recommendations has been established, what good might be expected from the nutrition guidance given by GP trainees, and which elements did they incorporate in their advice? This 
generated a fourth objective: to identify the content of nutritional advice, focusing on the items on which the GP urainees showed improvement.

\section{SUBJECTS AND METHODS}

We carried out a controlled trial between July 2000 and July 2001 . Below is a brief description of the general design of this trial. For a more comprehensive description we refer to a previously published study $(9)$.

\section{SUBJECTS, INTERVENTION AND DESIGN}

All 49 GP trainees who entered GP vocational training in 2000 at Maastricht University took part in the study. The selection committee at the Department of GP Vocational Training allocated the trainees to four groups of which two were to constitute the experimental group $(n=25)$ and wo the control group $(n=24)$.

Trainees in the experimental group followed a newly developed computer-based nutrition training, a simulation of general practice involving 12 interactive streaming-video patient cases. The course was scheduled on their regular vocational training days, in addition to the standard vocational training program. The trainees took an average of 6 hours of self-directed, individual training. The control group merely underwent the standard vocational training program.

We assessed all GP trainees before and after the educational intervention (pretest/posttest format) by means of checklists completed by standardized patients who visited the trainees incognito at regular consultation times. The practice test with incognito standardized patients is described below.

\section{INSTRUMENTS: INCOGNITO STANDARDIZED PATIENTS}

We used incognito standardized patients (SPS) to obtain as accurate an assessment as possible of what GP trainees actually do in daily practice (performance) and to present standardized nutrition-related cases to all trainees $(16,17)$. Un order to cover the whole domain of our CBI, which is built up around 6 nutrition topics (food pyramid, overweight/obesity, diabetes mellitus, hypercholesterolemia, hypertension, and irritable bowel syndrome/constipationi, we needed to incorporate all of these themes into the SP roles as well. Since feasibility issues meant that we considered 3 cases to be the maximum, the SP roles to some extent combined nutrition topics. In the end we constructed 1 male role, reflecting an overweight diabetic, and 2 female roles: one a middle-aged woman with moderately elevated serum cholesterol and blood pressure and one a woman with abdominal complaints and constipation (Figure 1). Aspects of the food pyramid were present in each case. The nutrition-related contents of pre-and posttest roles were similar, and all roles provided similar room for improvement of the trainees" performance regarding the issue of regular food intake. 


\section{Case 1: Intestinal problems}

Female, 38 years old, owner of fashion store

Main complaint. "I"ve got that uncomfortable sensation in my belly again, and for the last few months l've been having problems with my stools again".

Confext: periodic problems with defecation and abdominal discomfort; has received all kinds of well-meaning advice from friends and tamily

Question: "I hope you can give me some useful advice on this problem. 1 prefier a natural approach to my problems".

Food intake: often skips breakfast, insufficient fibers (bread, frut, vegetables), marginall fluid intake. Physical findings: $B M 121.6 \mathrm{~kg} / \mathrm{m}^{2}$; Abdomen: normal

\section{Case 2: Cardiovascular disease/Hypertension}

Female, 50 years old, housewite

Main complaint: "I feel uneasy about the results of the population screening that I take part in.

Some figures are really high, such as my blood pressure and cholesterol".

Context: shows results of population screening; father suffered from elevated cholesterol and died of heart disease.

Question: "I really want to mind my lipids and blood pressure. 1 am not looking for a prescription, but î́ necessary..."

rood intake: snacks now and then, falt intake too high (butter, sandwich fillings, meat), fair amounts of fruit and vegetables.

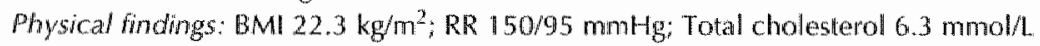

\section{Case 3: Overweight/Düabetes mellitus}

Male, 47 years old, police officer

Main complaint: "Two days ago I again sprained my ankle and according to my wite it has to do with my weight".

Context: friend, diabetic, suffered a diabetes-related myocardial infarction one week ago.

Question: "I now want to take my health more seriously. Shouldn't I start losing weight or have some prescription for my diabetes or take some speciall products for diabetics?"

Food intake: many snacks, fat intake too high (sandwich fillings, meat), insufficient fruit and vegetables.

Physical hindings: BMll $27.1 \mathrm{~kg} / \mathrm{m}^{2}$; RR $13090 \mathrm{mmHg}$ : Waist circumference $99 \mathrm{~cm}$

Figure 1. Summary of the content of the 3 standardized patients' cases at posttest in the Nutrition Educattion by Computerized Training and Research (NECTAR) study.

The contents of the checklists were developed together with the experts who had also contributed to the content of the CBI. Checklist items were derived from the items used in the $\mathrm{CBI}$, and the items of each checklist were attuned to represent the perfect handling of the patient. The format of the items is shown in Figure 2. Checklists consisted of an average of 39 items (range 35-42). Immediately after they had visited a GP trainee, the SPs assessed the trainee using their case-specific checklist. We computed the score for each case as the number of correctly performed items (incorrectly, dubiously ar not performed items scoring zero) per checklist. Subsequently we converted this score into a percentage score to enable comparison of cases. 


\section{Diabetes mellitus/Overweight}

During the consultation (i.e. history taking), the general practititioner (GP) trainee paid attention to:

Recent changes in weight

Micturition problems

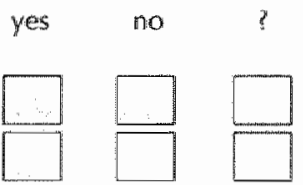

\section{Diet history taking}

Type of bread and number of slices.

Frequency and quantity of eating fruit

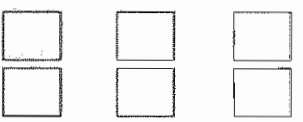

\section{During physical examination:}

The GP trainee measured weight

The CP trainee measured waist circumference

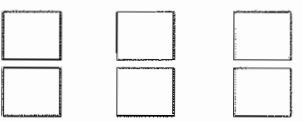

During the consultation (i.e. nutrition guidance), the GP trainee:

Explained the meed for a 5-10\% weight reduction

Advised against special products for diabetics

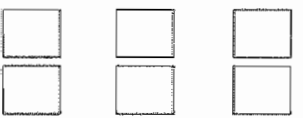

Figure 2. Examples of items from the individual consultation categories in one of the standardized patients checklists at posttest in the Nutrition Education by Computerized Training and Research (NECTAR) study.

Within each checklist, items were divided into four categories: general history taking, diet history taking, physical examination and nutrition guidance (Figure 2). General history taking comprised lifestyle and disease-related questions, whereas diet history taking aimed at assessing regular food intake (food frequency and usual intake method). For the total score of each category, we computed the mean of the category scores per checklist.

The total set of nutrition guidance items in each of the SPs" checklists at posttest is shown in Table 1. To compare the experimental and control groups at the level of the nutrition guidance content per case, we computed the mean score of the component itens (ranging from 0 to 1). We considered differences of at least 0.20 between the experimental and control groups to be relevant.

\section{STATISTICS}

We used analysis of covariance to assess the significance of experimental versus control group differences in scores on the $3 \mathrm{SP}$ cases and on the consultation categories at posttest, using the pretest score as covariate (18). This allowed us to correct for differences between the experimental and control groups at baseline. The validity of the analysis 
Table 1 Case-specific nutrition guidance items in the three standardized patients" checklists at post test in the Nutrition Education by Computerized Training and Research (NECTAR) study

\section{Intestinal problems}

Emphasized a voluminous, non low fat breakfast

Recommended more and fiber-rich bread

Recommended more potatoes (alternating with wholemeal pasta/unpolished rice)

Recommended more vegetables (pulse, beans and salads)

Emphasized more fruit (unpared apples, citrus fruits)

Recommended gradually increasing the use of fibers

Recommended increasing the intake of fluids to 2 liters/day

Emphasized taking sufficient time to defecate

Handed patient brochure about fiber-rich foods

Recommended keeping a food record

Cardiovascular disease/hypertension

Explained risk of cardiovascular disease

Underlined positive elements of current food intake

Recommended diet margarines

Recommended less fatty sandwich fillings (smoked beef, chicken breast)

Recommended less fatty meat (rump steak, chicken without skin)

Eunphasized minimizing snacks

Recommended regularly including fish meals

Emphasized the importance of weight control

Advised against adding salt

Advised against ready-to-serve products

Handed patient brochure about cholesterol low foods

Recommended keeping a food record

Overweight/diabetes mellitus

Explained the need for a $5 \%$ weight reduction

Emphasized the necessity of physical exercise

Explained the non-existence of a specific diabetes diet

Advised against special products for diabetics

Recommended less fatty sandwich fillings (smoked beef, chicken breast)

Advised less fatty meat (rump steak, chicken without skin)

Emphasized minimizing snacks

Reconmended regularly including fish meals

Advised more and fiber-rich bread

Recommended more potatoes (alternating with wholemeal pasta/unpolished ricel

Recommended more vegetibles (pulse, beans and salads)

Emphasized more fruit (unpared apples, citrus fruits)

Handed patient brochure about diabetes mellitus

Recommended keeping a food record

Suggested referral to dietician

models was checked using residual plots. We also used analysis of covariance to elicit and correct for confounding variables. Variables whose introduction into the analys is of covariance provoked a change in the group difference of $10 \%$ or more were regarded as 
Table 2 Percentage of correctly performed checklist items per case and consultation categony, based on all standardized patients wisis $(n=287)$ before and after educational intervention for control and experimental groups of general practitioner trainees in the Nutrition Education by Computerized Training and Research (NECTAR) study

\begin{tabular}{|c|c|c|c|}
\hline & $\begin{array}{c}\text { Before } \\
\text { intervention }\end{array}$ & $\begin{array}{c}\text { After } \\
\text { interwention }\end{array}$ & $p-$ value $^{2}$ \\
\hline \multicolumn{4}{|l|}{ Cases } \\
\hline \multicolumn{4}{|c|}{ Intestinal problems ( $k=38$ before, 35 after) } \\
\hline Control ${ }^{3}$ & $34.2 \pm 9.8^{4}$ & $32.4 \pm 12.0$ & 0.260 \\
\hline Experimental & $32.3 \pm 12.2$ & $43.0 \pm 11.7$ & 0.003 \\
\hline \multicolumn{4}{|c|}{ Cardiovascular disease/hypertension $(k=38)$} \\
\hline Control & $10.9 \pm 5.0$ & $13.2 \pm 7.7$ & 0.353 \\
\hline Experimental & $11.3 \pm 9.4$ & $25.2 \pm 16.2$ & 0.003 \\
\hline \multicolumn{4}{|c|}{ Overweightriabetes mellitus $(k=42)$} \\
\hline Control & $15.4 \pm 7.3$ & $21.5 \pm 10.1$ & 0.020 \\
\hline Experimental & $16.7 \pm 10.6$ & $40.2 \pm 12.4$ & $<0.001$ \\
\hline \multicolumn{4}{|c|}{ Consultation categories } \\
\hline \multicolumn{4}{|c|}{ General history taking ( $k=39$ before, 36 after) } \\
\hline Control & $28.1 \pm 8.9$ & $27.7 \pm 8.2$ & $0.7 \| 5$ \\
\hline Experimental & $29.1 \pm 10.1$ & $36.4 \pm 11.4$ & 0.0\|\| \\
\hline \multicolumn{4}{|c|}{ Diet history laking ( $k=30$ ) } \\
\hline Control & $7.4 \pm 9.3$ & $15.3 \pm 16.2$ & 0.060 \\
\hline Experimental & $8.0 \pm 13.2$ & $34.2 \pm 20.7$ & $<0.001$ \\
\hline \multicolumn{4}{|c|}{ Physical examination $(k=12)$} \\
\hline Control & $14.1 \pm 8.8$ & $11.8 \pm 11.3$ & $0.2 \| 6$ \\
\hline Experimental & $16.0 \pm 10.0$ & $27.2 \pm 18.1$ & 0.004 \\
\hline \multicolumn{4}{|c|}{ Nutrition guidance $(k=36)$} \\
\hline Control & $23.4 \pm 8.8$ & $26.6 \pm 10.2$ & 0.217 \\
\hline Experimental & $20.9 \pm 10.4$ & $40.4 \pm 13.2$ & $<0.001$ \\
\hline
\end{tabular}

1: The educational intervention consisted of computer-based instruction on nutrition; 2 : Wilcoxon signed ranks test; $k$, number of standardized patients checklist items; $3: n=24$ before intervention; $n=23$ after intervention; $4: \bar{x} \pm S D ; 5: n=25$ before intervention; $n=24$ after intervention.

confounders (19). We thested the significance of the differences between pre- and posttest scores of the trainee groups with the help of Wilcoxon signed ranks tests.

To analyze the quantitative relation between diet history taking and nutrition guiclance and to assess inter-case correlation between scores we computed correlations by means of Pearson r for the total group of GP trainees. Two-sided P-values equal to or $<0.05$ were considered significant. We carried out all analyses in SPSS for Windows 9.0 (SPSS Inc, Chicago, IL) (20). 
Table 3 Differences between the experimental and control groups in scones on cases and constilation categories ${ }^{\prime}$ at posttest in the Nutrition Educaton by Computenzed Training and Research (MNECTAR) study: analysis of covariance based on all standardized patients "visits and on the subgroup of undetected visits

\begin{tabular}{|c|c|c|}
\hline \multicolumn{3}{|l|}{ All visits } \\
\hline \multicolumn{3}{|l|}{ Cases } \\
\hline Intestinal problems & 11.3 & 0.001 \\
\hline Cardiovascular disease/hypertension & 12.0 & 0.003 \\
\hline Overweight/diabetes mellitus & 18.1 & $<0.001$ \\
\hline \multicolumn{3}{|l|}{ Consultation categories } \\
\hline General history taking & 8.1 & 0.005 \\
\hline Diet history taking & 18.6 & 0.001 \\
\hline Physical examination & 13.9 & 0.002 \\
\hline Nutrition guidance & 14.3 & $<0.001$ \\
\hline \multicolumn{3}{|l|}{ Undetected visits $(n=213)$} \\
\hline \multicolumn{3}{|l|}{ Cases } \\
\hline Intestinal problems & 13,2 & 0.005 \\
\hline Cardiovascular disease/hypertension & 11.3 & 0.018 \\
\hline Overweight/diabetes mellitus & 21.0 & $<0.001$ \\
\hline \multicolumn{3}{|l|}{ Consultation categories } \\
\hline General history taking & 7.3 & 0.051 \\
\hline Diet history taking & 16.1 & 0.003 \\
\hline Physical examination & 13.8 & 0.036 \\
\hline Nutrition guidance & 15.5 & 0.003 \\
\hline
\end{tabular}

$$
\text { Corrected difference }{ }^{2} \quad P-\text { value }^{3}
$$

1: Scores based on the percentage of correctly performed checklist items during the standardized patients' visits; 2: Regression coefficient for group in ANCOVA; 3: ANCOVA with pretest scores as covariate.

\section{RESULTS}

The overall pre- and posttest scores on the SP in practice test showed a significant improvement in the experimental group, from $20.1 \%$ at pretest to $36.1 \%$ at posttest, whereas the control group showed a non-significant improvement, from 20.1 to $22.4 \%$ 19). The present study concentrated on the various cases and on the individual categories and nutritional recommendations in the SP consultations. Of the $2875 \mathrm{P}$ visits actually carried out, 74 were detected as such by GP trainees. Two trainees left the vocational training program in the posttest phase, one from each research group.

\section{CASES, CONSULTATION CATEGORIES AND NUTRITIONAL ADVICE}

The pre- and posttest scores for each of the 3 SP cases and for each consultation category, based on all wisits, are presented in Table 2. Trainees in the experimental group significantly improved on all cases and categories, whereas those in the control group only showed significant improvernent on the overweight/diabetes mellitus case. 
Tabile 4 Percentage of correctly performed checklist items per case and consultation category in the subgroup of undeltected standardized pattents wisits $(n)=2133$ before and after edicational intervention for control and experimental groups of general practitioner tranees in the Nutrition Education by Computerized Training and Research (NECTARI study"

\begin{tabular}{|c|c|c|c|}
\hline & $\begin{array}{c}\text { Before } \\
\text { intervention }\end{array}$ & $\begin{array}{c}\text { After } \\
\text { intervention }\end{array}$ & $p-$ walue ${ }^{2}$ \\
\hline \multicolumn{4}{|l|}{ Cases } \\
\hline \multicolumn{4}{|c|}{ Intestinal problems ( $k=38$ before, 35 after) } \\
\hline Control ${ }^{3}$ & $33.1 \pm 9.9^{4}$ & $30.6 \pm 10.6$ & 0.345 \\
\hline Experimental & $29.5 \pm 7.8$ & $43.1 \pm 10.1$ & 0.019 \\
\hline \multicolumn{4}{|c|}{ Cardiovascular disease/hypertension $(k=38)$} \\
\hline Control & $10.9 \pm 5.4$ & $12.2 \pm 7.1$ & 0.648 \\
\hline Experimental & $9.8 \pm 5.6$ & $22.9 \pm 17.3$ & 0.017 \\
\hline \multicolumn{4}{|c|}{ Overweight/diabetes mellitus $(k=42)$} \\
\hline Control & $15.7 \pm 7.6$ & $20.2 \pm 9.5$ & 0.038 \\
\hline Experimental & $14.5 \pm 7.5$ & $38.3 \pm 12.9$ & 0.003 \\
\hline \multicolumn{4}{|c|}{ Consultation categories } \\
\hline \multicolumn{4}{|c|}{ General history taking ( $k=39$ before, 36 after) } \\
\hline Control ${ }^{5}$ & $28.2 \pm 10.6$ & $28.0 \pm 7.4$ & 0.215 \\
\hline Experimental ${ }^{6}$ & $28.5 \pm 8.1$ & $36.2 \pm 13.3$ & 0.022 \\
\hline \multicolumn{4}{|c|}{ Diet history taking $(k=30)$} \\
\hline Control & $5.3 \pm 9.7$ & $12.5 \pm 13.1$ & 0.070 \\
\hline Experimental & $4.6 \pm 8.6$ & $27.1 \pm 18.4$ & 0.001 \\
\hline \multicolumn{4}{|c|}{ Physical examination ( $k=12)$} \\
\hline Control & $15.6 \pm 10.7$ & $12.0 \pm 13.4$ & 0.148 \\
\hline Experimental & $15.9 \pm 9.2$ & $23.6 \pm 22.9$ & 0.187 \\
\hline \multicolumn{4}{|c|}{ Nutrition guidance $(k=36)$} \\
\hline Control & $21.8 \pm 9.9$ & $23.3 \pm 9.3$ & 0.435 \\
\hline Experimental & $19.0 \pm 7.6$ & $37.9 \pm 17.1$ & 0.001 \\
\hline
\end{tabular}

I: The educational intervention consisted of computer based instruction on nutrition; 2: Wilcoxon signed ranks test: $k$, number of standardized patients checklist items; $3:$ for control and experimental groups differed between cases due to different numbers of detected visits per case; $4: \bar{x} \pm 50 ; 5: n=21$ before intervention: $n=20$ after intervention; $6: n=23$ betore intervention; $n=18$ affer intervention.

As Table 3 shows, all differences between experimental and control groups for cases and categories at posttest were found to be significant, based on analysis of all visits. Relative to the mean pretest scores, these differences imply that the performance of the Irainees in the experimental group increased by $34 \%$ for the intestinal problems case and doubled for the cardiovascular disease (CVD)/hypertension and overweighv/diabetes mellitus cases. In terms of the individual categories, these differences imply performance improvements by the trainees in the experimental group of $28 \%$ for general history taking $93 \%$ for physical examination and $65 \%$ for nutrition guidance. For the scores on diet history taking, the difference meant a 2.4 fold improvement. Inter-case correlations between all cases appeared to be low to moderate (intestinal problems with $C V D / h y p e r t e n s i o n ~ r=0.389, P=0.007$; intestinal problems with over- 
weight/diabetes mellitus $r=0.554, P<0.001 ; C V D / h y p e r t e n s i o n$ with overweight? diabetes mellitus $r=0.450, P=0.001$ ). The correlation between diet history taking and nutrition guidance at posttest was high for the total group of GP trainees $(r=0.736, P<$ 0.001 ).

As regards nutritional advice at posttest, trainees in the experimental group showed a relevant performance improvement for the intestinal problemis case, in terms of correct advice on fluid intake and the intake of wegetables and fruits. They were also more likely to recommend that the patients complete a food record. In the CVD/hypertension case, trainees in the experimental group outperformed their controls on the item "underlining positive elements of current food intake", and on the issue of tat intake as a whole, by recommending other types of butter or margarine, a reduction of fatty sandwich fillings, spreads and meat, regular fish intake, and minimizing snacks. The same "fat" items emerged from the overweight/diabetes mellitus case, supplemented with correct advice on fruit intake and physical exercise. In the latter case, trainees in the experimental group were also more likely to advise patients to complete a food record and referred patients to a dietician less frequently.

\section{DETECTION OF VISITS}

Since the unmasking of SPs during 74 visits might have led to a spuriously high score for the GP trainee for this visit, we carried out the same analyses of SP cases and consultation categories in the subgroup of undetected visits. In these analyses, the improvement between pre- and posttest scores in the experimental group remained significant for all cases and categories, with the exception of the physical examination category (Table 4). Experimental versus control groups differences at posttest were significant for all cases and categories, with the exception of the general history taking category (Table 3).

\section{CONFOUNDING VARIABLES}

Our search for confounding variables yielded significant differences between male and female GP trainees in the pretest scores for the intestinal problems and overweight/diabetes mellitus cases: $6.6 \%(P=0.034)$ and $7.2 \%(P=0.002)$ respectively. With regard to the scores on consultation categories, we found the following significant pretest differences between male and female trainees: $8.0 \%(P=0.00 \pi)$ on general history taking and $7.7 \%(P=0.005)$ on diet history taking. Pretest differences on nutrition guidance $(6.4 \% ; P=0.019)$ emerged between $G P$ trainees who had graduated from Maastricht University and those who had gracluated from other institutions, whereas posttest differences between these categories related to physical examination ( $10.9 \%$; $P$ $=0.033$ ). Introducing the sex and university of undergraduate studies into the analysis of covariance only yielded the university of undergraduate medical studies as a confounding variable for physical examination at posttest (19). 


\section{DISCUSSION}

The controlled trial we conducted to assess the effectiveness of our newly developed CBI showed a substantial enhancement of overall practice behavior among GP trainees on the subject of nutrition in initial analysis (9). The results for the various nutrition-related cases and individual consultation categories presented in the present article strongly support this previous finding. The present study concentrated on the nutrition knowledge and skills that the GP trainees showed in daily practice, in actually dealing with patients with nutrition-related complaints.

Results for the 3 cases (intestinal problems, CVD/hypertension and overweigh/diabetes mellitus) in the SP test all showed distinct effects, not only within the experimental group but also between the experimental and control groups. Since all cases, which together cover the whole domain of the $\mathrm{CBI}$, seem to contribute to the overall effect, this finding suggests a certain case-independence, which is supported by the low to moderate inter-case correlations. The presumed absence of content-specificity - a major obstacle reported in the literature on medical edlucation - encourages us to expect that newly developed cases on other nutrition topics, presented to GP trainees in our CBI, will have similar effects on practice behavior. Furthermore, the pretest scores for the various cases confirm the perceived lack of practical knowledge in a broad section of the field of nutrition.

However, we also found some differences between cases. The intestinal problems case led to both a higher pretest score and a lower rate of improvement than the 2 other cases. The high incidence of intestinal complaints in daily practice may have led to some degree of self-tuition among GP trainees in addition to the CBI. The content of the trainees' recommendations in this case is promising, as they improved on several key features of this topic. On the other hand, the trainees' posttest scores for the CVD/hypertension case were relatively poor. One could theorize that GP trainees were too easily satisfied with assessing the cardiovascular risk and explaining the low risk to the patient. However, the major improvement found in the experimental group implies that the program did enable these trainees to deliver the correct message about fat intake. Finally, the solid improvement for the overweight/diabetes mellitus case is certainly encouraging. The increasing incidence of both overweight/obesity and diabetes mellitus emphasizes the need for GPs and GP trainees to be adequately trained in the nutritional aspects of these entities (21). As regards the nutritional advice for this case, the GP trainees seemed to stress the importance of adequate fat intake, physical exercise and, to some extent, fiber intake. We feel that the decline in referrals to dieticians by the trainees reflects a certain overestimation of their own knowledge and skills.

As regards the individual consultation categories, we feel confident about the effects on all categories, both within the experimental group and between the experimental and control groups. We think this finding reflects consistent improvement in the adequacy of consultations by the GP trainees for patients with nutrition-related complaints. 
The improvement in diet history taking is striking. Given the limited consultation time and the fact that the trainees mention this limitation as an important barrier to providing nutrition guidance (2), the absolute level achieved means that diet history taking had undoubtedly become a substantial component of the consultations in our study. The same applies to nutrition guidance. Since GPS normally spread rather extensive advice over several consultations (22), we regard the fact that GP trainees achieved $40 \%$ of the "perfect" nutrition guidance score within the limited scope of one consultation as a highly satisfactory result. The improvement in terms of physical examination must be evaluated with some caution. The number of items on which physical examination scores are based is relatively small, which means that small changes in absolute scores yield large changes in the percentage scores used in our analysis. Although the scores seem to suggest that GP trainees understand the importance of measuring height, weight and body circumference of their patients, we cannot draw any definite conclusions. The finding that the trainees who had graduated from universities outside Maastricht performed better on this issue at posttest, whereas no such difference was found in the pretest, can be attributed to the same flaw (small number of items). Changes in general history taking were modest relative to the improvement in other aspects of the consultation. The absolute level, however, was relatively high, especially at pretest. The most logical assumption is to attribute this pretest level to the more lifestyle-directed, i.e. not specifically nutrition-linked, character of the items in this consultation category, which means that these items are also included in the standard vocational training program.

The finding that diet history taking was strongly correlated with nutrition guidance indicates the consistency of the consultation as a whole. Together with the fact that the trainees in the experimental group improved on all consultation categories and on the item "underlining positive elements of current food intake", it provides some insight into the way GP trainees apply their practical knowledge and skills. We think these findings imply that the trainees tailor their nutritional advice to the patients' current food intake, rather than applying a fixed protocol of nutrition guidance. This kind of tailoring has proved to have a much greater influence on patients (15).

Our analysis of the subgroup of undetected visits indicates that there was no substantial influence of the unmasking of SPs during their visits. All of the effects in terms of cases and categories emerging from the analysis (of covariance) of all visits were also found in the subgroup of undetected visits, with the exception of the effect on general history taking. We conclude that adding other nutritional topics to the content of our $\mathrm{CBI}$, and assessing of the accessory effects, will be a worth whille future approach. We hope that this will provide GP trainees with a broader practical knowledge on nutrition and with an even more practical consultation format for handling patients with nutrition-related complaints. 


\section{REFERENCES}

1. Hiddink Gl. Hautvast 1G, van Woerkum CM, Fieren Cl, van 't Hof MA. Consumers' expectations about nutrition guidance: the importance of primary care physicians. Am I Clin Nutr $1997 ; 65: 19745-9 s$.

2. Maiburg HJ, Hiddink GJ, van 't Hof MA, Rethans ll, van Ree JW. The NECTAR study: dewelopment of nutrition modules for general practice vocational training; determinants of nutrition guidance practices of CP-trainees. Eur I Clin Nutr 1999;53:583-8.

3. Hiddink Cl, Hautvast JC, van Woerkum CM, Fieren CJ, wan t Hof MA. Nutrition guidance by primary-care physicians: perceived barriers and low involvement. Eur I Clin Nutr $1995 ; 49: 842-51$

4. American Academy of Family Physicians. Nutrition: recommended curriculum guidetines for family practice residents. June 2000 . Internet: http:// www. aafp.org/ $\times 16543 . \times \mathrm{ml}$ accessed 19 February 2003).

5. The Group on Nutrition, Society of Teachers of Familly Medicine. Physician's curriculum in clinical nutrition: primary care. 2nd ed. 2001. Internet: htp:/www.stfm.org/pdfs/Groupon Nutrition.pdf (accessed 18 Febiuary 2003).

6. Kohlmeier $M$, Althouse $L$, Stritter $F$, Zeisel SH. Introducing cancer nutrition to medical students: effectiveness of computer-based instruction. Am / Clin Nutr 2000;71:873-7.

7. Cohen PA, Dacanay $L S$. Computer-based instruction and health professions education: a meta-analysis of outcomes. Eval Health Prof 1992:15:259-81.

8. Fletcher-Flinn $C M$, Gravatt B. The efficacy of computer assisted instruction (cai): a meta-analysis. I Educ Comput Res 1995;12:219-42.

9. Maiburg HI, Rethans If. Schuwirth LW, Mathus-Vliegen EM, van Ree IW. Controlled trial of effect of computer-based nutrition course on knowledge and practice of general practitioner trainees. Am I Clin Nutr 2003;77(suppl):1019s-24s.

10. Casebeer $L L$, Klapow $J C_{*}$ Centor $R M_{*}$ et al. An intervention to increase physicians' use of adherence-enhancing strategies in managing hypercholesterolemic patients. Acad Med $1999 ; 74: 133: 4-9$.

11. Turner RE, Evers WD, Wood OB, Lehman JD, Peck LW. Computer-based simulations enhance chinicat expenence of dietetics interns. I Am Diet Assoc 2000; 100:183-90.

12. van der Vleuten CPM, Swanson DB. Assessment of clinical skills with standardized patients: state of the art. Teach Leam Med 1990;2:58-76.

13. Vu VN. Barrows HS. Use of standardized patients in clinical assessments: recent developments and measurement findings. Educ Res 1994:23:23-30.

14. Roberts), Noman G. Reliability and learning from the objective structured clinical examination. Med Educ 1990:24:210-23

15. Brug I, Steenhuis I, wan Assema P, de Vries H. The impact of a computer-tailored nutrition intervention. Prev Med 1996:25:236-42.

16. Gorter SL, Rethans 11, Scherpbier AJJA, at al. How to introduce incognito standardized pattients into outpatient clinics of specialists in rheumatology. Med Teach 2001;23:138-44.

17. Rethans II, Westin S, Hays R. Methods for quality assessment in general practice. Fan Pract $1996: 13: 468-76$.

18. Vickers AI. Altman DG. Statistics Notes: Analysing controlled trials with baseline and follow up measurements. BMJ 2001;323:1123-4.

19. Maldonado $G$, Greenland S. Simulation study of confounder-selection strategies. Am J Epidemiol 1993; 138:923-36. 
20. Huizingh KRE. Inleiding SPSS 9.0 voor Windows en data entry fintroduction to SPS5 9.0 for Windows and data entry). Schoonhoven: Academic Service, 2000 (in Dutch).

21. Thomas 5, Geijer RMM, van der Laan \R, Wiersma T, eds. NHG-Standaarden voor de huisarts (Practice guidelines for the general practitioner). Utrecht: Wetenschappelijke uitgeverij Bunge, 1996 (in Dutch).

22. van Weel $\mathbb{C}$. Nutritional guidance in general practice - a conceptual framework. Eur $\mathbb{C}$ Cin Nutr $1999 \cdot 53$ (supplis $5108-11$. 
92

z

tiv

I 
CHAPTER EIGHT

GENERAL DISCUSSION 
The NECTAR study aimed to enhance the knowledge, skills and attitudes of Dutch GP trainees on the subject of nutrition by means of computer-based instruction (CBI). To achieve this general objective, we had to develop a new nutrition CBI and assess its effectiveness. We operationalised the general objective into six specific objectives, three of which were related to the development of the CBI and three to the controlled trial carried out to assess its effectiveness.

The first specific objective was to map out the baseline situation on the subject of nutrition among Dutch GP trainees in terms of nutrition guidance practices. These practices were needed to guide the educational development of a CBI. We constructed models of determinants of nutrition guidance practices of GP trainees, representing predisposing factors, driving forces and perceived barriers of trainees towards nutrition guidance. The second objective was to draw up a concise priority list of nutrition topics, reflecting the needs of Dutch GPs for nutrition education, in order to determine the main topics and educational content of the CBI to be developed. We ended up with a top-five list of topics for nutrition education to GPS and GP trainees.

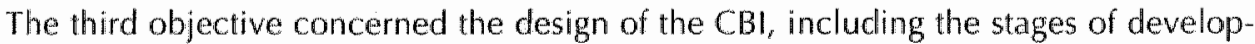
ment, the ultimate structure and content of the CBI and the didactic principles incorporated in it. Together with an educational technologist, we created a computer simulation of general practice, called SIMGP Nutrition in General Practice.

The fourth objective of our study was to describe the development and deployment of one of the measuring instruments of the trial, that of incognito standardized patients (SPs) pretending to be "known" patients. During regular consultation hours, we sent three incognito SPs to the GP offices where trainees worked, both in the pretest and the posttest of our trial.

The fifth and sixth objectives were to assess the improvement of GP trainees' factual knowledge of nutrition and the adequacy of their consultations performed in real practice with patients with nutrition-related complaints, as a result of the CBIl. We found a distinct increase in factual knowledge and a remarkable improvement of practice behaviour among the trainees.

The individual Discussion sections of the preceding chapters have already reviewed the outcomes of the various parts of our study. The present chapter discusses in some more detail the new insights generated by our study, together with their implications for further research.

\section{THE LISREL MODELS OF DETERMINANTS OF TRAINEES' NUTRITION GUIDANCE PRACTICES}

We first sent questionnaires to GP trainees throughout the Netherlands to analyse determinants of trainees ${ }^{*}$ nutrition guidance practices, and subsequently used linear structural relationship analysis (LISREL) to obtain models of the mechanism of action of these 


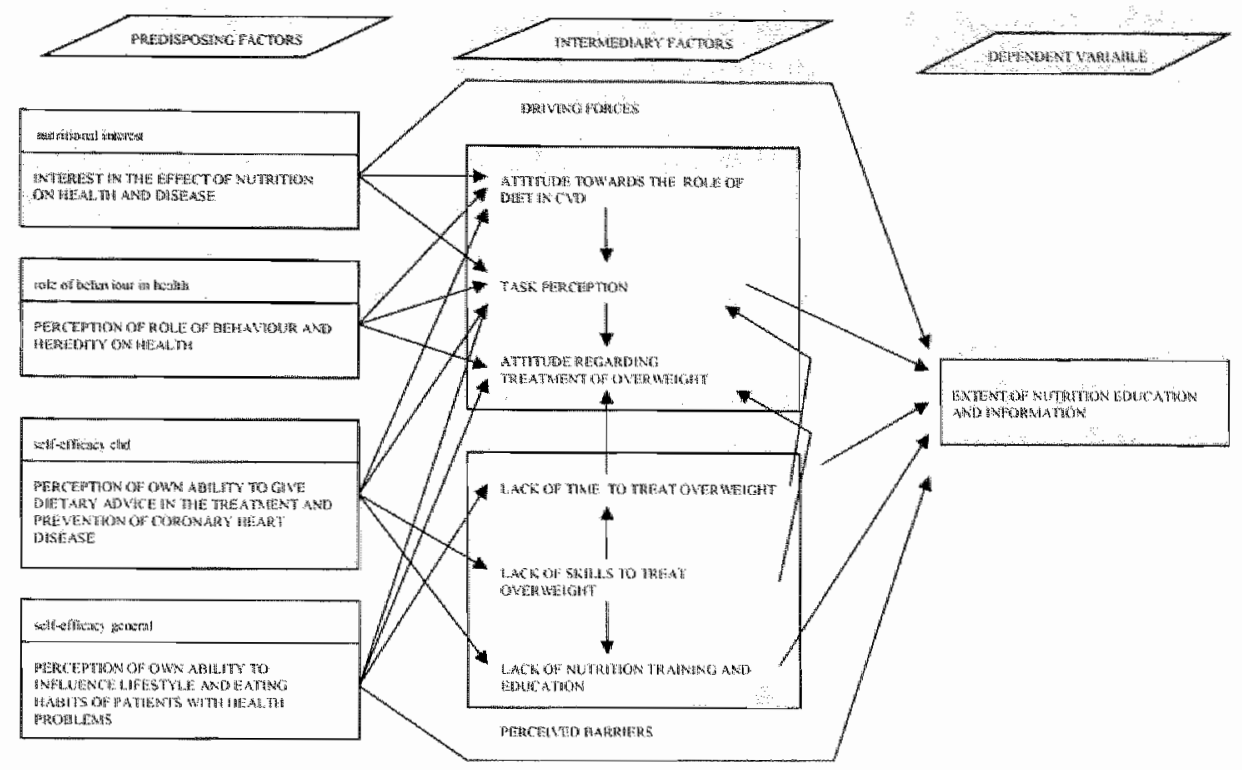

Figure 1. GP trainee model of mechanism of action of determinants of "extent of nutrition education and information".

determinants. Figure 1 displays the model of the variable "the extent of nutrition education and information".

This model, like a second model on "noticing patients' overweight and guidance of treatment", shows predisposing factors, driving forces and perceived barriers of trainees towards providing patients with nutrition guidance, and the mechanism of action of these determinants. This resulted in the desired information about the baseline situation on the subject of nutrition among Dutch trainees in the year 1998, allowing us to tailor the $\mathrm{CBI}$ - at that time still to be developed - to these findings.

We feel it is important to note that the idea that nutrition guidance is an essential part of a GP's task - which emerges from the basic job description for Dutch GPS - has been underlined by the outcome of the first part of our study. Almost all participating trainees $(98 \%)$ considered the provision of nutrition information, especially for the purpose of secondary and tertiary prevention, as a part of their task. Given these findings, it is important to define the role of the GP in the field of nutrition information providers. We elaborate on this issue in the section on the SIMGP Nutrition in Ceneral Practice program.

\section{RECOMMENDATIONS FOR FUTURE RESEARCH}

It would be interesting to see what would happen to the LISREL models if the selected group of trainees who attended the nutrition $\mathrm{CBI}$ completed the questionnaire. The program may well have addressed most of the barriers and driving forces, and some of 
the predisposing factors. We have asked ourselves whether the models would reveal changes in the determinants of nutrition guidance (or their mechanism of action), which have certainly been revealed by the outcome of the practice assessment of these trainees in our controlled trial. However, the limited number of trainees that would be available for such assessment would not only make it difficult to obtain a reliable model, but the outcome would be stating the obvious.

We feel that a more obvious option for future research would be to send our questionnaire to a representative group of trainees who are currently attending GP vocational training in the Netherlands. After all, the questionnaire used in the NECTAR study was completed by a group of trainees who have already completed their vocational training. Hence, sending a questionnaire to actual trainees could ascertain whether there have been any general changes over time in the way trainees address nutrition guidance (comparable to the work by Hiddink among CPS) (1). It seems plausible to expect that the increased attention paid to nutrition in general and the increasing incidence of obesity and diabetes mellitus in general practice in particular have changed trainees" daily practices. If so, we would feel obliged to ewaluate the necessity to attune our nutrition $\mathrm{CBI}$ to current practices.

\section{THE TOP-FIVE NUTRITION TOPICS OF PRACTICE-ORIENTED NUTRITION EDUCATION}

We tried to define a concise priority list of nutrition topics, reflecting the needs of practicing GPs for practice-oriented nutrition education, by carrying out a two-round Delphi study among Dutch CPS. Starting from a 77-item list of nutrition topics in GP practice, we finally generated the following list of five main items for nutrition education: weight problems, diabetes mellitus, hypercholesterolemia, intestinal complaints and hypertension. The Delphi procedure turned oul to be fairly easy to implement, and the discussion with about forty colleagues went smoothly. However, there appeared to be some methodological catches.

To begin with, the list generated by the procedure could be easily taken for a frequency list of nutrition topics in practice. Although the content of the list was probably partly based on the incidence and prevalence of nutrition-related diseases, issues like the level of difficulty of certain topics and existing knowledge among GPS on other topics will also have contributed to the selection respondents made for their personal top-ten lists in the two Delphi rounds. Secondly, it was disputable whether enough GPs participated in the Delphi panel. While increasing the number of respondents would have made the processing of their questionnaires rather laborious, it would have enhanced the external validity of our findings. However, the scores of the top-five topics and the percentage of respondents who selected these topics make it rather unlikely that engaging more respondents would have considerably changed these figures. 
On the wholle, we feel we have generated a concise list of nutrition topics, based on the views of practicing GPs and ranked by their importance for everyday practice. The list was meant to be used to decide upon the main topics to be included the CBI, which was being developed at the time we drew up the list. The nutrition topics included in the cases developed for the computer simulation matched the top-five list precisely. In developing future cases, it would be usefull to select the next topic from the priority list of nutrition topics presented in chapter three.

To avoid the list becoming outdated, new Delphi studies should be held regularly. Emplaying the same group of respondents would allow some sort of monitoring group on nutrition to be established.

We developed a new computer-based instruction, simulating general practice (SMMGP) on the subject of nutrition. The program is composed of two main parts: the non-content SIMGP part and the Nutrition in General Practice part. The SIMGP program resembles the structure of a general practice consultation, with separate screens for the various consultation phases - each screen showing a fixed set of items with accessory background information - and the use of streaming video for the reason-for-encounter and feedback screens. The Nutrition in General Practice program adds nutritional content on the following subjects: overweight/abesity, diabetes mellitus, hypercholesterolemia, hypertension and intestinal problems. At present, the program consists of 12 patient cases in which patients are followed from the moment they enter the waiting room of the GP's office until they leave the consultation room. The computer simulation has been developed as an Internet program, using software which runs on the World Wide Web. We have also produced a CD-ROM version of the program, with exactly the same appearance and features as the WWW version.

This section first discusses some aspects of the use of the program and then some issues with regard to its content.

\section{THE USE OF THE NUTRITION CBI}

In discussing some aspects of the use of the nutrition CBI, we would like to recall two statements made earlier about this program. First, from a didactic point of view, the nutrition CBI might be called "multipotential", as it addresses "predisposing factors" (nutrition knowledge base), "enabling factors" lexpent video recordings of consultations) and "reinforcing factors" (feedback on cases) as described by Davis (2). Although Davis referred to a range of continuing medical education (CME) interventions applied over time, we would like to contend that these factors can also be found within a single intervention or should even be incorporated into each CME course. Secondly, the CBI is 
expected to benefit both visually and verbally oriented users, as both types of orientaw loon are being served by its design.

Users of the program were offered the opportunity to proceed with the cases at their own pace, and actually did so, their pace speeding up in consecutive sessions. Users could also take their own route through the program, selecting the straightforward consultation route or taking the time to explare background information and expert videos. We regard the program as "user-tallored", providing a type of education which is situated at the constructivist end of the scale of educational programmes (3). We think the ultimate fllustration of this constructivist nature was provided by one of the attending trainees, who constructed a practice guideline on nutrition, derived from the CBI, in the format of existing Dutch guidelines for GPS.

We regard the World Wide Web as the medium of choice to implement the nutrition $\mathrm{CBI}$ on a larger scale. The program's test phase proved that it was possible to use all its features via the Internet, including pictures and video clips, provided high-speed Internet connections were used. Reaching a broad forum of potential users will require an English version of the program to be produced: in addition to a straightforward translation of the program and re-shooting the videos, this also will require some fine-tuning with GP authorities in different countries to reach a standard of nutrition education which is internationally acceptable. A carefully considered implementation plan should guide the future use of the program (4).

\section{THE CONTENT OF THE NUTRITION CBI}

The domain of the nutrition CBI can be summarised as that of the Dutch "Guidelines for a healthy diet" and the Dutch food guide derived from these guidelines $(5,6)$. The aspects of history taking and nutrition guidance included in our program aim at achieving the ideal situation described in these guidelines. Although the major nutrients and their presence in the diet are discussed in the CBI, information about food specialities or branded goods is not included in the program.

By making these choices in terms of the content of the $\mathrm{CBI}$, we have in a way separated the role of GPs as providers of nutrition information from that of dieticians. We think CPS should not take a detailed diet history and compute the diet composition in terms of energy and macronutrients but merely assess usual food intake by asking for food frequencies and the usual intake of the main food components. Likewise, we think GPS should not provide patients with detailed dietary advice or exchange lists (for foods), but give clear recommendations on the main food components (7). We feel the performance test in our controlled trial has proved these assumptions to be realistic in everyday practice. Furthemore, a clear distinction between the tasks of GPs and dieticians will enhance their collaboration, which tends to leave much to be desired (8).

We consider the recent development of so-called "patient letters on nutrition" to be supplementary to our nutrition CBI (9). These letters contain information on the role of nutrition in several diseases. Diet history taking and clear recommendations by the GP (or GP trainee) tailor the general information in these letters to patients, thus increasing 
their value (10). The letters then serve as a practical reminder for patients lenhancing compliance) as well as GPs (reinforcing knowledge on nutrition).

The decision to produce the computer simulation as an Internet program facilitates its regular updating. As soon as new information has been incorporated into the program, the new version can be used on the World Wide Web.

We consider our SIMGP Nutrition in General Practice program - a basic course on nutrition - to be a first step in nutrition education directed at the level of novices in the subject of nutrition. The program can be used independently of other parts of the GP vocational training programme. It should be followed by nutrition education which is embedded in regular courses on somatic diseases, thus becoming a recurrent theme in these courses. This could be accomplished by using the same format of simulations (SIMGP) and widening the content of these simulations by introducing all kinds of elements not related to nutrition.

\section{STANDARDIZED PATIENTS IN THE NECTAR STUDY}

To assess the effectiveness of our nutrition $\mathrm{CBI}$, we decided to measure the improvement in the performance of the trainees. To this end, we developed and fielded standardized patients (SPs), laymen taught to portray patients in a standardised and consistent way. We sent SPS incognito to the GPs" offices where trainees worked; they pretended to be "known" patients, that is, patients who are registered at the practice and have previously visited it. We concluded that fielding incognito SPs as "known" patients was feasible, and that the pretest/posttest format of the study made their use more efficient instead of complicating it.

Right from the start of the trial in which SPs figured as one of the measuring instruments, the use of incognito SPs was considered a challenging research method. GP trainers in whose practices trainees worked appeared to be rather sceptical about the feasibility of the method. Trainees became rather excited about the notion that they would be visited by several incognito $\mathrm{SPS}_{\text {, }}$ thus making genuine patients with nutrition-related complaints more or less "suspect". After $S P_{S}$ had carried out a total of 287 primary visits, the trainees had reported 77 suspected SPs; three reports were found to refer to genuine patients.

Since detection rates of SPS generally range from 0 to $18 \%(11)$, the detection rate in our study can be regarded as rather high. However, these figures derive from studies of which the great majority can be designated as cross-sectional. We have been unable to find detection reports from studies using SPs in a pretest/posttest design (trials) $(12,13)$. It is to be expected that detection rates in trials will generally exceed those in cross-sectional designs, as subjects in trials may become familiar with the SP style in the pretest phase, making them better prepared to detect SPs in the posttest phase. A general remedy against detections would be to prolong the latent period between the announcement of the intended use of SPS and their actual fielding. 
We wonder to what extent the detection of SPs has disturbed our performance-based assessment of the trainees at the level of groups. First, we question whether trainees have reported all suspected SPs to the researcher, and presume that they probably did not. Second, it is often assumed that SP detection leads to over-performance by trainees. In our opinion, however, this is not automatically or generally the case. After all, the trainees' reports on detection of SPs revealed that about half of the trainees had inadvertently omitted parts of the consultation as a result of being distracted by the possibility that they were dealing with a SP (some skipping parts of the consultation to gain time) and had thus showed under-performance. There are also other factors that can affect a trainee's concentration during a consultation (e.g. having been on a night-shift, a difficult preceding consultation, being called away on an emergency), each of which will worsen actual performance, even in the case of a presumed SP. Nevertheless, from an ethical point of view, we might expect trainees to produce an optimal performance with any patient during their consultations.

A final, interesting aspect of the issue of assessing performance is the fact that trainees apply standard scripts - handling patients with specific complaints in a standardised way - as soon as they have mastered these scripts (as several trainees commented in their SP detection forms) (14). This implies that, at some point during the consultation, trainees consider whether or not to apply such a script, regardless of the presumption of being visited by an SP.

On the whole, it is possible that over- and under-performance by trainees due to the presumption of dealing with a SP were evenly balanced for the total group of trainees during our study. This assumption is supported by the virtual absence of differences between the total group of visits and the subgroup of undetected visits. If our assumptions are correct, the necessity for SPs to remain incognito during their visits would be diminished, making the preparation of such visits even more feasible. Hence, this would also favour the use of SPs in practice on a larger scale in GP vocational training.

\section{IMPROVEMENT OF GP TRAINEES' COMPETENCE AND PERFORMANCE}

To assess the effectiveness of the nutrition CBI in terms of the improvement of GP trainees' competence and performance, we carried out a controlled trial, using a 79-item knowledge test and three incognito SPs in a pretest/posttest format. Our subjects were 49 trainees, 25 of whom constituted the experimental group lattending the CBI during vocational training days) while 24 served as controls (taking only the regular vocational training programme). An analysis of covariance showed that the trainees in the experimental group outperformed their controls by $28 \%$ on factual knowledge and by $68 \%$ on practice behaviour. Focussing on the progress of practice behaviour, we not only found that trainees in the experimental group significantly improved on all cases and consultation categories, but also that experimental versus control group 
scores differed significantly at posttest. Posttest scores on all cases appeared to be significantly correlated, as were scores on diet history taking and nutrition guidance.

Our controlled triall can be designated as group-randomised, stratifying trainees according to their sex and the university where they had completed their undergraduate medical programme. We achieved adequate similarity between the experimental and control groups in terms of trainees' characteristics. SP scores did not differ between the two groups at pretest. Sex or university of undergraduate medical studies did not confound the scores on the knowledge test or the practice test. Nor were differences. between GP trainers in whose practice trainees worked found to confound these scores. Therefore, we feel we can attribute our findings to the effects of the nutrition CBI.

Our controlled trial can be regarded as small in terms of the number of participating trainees (about $5 \%$ of all Dutch trainees). In computing the number of subjects required for our study, we started from the assumption that trainees would improve by at least one standard deviation, which implied we would require groups of at least 21 trainees $(\alpha=0.05$ and $\beta=0.10)$. As we found improvements considerably beyond the "one standard deviation" level and used groups of 25 and 24 trainees, we think our study had adequate power.

On the other hand, the total number of visits carried out by SPs in our study (about 300) was high compared to those in many other studies using SPs in practice. Since feasibility issues prevented us from including more than three cases in the pre-and posttests, we were quite satisfied with the reliability levels we found for the SP test $\$ .67$ for the pretest and .72 for the posttest). We assume that the findings of our controlled trial have ample external validity, based on the following aspects of the study: absence of confounding by the university where trainees had taken their undergraduate medical studies, sufficient statistical power, satisfactory reliability of tests and an easy-to-duplicate educational intervention.

The NECTAR study aimed at assessing competence and performance of trainees on the subject of nutrition. While competence is generally regarded as an important prerequisite for performance, the exact relationship between competence and performance is assumed to be complex (15). We operationalised these respective stages or levels of assessment as factual knowledge (assessed by means of a written knowledge test) and practice behaviour (assessed by means of checklists completed by incognito SPs). In terms of Miller's triangle, we aimed to assess our trainees at the "knows" and "does" levels (16). We feel it is important to stress that we chose to explore the extremities of Miller's triangle to reveal the effectiveness of our nutrition CBI at these levels, rather than to seek any concurrent walidity of tests icorrelation between knowledge and practice behaviour).

At this point, we want to specify some elements of the test using SPs to assess performance. Firstly, SPs merely recorded what trainees asked, measured or recommended during the "real-life" consultations, which represents the final outcome of their practical knowledge, clinical decision-making and insight into nutrition-related complaints. The knowledge used ${ }^{\prime}$ the transfer and translation of this knowledge into everyday prac- 


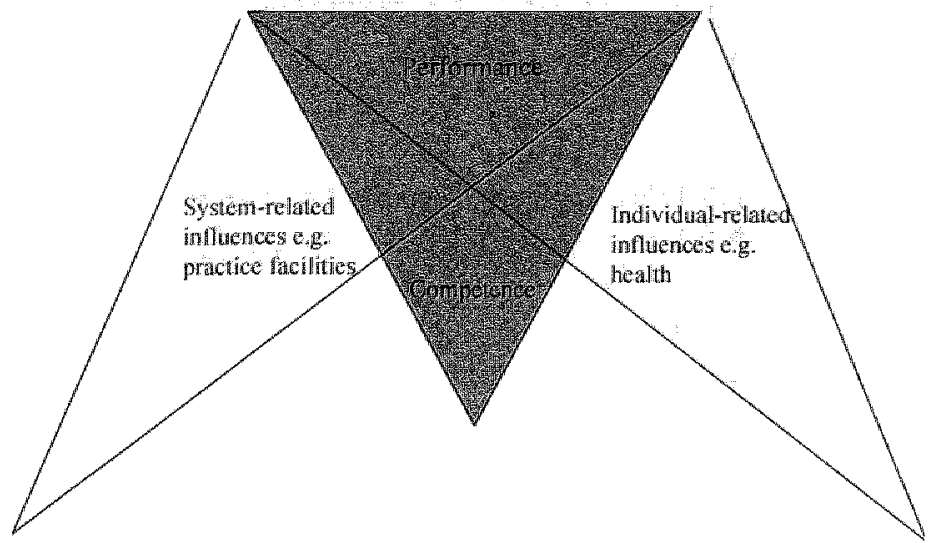

Figure 2. The Cambridge model of competence and performance (reproduced with the author's permission).

tice behaviour, and the decision-making process itself, remained unrecorded. Thus, practice behaviour (performance) reflects factual knowledge (competence). We can illustrate this with a clear example. If a SP ticks off the item "trainee measured the waist circumference" as "performed correctly" in her checklist, we might assume that the trainee has carried out this measurement correctly. We do not know whether this trainee has correctly interpreted the figure found, or how he has used this finding in his nutritional recommendations to the SP.

In terms of the Cambridge Model for delineating performance and competence (Figure 2), we can highlight a second aspect of the SP test. Our practice test addressed the main triangle of the model (the competence - performance axis), and did not explicitly distinguish system-related influences (like patient expectations and consultation time) or individual-related influences (like the trainee's physical and mental health) on performance. Since, however, such influences will modify the trainees' practice behaviour, they are implicitly recorded in the checklists completed by the SPs.

In terms of the general domain of our nutrition CBI, we limited our program to the medical-somatic aspects of consultations. We deliberately omitted the training of communication skills and skills on promoting life-style changes from the teaching goals of the CBI, as training in these skills is amply provided by the regular GP vocational training curriculum. Therefore, SP checklists did not contain any items pertaining to these skills. It is generally to be expected that these skills will influence the doctor-patient relationship during consultations with patients with nutrition-related complaints (like our SPS) and thus affect the content of the consultation. However, we trained SPs to present their role in a standardised way, ignoring as much as possible the way they were treated by trainees, without making the consultation look unnatural.

Two final issues addressing the performance assessment of trainees from a different point of view need to be discussed here. One relates to the domain-specificity of the 
practice test, the other to the idiosyncrasy of the way in which trainees solve nutr. tion-related problems.

In addressing the first issue, we refer to what we said about the nutrition domain of the CBI in the preceding section, discussing the SIMGP Nuttition in General practice program. We also have to recall the absence of case-specificity pointed out in chapter seven about progress in trainees' practice behaviour. At first sight it was surprising to find a moderate level of inter-case correlations, since such correlations generally tend to be poor or absent (17). However, a closer look at these cases and the accessory SP checklists shows that the diet history items included in each checklist le.g. number of slices of bread, intake of fruits) were almost the same. Furthermore, the nutrition guidance items in the various cases always refer to the achievement of the ideal situation as described in the Dutch "Guidelines for a healthy diet" (e.g. recommending less fatty meat), with a limited number of specifically disease-related items (e.g. advising against special foods for diabetics). We think these checklist issues largely explain the absence of case-specificity. Therefore, we might expect that newly developed cases on other nutrition topics, as presented to trainees in our CBI, will have similar effects on practice behaviour. However, we expect a domain-specificity with regard to the previously delineated domain of our nutrition $C B$. This means that if we develop new simulations on different domains of general practice - using the same format as that of our nutrition CBI - the effectiveness of this new program has to be assessed again.

A final performance-related issue we would like to address is the idiosyncrasy of problem solving. It is well-documented that different experts use different approaches to solve the same problem (see Chi 1982 for an overview) (18). It can also be expected to occur with trainees handling the various nutrition-related cases during the consultations with incognito SPs. Despite this idiosyncrasy, we consider a patient-tailored advice on nutrition to be the ultimate intended outcome of our study. The finding that diet history taking was highly correlated with nutrition guidance, whereas trainees improved on all consultation categories, seems to indicate that this outcome was indeed achieved. The fact that the remaining consultation categories were found to show low correlations (without statistical significance) corroborates the supposed idiosyncratic way in which trainees solved these patient problems. We feel that this type of coping with nutrition-related complaints is favoured by the nutrition CBI, as the CBI itself allows an idiosyncratic method of solving the patient cases in the program: the user determines to what extent he elaborates the individual consultation categories (and uses background information) and even which categories are addressed. The "user-tailored" format represents a major advantage of the program, companed with formats involving teacher-dependent small group instruction in which the group, together with the tutor, determines the progression through a patient case. Nevertheless, teacher-dependent small group instruction still tends to be the preferred format in GP vocational training. 

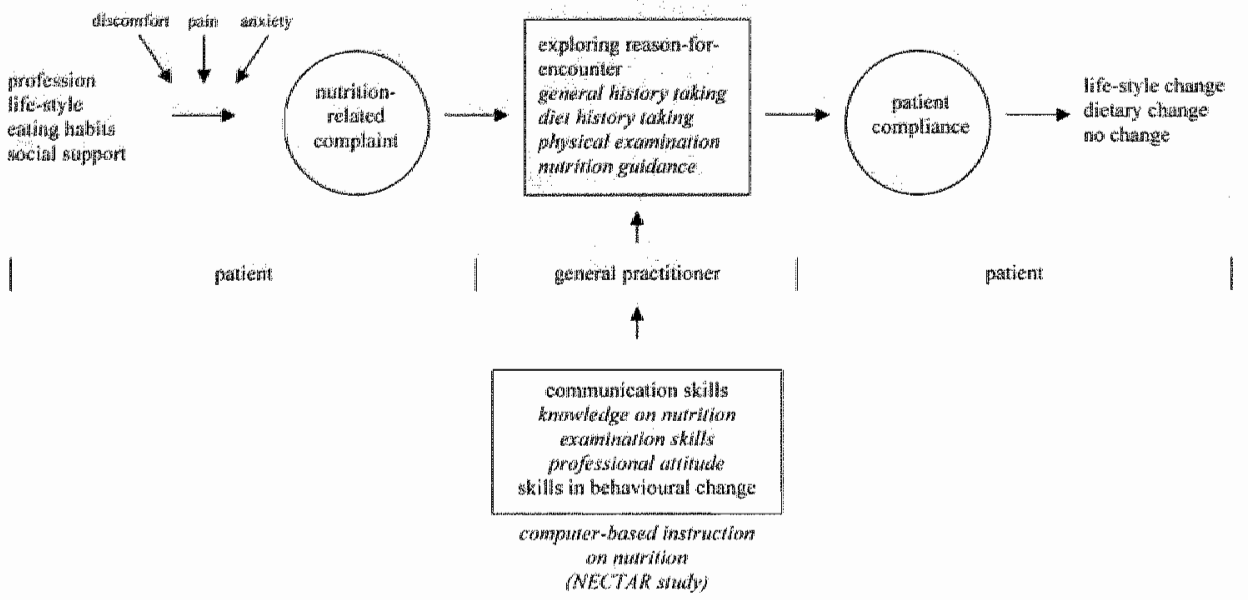

Figure 3. Model of the health care process (patients' and general practitioners' roles) for patients with nutrition-related complaints, indicating the part of the process to which the NECTAR study relates (components of NECTAR study shown in italics).

\section{RECOMMENDATIONS FOR FUTURE RESEARCH}

To conclude this section on competence and performance of trainees, we would like to provide some suggestions for future research on the nutrition CBI. First, as stated in chapter six, the progress made by trainees in their practice behaviour on the subject of nutrition has to be characterised as short-term (being assessed an average of one month after the conclusion of the intervention). Further research should reveal whether the effects of the $C B I$ we found are sustained over time in the group of trainees who used the program. By this time, almost all experimental group trainees have completed their GP vocational training programme, which implies that such an assessment should be carried out in the practices where they start to work as registered GPs. We think this will entail new challenges in terms of practice testing with the help of SPs. We also presume that any sustained effect of the nutrition $\mathrm{CB}$ I thus found would reflect the practical value of the program.

Furthermore, the effectiveness of the program should also be examined when implemented among practicing GPs. The similarity between the LISREL models on the determinants of nutrition guidance among practicing GPs and GP trainees justifies the assumption that the $\mathrm{CBI}$ would have a similar effect on $\mathrm{GPs}$ as on trainees. If found, such an effect would be another indication of the practical value of the program.

To conclude this chapter, we want to stress that our study is limited to what happened during GP consultations. Figure 3 shows a possible sequence of phases that patients with nutrition-related complaints go through from the moment they become aware of discomfort, pain or anxiety. Consulting a GP is only one part of the total process, and its 
outcome in terms of patient compliance with the GP's advice is rather uncertam. However, we believe that the nutrition CBI thas clearly prowded our trainees with a level of practical knowledge and skills which should enable them to make their patients aware of some less than healthy eating habits and to give them some sound advice on nutrition. Ultimately, however, it is the patients who have to decide whether or not to comply with these recommendations.

\section{REFERENCES}

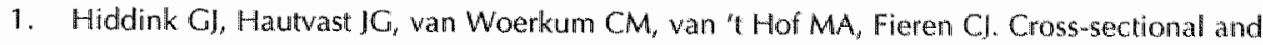
longitudinal analyses of nutrition guidance by primary care physicians. Eur I Clin Nutr 1999,53 (suppl):S35-43.

2. Davis DA, Thomson MA, Oxman AD, Haynes RB. Changing physician performance. A systematic review of the effect of continuing medical education strategies. IAMA 1995;274(9):700-5.

3. Reeves TC. Evaluating what really matters in computer-based education. November 1997. Internet: http:/www.educationau.edu.au/archives/cp/reeves.htm (accessed 18 felbruary 2003).

4. Greenhalgh T. Computer assisted learning in undergraduate medical education. BMI 2001;322(7277):40-4.

5. Nutrition Council. Guidelines for a healthy diet. The Hague: Nutrition Council; 1986.

6. The Netherlands Nutrition Centre. De Voedingswijzer. Toelichting en achtergronden. Criteria voor voedingsmiddelen (The food guide. Explanation and backgrounds. Criteria for food components). The Hague: The Netherlands Nutrition Centre; 1997 (in Dutch).

7. Truswell AS. ABC of Nutrition. Third ed. London: BMJ Publishing Group; 1999.

8. Paas GRA, Friele RD. Plaats en functie van de diëtist in de Nederlandse gezondheidszorg (Place and function of the dietician in health care in the Netherlands). Utrecht: Netherlands Institute of Health Services Research; 1996 (in Dutch).

9. van Binsbergen IJ, Drenthen AJ. Patient information lletters on nutrition: development and implementation. Am I Clin Nutr 2003;77:10355:85.

10. Brug l, Steenhuis I, van Assema $P$, de Vries $H$. The impact of a computeratalored nutrition intervention. Prev Med 1996;25(3):236 42.

11. Rethans. ff. Needs assessment in continuing medical education through standardized patients. I Contin Educ Health Prof 1998; 18:172-8.

12. Casebeer $\mathrm{LL}$, Klapow $J \mathrm{C}$, Centor RM, et al. An intervention to increase physicians' use of adherenceenhancing strategies in managing thypercholesterolemic patients. Acad Med $1999 ; 74(12) \div 1334-9$.

13. Wilk $A l$, Jensen NM. lnvestigation of a brief teaching encounter using standardized patients. I Gen Inter Med 2002;17(5):356-60.

14. Boshuizen HPA, Schmidt HG. De ontwikkeling van medische expertise; implicaties voor het praktisch en theoretisch medisch onderwijs (The development of medical expertise; implications for practical and theoretical medical educationy. In: Metz JCM Scherploier AllA, wan der Vleuter CPM, eds. Medisch onderwijs in de praktijk. Assen: Van Gorcum; 1995: 25-39 (in Dutch). 
15. Rethans II, Norcin IJ, Baron-Maldonado $M$, et al. The relationship between competence and performance: implications for assessing practice performance. Med Educ 2002;36:901-9.

16. Miller GE. The atssessment of clinical skillsicompetence/prerformance. Acad Med 1990;65:\$63 -7.

17. Roberts J, Norman $G_{\text {. }}$ Reliability and leaming from the objective structured clunical examination. Med Educ 1990;24(3):219-23.

18. Chi MTH, Glaser R, Rees E. Expertise in problem solving. In: Sternberg R], ed. Advances in the psychology of human intelligence. Hillsdale NJ: Lawrence Erlbaum Associates; 1982:7-76. 
SUMMARY

$\frac{107}{\frac{0}{2}}$ 
This thesis discusses the development of a computer-based instruction on nutrition for Dutch general practitioner (GP) trainees and the assessment of its effectiveness. Chapter one introduces the background and objectives of the studies presented in this thesis, discussing the poorly developed role of nutrition in vocational training for general practice and the lack of necessary expertise among GPs on this subject. Based on the apparent need for nutrition education in GP vocational training, we decided to develop a new nutrition course that would provide an attractive, teacher-independent and innow vative method of teaching GP trainees. We felt that computer simulations would be the best didactic format for such a course.

The main abjective of the study was to enhance the knowledge, skills and attitude of Dutch GP trainees on the subject of nutrition by computer-based instruction. We divided our study, called NECTAR (Nutrition Education by Computerised Training and Research), into two stages: one developing the simulation of the nutrition aspects of general practice, and one assessing its effectiveness. We formulated two general research questions pertaining to these stages:

1. What is the best way to develop a simulation of the nutrition aspects of general practice, taking into account the required standard educational components of course development?

2. To what extent does the newly developed simulation program improve the competence and performance of GP trainees?

This thesis discusses the course development stage in terms of assessing the baseline situation of GP trainees on the subject of nutrition, designing the content of the computer-based instruction (CBI) on nutrition, and describing the development of the nutrition CBI. Next, it reports on the controlled trial we carried out to assess the effectiveness of the nutrition course. The first aspect discussed is the fielding of incognito standardized patients - one of our measuring instruments. This is followed by the overall results of the trial and a detailed review of the improvements found in the trainees' practice behaviour. The thesis is concluded by discussing the findings of the various chapters.

Chapter two presents the results of a questionnaire sent to all Dutch GP trainees (n=985) to identify determinants of their nutrition guidance practices, which could be used to guide the educational development of the nutrition CBI. The net response rate was $59 \%$. Allmost all trainees $(98 \%)$ saw the provision of nutrition information as a part of their task, while $89 \%$ felt that paying attention to disease-related nutrition topics in vocational training was important or very important. The reported incidence of patients with nutrition-related complaints was once or twice a day, while the number of patients who received nutrition guidance from trainees averaged fewer than one a day. The main determinants of nutrition guidance by trainees to emerge from a LISREL. model analysis were the perceived barriers "lack of nutrition training and education" and "lack of skills to treat overweight", and the predisposing factor "perception of own ability to give dietary advice in the treatment and prevention of coronary heart disease". In terms 
of our objective, the barrier "lack of time to treat overweight" and the driving force "task perception" were also important.

We concluded that these findings underlined the need for nutrition education in GP vocational training. The nutrition program to be developed should implicitly address the issues of identifying nutrition topics withir patients' complaints and trainees' task perception. Furthermore, we considered it wise to use an easily implemented strategy on nutrition in the program and to include the topics of hypercholesterolemia and obesity. Since the LISREL models of nutrition guidance by trainees correspond largely to those of practicing GPS, we presumed that a nutrition CBI that affects the nutrition guidance practices of trainees would also be useful to GPs.

Chapter three presents the results of a two-round Delphi study carried out among Dutch GPs $(n=41)$ with the aim of drawing up a concise list of nutrition topics that would reflect the needs of Dutch GPs for nutrition education geared to everyclay practice. We intended to use this list to decide on the main topics and educational content of the nutrition CBI. The GP respondents were recruited from a list of participants to a national refresher course on nutrition. The response in both Delphi rounds was high (93 and $95 \%$ ). Analysis of the Delphi questionnaires in both rounds yielded a priority list of disease-related nutrition topics, with the fourteen highestranking topics being identical in both rounds. A fifteenth topic, anly found in the second questionnaire, completed the priority list. The list was accompanied by respondents' summarised comments on the nutrition topics. A small group of experts, including an experienced GP, a professor of general practice and a professor of clinical nutrition, assessed this list as fully acceptable.

Based on the priority list and the proposals made by the respondents and experts for the integration of certain items, we finally compiled the following list of five priority topics: weight problems, diabetes mellitus, hypercholesterolemia, intestinal complaints and hypertension. From the point of view of nutrition education, it was interesting that this top-five covers the main categories of nutrients and energy equilibrium.

Chapter four describes the various stages of development of the nutrition CBI, its final structure and content, and the didactic principles incorporated in its design. We first carried out a comparative requirements analysis and usability study among a group of interested practicing GPs, and held an evaluation session with three experts in the field of nutrition to meet the needs and expectations of these target groups. The structure of the simulation we constructed closely resembles the general structure of a real GP consultation and is presented by individual screens for each consultation phase. All actions are selected by means of key words (items) visible on the screen. Background information for each item can be "popped up", this information being the same for all cases. The consultation part is followed by a debriefing, in which the user is provided with a form of peer review and feedback. Video recordings of a GP expert are used, both in the consultation and debriefing part, to provide a practical context for the consulta* tion and a kind of role model for users. After the feedback screens, the user can read a tutorial on the case and view a list of literature references on the subject. The individual 
user is free to choose his route through the simulation, resulting in a more constructivist mode of learning.

Secondly, after we had decided to use the Dutch food guide as the main domain for the simulation, we designed the general framework of items for the various consultation phase screens and drafted nutritional background information on the items - at the level of novices in the subject of nutrition - with the help of an expert panel on nutrition. Subsequently, we used the five topics of overwerght and obesity, diabetes mellitus, hypercholesterolemia, hypertension and intestinal problems which had emerged from the previously conducted studies (questionnaire and Delphi study). Based on literature study and expert panel feedback we then designed 12 disease-related cases on nutrition by completing the iterns, from the framework, assigning scores to these items to reflect their importance, and shooting videos in a genuine GP consultation room.

We concluded that we had developed a multipotential nutrition program using a multidisciplinary approach.

Chapter five describes the development and implementation of an assessment method using incognito standardized patients (SPS) as a measuring instrument to assess the effectiveness of the newly developed CBI. We wanted to establish the feasibility of introducing SPS as "known" patients into practices (i.e. pretending they had previously visited the practice), as well as to indicate the practice preparations required to allow this, and to describe the various aspects of using SPS in a trial (pretest/posttest format). SPs received a two-day training in role-playing and completing checklists. Halfway through their series of practice visits, we organised one day of remedial training. SP roles and checklists were developed in collaboration with the same expert panel who had contributed to the composition of the content of the nutrition CBI. We compiled comprehensive practice information folders for each practice to be visited, including pictures of the exterior and interior of the practices, ground plans of and routes to practices, consultation hours, specific practice routines (e.g. the appointment system) and telephone numbers. Real personal data (and those of family members) and faked medical data of previous consultations by the SPs were entered into the file systems of each practice. Apart from having SP roles with a slightly different reason-for-encounter and different $S \mathrm{Ps}_{\mathrm{s}}$, the same training protocol and the same checklists and practice information folders were used in the posttest.

All practices involved prepared the required patient records for the SP visits in a more or less authentic practice style. Some SPs underwent unintended physical examination or blood sampling. Trainees correctly detected the SP in 74 visits lout of 287 visits carried out). The main reasons for detection were imperfections in patient records and elements of $\mathrm{SP}$ roles or role-playing.

We concluded that fielding incognito SPS as "known" patients was feasible but labour-intensive. Special care had to be taken to achieve suitable simulation of previous visits by preparing the patient records and familiarising SPS with the practices to be visited. Using SPs in a study with a pretest/posttest format made their use more efficient, rather than complicating it. 
Chapter six presents the results of the group-randomised controlled trial carried out to determine the degree to which GP trainees' factual knowledge improved as a result of the $\mathrm{CBI}$ and to examine whether the nutrition $\mathrm{CBI}$ improved the adlequacy of consultations performed by GP trainees in real practice with patients with nutrition-related complaints. Subjects were 49 first-year trainees divided into experimental groups ( $n=25$, attending the $\mathrm{CBI}$ during and in addition to their vocational training programme) and control groups ( $n=24$, taking only the regular vocational training programme). We used a pretest/posttest design in which trainees took a 79-item written knowledge test and were visited by three incognito SPs during regular consultation hours, both in the pretest and the posttest.

Analysis of covariance of the knowledge test scores, using pretest scores as covariate, showed a significant experimental versus control group difference at posttest: $9.2 \%(P=$ 0.002 ). Relative to the mean pretest score, this implied a $28 \%$ improvement in the experimental group. Based on all SP visits, the scores of the SP test (as assessed by checklists) revealed a significant group difference at posttest of $13.7 \%(P<0.001)$ in the analysis of covariance, implying a $68.2 \%$ improvement in the experimental group relative to the mean pretest score. Trainees unmasked SPs in $26 \%$ of visits. Subgroup analysis of undetected visits showed a group difference of $12.8 \%(P<0.001)$ at posttest, implying $68.4 \%$ improvement in the experimental group. Dropout among trainees was limited to one trainee in both groups during the posttest phase. No confounding variables were found. We concluded that the nutrition CBI had proved its effectiveness both by increasing factual knowledge and by substantially improving GP trainees' practice behaviour on the subject of nutrition.

Chapter seven focuses on the results of the SP practice test of our controlled trial, especially on the content-specificity of the various nutrition-related problems simulated by the SPs, the consistency of trainees' consultations (in terms of nutrition-based consultation categories) and the content of nutritional advice given by trainees.

Analysis of covariance revealed a significant experimental versus control group difference at posttest for all cases (intestinall problems $11.3 \%, P=0.001$; cardiovascular disease/hypertension $12.0 \%, P=0.003$; overweight/diabetes mellitus $18.1 \%$, $P<$ 0.001 ) and consultation categories (general history taking $8.1 \%, P=0.005$; diet history taking $18.6 \%, P=0.001$; physical examination $13.9 \%, P=0.002$; nutrition guidance $14.3 \%, P<0.001)$. Relative to the mean pretest scores, these differences imply that the performance of the trainees in the experimental group increased by $34 \%$ for the intestinal problems case and doubled for the cardiovascular disease/hypertension and overweight/diabetes mellitus cases. In terms of the individual consultation categories, these differences imply performance improvements by the trainees in the experimental group of $28 \%$ for general history taking, $93 \%$ for physical examination and $65 \%$ for nutrition guidance. In terms of the scores on diet history taking, there was a 2.4 fold improvement.

The posttest revealed significant, low to moderate inter-case correlations between all cases and a significant, high correlation between diet history taking and nutrition guid- 
ance scores for the total group of trainees. As regards nutritional advice, trainees in the experimental group more often recommended that patients should complete a food record, and outperformed their controls on the issue of fat intake as a whole and some aspects of fibre intake throughout the cases in the posttest.

We concluded that the effects of the nutrition CBI appeared to be case-independent and that the program provided GP trainees with a consistent method of handling nutrition-related medical problems. Nutritional advice given by GP trainees improved most obviously for the fat-intake issue.

Chapter eight reviews and discusses the findings of the various chapters and puts these 112 into perspective. We report the important contributions of the questionnaire study among trainees and the Delphi study among GPs, which helped define the content, and partly also the structure, of the nutrition CBI. The development of the program itself required a multidisciplinary approach. Finally, we feel we have generated a nutrition course that can be regarded as "user-tailored" and provides a rather constructivist mode of education. It separates the role of GPs in the field of nutrition from that of dieticians, as it teaches users to assess only the usual intake of the main food components and to give clear recommendations on these components.

In assessing the effectiveness of the nutrition CBI, our use of incognito SPs as "known" patients included some - to our knowledge - innovative aspects, such as entering faked SP patient records on previous consultations into the practice files. In addition, only a minority of educational programs have been assessed for their effectiveness at the levels of factual knowledge (competence) and practice behaviour (performance) in a pretest/posttest format. The effects found in the experimental group can be regarded as encouraging at the level of competence and remarkable at the performance level.

Our performance assessment related to the final outcome of the whole gamut of trainees' knowledge, skills and insights in relation to the subject of nutrition. We did not distinguish system-and individual-related influences on performance, and deliberately omitted communication skills and skills relating to life-style change from the assessment. We discuss the absence of case-specificity (which is a favourable aspect) and the expected nutrition domain-specificity. We argue that the nutrition $C B$ allows an idiosyncratic method of solving patient problems.

Major topics for further research include the long-term effect of the CBI and the effectiveness of the program when implemented by practicing GPS. 
SAMENVATTING

11 
Dit proefschrift bespreekt de ontwikkeling van een computerondersteund onderwijsprogramma over voeding voor Nederlandse huisartsen-in-opleiding en het vaststellen van de effectiviteit van het programma. Hoofdstuk 1 betreft een inleiding over de achtergronden en de doel- en vraagstellingen van de onderzoeken in dit proefschrift. We bespreken de achtergebleven rol van voeding binnen de huisartsopleiding en het gebrek aan expertise op het gebied wan voeding van praktiserende huisartsen. Gezien de adnwezigheid van een duidelijke behoefte aan voedingsonderwijs binnen de huisartsopleiding, besloten we om een nieuw onderwijsprogramma over voeding te ontwikkelen. Dit programma zou een attractieve, docentonafhankelijke en innovatieve vorm van onderwijs aan huisartsen-in-opleiding (haio's) moeten bieden. We veronderstelden dat computersimulaties de beste didactische werkvorm voor een dergelijk programma zouden zijn.

De hoofddoelstelling van het onderzoek was het verbeteren van de kennis, vaardigheden en attitude van haio's op het gebied van voeding door middel van een computerondersteund onderwijsprogramma (COO). We onderscheidden twee delen aan het onderzoek, dat de naam NECTAR (Nutrition Education by Computerized Training and Research) kreeg: het eerste deel betrof de ontwikkeling van de simulatie van huisartsconsulten op het gebied van voeding, het tweede deel het vaststellen van de effecten wan het programma. Met betrekking tot de respectievelijke delen van het onderzoek formuleerden we de volgende twee algemene onderzoeksvragen:

1. Op welke manier kan een simulatie van huisartsconsulten op het gebied van voeding het best ontwikkeld worden, rekening houdend met de bij het ontwikkelen van onderwijs standaard vereiste onderwijskundige elementen?

2. In welke mate verbetert de nieuw ontwikkelde computersimulatie competence en performance van haio's?

De ontwikkeling van het onderwijsprogramma wordt in dit proefschrift besproken aan de hand van het bepalen van de onderwijskundige beginsituatie van haio's op voedingsterrein, het vaststellen van de leerinhouden van het COO over voeding, en het beschrijven van het verloop van de ontwikkeling van het COO over voeding. Vervolgens wordt de gecontroleerde trial besproken die door ons is uitgevoerd om de effectiviteit van het onderwijsprogramma over voeding vast te stellen. Hierbij wordt allereerst het inzetten van incognito simulatiepatiënten, één van de door ons gebruikte onderzoeksinstrumenten, beschreven. Daarna volgt een bespreking van de overall resultaten wan de trial en een gedetailleerd overzicht van de verbetering van het praktijkhandelen van haio's. Het proefschrift wordt afgesloten met een algemene beschouwing van de bevindingen uit de verschillende hoofdstukken.

Hoofdstuk 2 geeft de resultaten van een onder alle Nederlandse haio's ( $n=985$ ) gehouden schriftelijke enquête weer. Doel van deze enquête was om determinanten van het handelen van haio's op het gebied van voedingsvoorlichting en advisering te achterhalen. Deze determinanten zouden gebruikt kunnen worden om richting te geven aan de ontwikkeling van het voedingsprogramma. De netto respons was $59 \%$. Bijna alle haio's $(98 \%)$ beschouwden het geven van informatie over voeding als een 
onderdeel van hun taak, terwijl $89 \%$ van hen aangaf het belangrijk tot zeer belangrijk te vinden dat in de huisartsopleiding op ziektegerelateerde wijze aandacht wordt besteed aan voedingsonderwerpen. De gerapporteerde incidentie van voedingsgerelateerde klachten bedroeg één tot tweemaal per dag, terwijl gemiddeld minder dan éen patiënt per dag voorlichting en advies ontving op voedingsgebied.

Als voornaamste determinanten van voedingsvoorlichting en advisering door haio's kwamen de gepercipieerde barrières "gebrek aan voedingskennis en training" en "gebrek aan vaardigheden om overgewicht te behandelen", en de predisponerende factor "perceptie van de eigen mogelijkheden om voedingsadviezen te geven bij de behandeling en preventie van coronaire hartziekten" tevoorschijn uit een analyse met LISREL modellen. Met het oog op onze doelstelling waren ook de barrière "gebrek aan tijd om overgewicht te behandelen" en de drijvende kracht "taakopvatting" van belang. We concludeerden dat deze bevindingen de behoefte aan voedingsonderwijs binnen de huisartsopleiding benadrukten. Het te ontwikkelen onderwijsprogramma over voeding zou zich impliciet moeten richten op het signaleren van voedingsaspecten binnen het klachtenpatroon van patiënten en op de taakopvatting van haio's. Bovendien leek het ons verstandig om in het programma een op eenvoudige wijze toe te passen voedingsstrategie te gebruiken en de onderwerpen hypercholesterolemie en obesitas op te nemen. Aangezien de LISREL modellen over voedingsvoorlichting en advisering door haio's grote overeenkomsten vertonen met de bij praktiserende huisartsen gevonden modellen, veronderstelden we dat een COO over voeding dat het handelen van haio's op het gebied van voedingsvoorlichting en advisering beïnvloedt ook van nut zal zijn voor huisartsen.

Hoofdstuk 3 geeft: de resultaten weer van een in twee rondes uitgevoerd Delphi-onderzoek onder Nederlandse huisartsen $(n=41)$. Doel van dit onderzoek was het genereren van een beknopte lijst met voedingsonderwerpen die een afspiegeling zou moeten zijn van de door Nederlandse huisartsen ervaren behoefte aan op de dagelijkse praktijk gerichte scholing over voeding. Onze bedoeling was om de lijst te gebruiken voor het vaststellen van de hoofdonderwerpen en de leerinhoud op hoofdlijnen van het $\mathrm{COO}$ over voeding. De huisarts-respondenten werden geworven via een lijst van deelnemers aan een landelijk georganiseercle nascholing over voeding. De respons in beide rondes van het Delphi-onderzoek was hoog (93 en $95 \%$ ). De analyse van de in beide rondes gebruikte Delphi-formulieren leverde een prioriteitenlijst van ziektegerelateerde voedingsonderwerpen op. De 14 hoogst scorende onderwerpen waren in beide ronden identiek. De prioriteitenlijst werd aangevuld met een vijftiende onderwerp dat alleen op het Delphi-formulier van de tweede ronde voor kwam. Aan de lijst werd een samenvatting van het commentaar van respondenten op de voedingsonderwerpen toegevoegd. Een kleine groep experts, bestaande uit een ervaren huisarts, een hoogleraar huisartsgeneeskunde en een hoogleraar klinische voeding, beoordeelden de lijst als volledig acceptabel.

Uitgaande van de prioriteitenlijst en het voorstel voor het samenvoegen van bepaalde onderwerpen van de kant van respondenten en experts, stelden we uiteindelijk de 
volgende top vijf wan onderwerpen samen: gewichtsproblematiek, diabetes mellitus, hypercholesterolemie, darmklachten en hypertensie. Vanuit het oogpunt van voedingsonderwijs was het een interessant gegeven dat deze top vijf de hoofdcategorieën van voedingsmiddelen en de energiebalans afdekte.

Hoofdstuk 4 beschrijft de verschillende stadia in de ontwikkeling van het COO over voeding, de uiteindelijke structuur en inhoud van het programma, en de bij het ontwerp toegepaste didactische principes. Als eerste stap voerclen we een vergelijkend warenonderzoek en bruikbarheidanalyse uit bij een groep van geïnteresseerde praktiserende hisisartsen, en hielden we een evaluatiesessie met drie experts op voedingsgebied teneinde tegemoet te komen aan de wensen en verwachtingen van deze doelgroepen. De structuur van de door ons ontworpen simulatie vertoont grote gelijkenis met de algemene structuur van een echt huisartsenconsult. ledere consultfase wordt weergegèven door middel van een apart scherm en alle acties worden geselecteerd aan de hand van steekwoorden (items) die op het scherm te vinden zijn. Achtergrondinformatie over ieder item kan worden "uitgeklapt" en is identiek voor alle casus. Na het gedeelte walarin het consult plaatsvindt volgt een nabespreking, waarin de gebruiker een vorm van peer review en feedback ontvangt. Video-opnames van een huisartsexpert worden zowel in het consult- als nabesprekinggedeelte gebruikt en bieden een praktijkcontext en dienen als rolmodel voor de gebruiker. Na het doorlopen van de feedbackschermen kan de gebruiker een resumé van de casus lezen en literatuurreferenties over het onderwerp nalopen. Het staat de individuele gebruiker vrij om zijn eigen route door de simulatie te bepalen, waardoor een meer constructivistische wijze van leren ontstaat.

Als tweede stap, na het besluit om de Voedingswijzer te gebruiken als het hoofddomein voor de simulatie, ontwierpen we het stramien van de items ten behoeve van de schermen van de verschillende consultfasen en stelden we de teksten op van de achtergrondinformatie over de items - op het niveau van beginners op voedingsgebied - met behulp van een panel van voedingsexperts. Vervolgens richtten we ons op de vijf onderwerpen overgewicht en obesitas, diabetes mellitus, hypercholesterolemie, hypertensie en darmklachten afkomstig uit eerder uitgevoerd onderzoek (haio-enquête en Delphi-onderzoek). Gebaseerd op literatuuronderzoek en de feedback van een panel van experts maakten we 12 ziektegerelateerde voedingscasus. Hiertoe vulden we voor ieder casus het stramien van de items in, gaven we ieder item een score die het belang van het betreffende item weergeeft, en namen we in een bestaande huisartspraktijk video's op.

We concludeerden dat we op multidisciplinaire wijze een onderwijsprogramma over voeding ontwikkeld hebben, dat als "multipotential" beschouwd kan worden.

Hoofdstuk 5 beschrijft de ontwikkeling en de implementatie van een toetsingsmethode waarbij incognito simulatiepatiënten (SP's) worden gebruikt om de effectiviteit van het nieuw ontwikkelde $\mathrm{COO}$ te bepalen. We wilden de haalbaarheid vaststellen van het in de huisartspraktijk introduceren van $S P^{\prime}$ 's als bekende patiënt van de praktijk (d.w.z. simulerend dat zij al eerder de praktijk bezochten), de hiervoor in de praktijk vereiste 
voorbereidingen aangeven, en de diverse aspecten beschrijven van het gebruik van $S P^{\prime}$ s in een trial (voor-en nameting design).

We trainden de SP's gedurende twee dagen in het spelen van hun rol en het invullen van hun checklist. Op het moment dat de SP's de helft van hun bezoeken aan de praktijken hadden afgelegd, kregen zij een dag remedial training. De rollen en checklists van SP's werden ontwikkeld in samenwerking met hetzelfde panel van experts, dat had bijgedragen aan het samenstellen van de inhoud van het $\mathrm{COO}$ over voeding. We stelden mappen samen met uitgebreide informatie over de te bezoeken praktijken. In de mappen waren foto's van het praktijkgebouw (van de buitenkant en binnen in de praktijk genomen), plattegronden van en routes naar de praktijk, spreekuurtijden, praktijkprocedures (bijv. het afspraaksysteem) en telefoonnummers opgenomen. In de patientenbestanden van alle praktijken werden de echte persoonsgegevens van de SP'sten hun gezinsleden) ingevoerd tezamen met gefingeerde medische gegevens over voorgaande consulten. Afgezien van het gebruik van SP-rollen met licht gewijzigde contactredenen en de inzet van andere SP's, werden in de nameting hetzelfde trainingsprotocol en dezelfde checklists en praktijkinformatiemappen gebruikt.

Alle betrokken praktijken maakten de patiëntenkaarten aan die nodig waren voor de spreekuurbezoeken van de SP's op een voor de betreffende praktijk min of meer authentieke wijze. Enkele SP's werden onderworpen aan lichamelijk onderzoek of bloedafname hetgeen we in opzet geprobeerd hadden te voorkomen. Haio's ontmaskerden SP's tijdens 74 spreekuurbezoeken (op een total van 287). Voornaamste redenen voor ontdekking waren onvolkomenheden in de patiëntenkaarten en elementen uit-cle SP-rollen of de wijze waarop de rollen gespeeld werden.

We concludeerden dat het inzetten van SP's als bekende patiënt van de praktijk haalbaar was maar arbeidsintensief. Met name diende aandacht geschonken te worden aan het op passende wijze simuleren van voorgaande consulten bij het aanmaken van de patiëntenkaarten, en aan het vertrouwd maken van SP's met de praktijken die bezocht moesten worden. Het gebruik van SP's in een voor-/nameting design was eerder bevorderlijk voor de efficièntie dan dat het leidde tot extra complicaties.

Hoofdstuk 6 geeft de resultaten weer van de op groepsniveau gerandomiseerde gecon troleerde trial die door ons is uitgevoerd. De trial had tot doel om vast te stellen in welke mate het $\mathrm{COO}$ over voeding de feitenkennis van haio's verbeterde en om te beoordelen of de consulten met patiënten met voedingsgerelateerde klachten die haio's in de praktijk voerden in voldoende mate verbeterden door het volgen van het COO over voeding. Als proefpersonen fungeerden 49 eerstejaars haio's die werden verdeeld in een experiment groep ( $n=25$, deze groep volgde het $\mathrm{COO}$ over voeding tijdens en in aanvulling op hun terugkomdagprogramma van de huisartsopleiding) en een controlegroep ( $n=24$, deze groep volgde alleen het reguliere terugkomdagprogramma). We pasten een voor-/nameting design toe, waarbij haio's zowel in de voor-als nameting een kennistoets bestaande uit 79 items maakten en tijdens het reguliere spreekuur in hun opleidingspraktijk werden bezocht door drie incognito SP's. 
Covariantie-analyse woegepast op de scores van de kennistoets, waarbij de scores uit de voormeting werden gebruikt als covariaat, toonde een significant verschil van $9.2 \%(P=$ 0.002 ) ussen de experiment en controlegroep in de nameting aan. Gerelateerd aan de geniddelde score in de voometing hield dit een verbetering in de experiment groep van $28 \%$ in. Uitgaande van alle spreekuurbezoeken van SP's lieten de scores op de SP-test (gemeten aan de hand van checklists) een signiffcant groepsverschil zien in de nameting van $13.7 \%(P<0.001)$ bij het toepassen van covariantie-analyse; dit hield een verbetering in van $68.2 \%$ in de experiment groep gerelateerd aan de gemiddelde score in de voormeting. Haio's ontmaskerden SP's in $26 \%$ van de spreekuurbezoeken. Subgroep-analyse op het niveau van niet-ontdekte spreekuurbezoeken toonde een groepsverschil van $12.8 \%(P<0.001)$ aan, hetgeen een verbetering van $68.4 \%$ inhield in de experiment groep. De uitval van haio's beperkte zich tot éen haio in beide onderzoeksgroepen gedurende de nameting. We hebben geen confounders kunnen aantonen.

We concludeerden dat het COO over voeding zijn effectiviteit had bewezen doordat het zowell de feitenkennis van haio's vergrootte als het praktijkhandelen van haio's op substantiële wijze verbeterde.

Hoofdstuk 7 concentreert zich op de resultaten van de praktijktest met SP's in onze gecontroleerde trial, met name op de inhoudsspecificiteit van de verschillende door SP's gesimuleerde voedingsgerelateerde patiëntproblemen, de consistentie van haio-consulten (ten aanzien van op voeding betrekking hebbende consultonderdelen) en de inhoud van door haio's gegeven voedingsadviezen.

Covariantie-analyse liet een significant verschil tussen experiment en controlegroep zien in de nameting voor alle casus darmklachiten $11.3 \%, p=0.001$; hartvatziekten/hypertensie $12.0 \%, P=0.003$; overgewicht/diabetes mellitus $18.1 \%, P<$ 0.001 ) en consultonderdelen (algemene anamnese $8.1 \%, P=0.005$; voedingsanamnese $18.6 \%, P=0.001$; lichamelijk onderzoek $13.9 \%, P=0.002$; voedingsvoorlichting en advies $14.3 \%, P<0.001 \%$. Gerelateerd aan de gemiddelde scores in de voormeting houden deze verschillen in dat de performance van haio's in de experiment groep $34 \%$ verbeterde bij de casus darmklachten en verdubbelde bij de hartvaatziekten/hyperlensie en overgewicht/diabetes mellitus casus. Met betrekking tot de afzonderlijke consultonderdelen houden deze verschillen een verbetering in van de performance van haio's in de experiment groep van $28 \%$ ten aanzien van algemene anamnese, $93 \%$ ten aanzien van lichamelijk onderzoek en $65 \%$ ten aanzien van voedingswoorlichting en advies. Met betrekking tot de scores voor voedingsanamnese verbeterden de haio's 2.4 ma.al.

De nameting liet voor de totalle groep haio's significante, lage tot matige correlaties tussen alle casus zien en een significante, sterke correlatie tussen de scores op voedingsanamnese en voedingsvoorlichting en advies. Ten aanzien van voedingsadwiezen, raadden haio's in de experiment groep vaker aan patiënten het bijhouden van een voedingsdagboek aan, en overtroffen zij in alle casus de haio's in de controlegroep 
op alle aspecten rond de inname van vet en op enkele aspecten rond de inname van vezels.

We concludeerden dat de effecten van het $\mathrm{COO}$ over voeding casusonathankelijk bleken te zijn en dat het programma haio's op consistente wijze leert ongann met voedingsgerelateerde medische problemen. Voedingsadviezen van haio's verbeterden het meest opvallend op het punt van de inname van vet.

Hoofdstuk 8 bespreekt de bevindingen uit de diverse hoofdstukken en plaatst deze in perspectief. De belangrijke bijdragen die het enquêteonderzoek onder haio's en het Delphi-onderzoek onder huisartsen geleverd hebben aan het bepalen wan de inhoud en deels ook aan de structuur van het COO over voeding worden aangegeven. De ontwik. keling van het programma zelf vereiste een multidisciplinaire aanpak. We zijn van mening dat we uiteindelijk een onderwijsprogramma over voeding hebben geproduceerd dat maatwerk levert voor de gebruiker en dat een vorm van onderwijs biedt die mag worden aangemerkt als constructivistisch. Het onderscheidt de nol van huisartsen op voedingsterrein van die van diëtisten, doordat de gebruiker word geleerd zich te beperken tot het bepalen van de gebruikelijke inname van de belangrijkste voedingsmiddelen en het geven van duidelijke aanbevelingen op het gebied van deze voedingsmiddelen.

Bij het vaststellen van de effectiviteit van het COO over voeding waren aan het gebruik van $\mathrm{SP}^{\prime} s$ als bekende patiënten van de praktijk een aantal, voor zover we weten, innovatieve aspecten verbonden, zoals het aanmaken van patiëntenkaarten met gegevens over gefingeerde voorgaande consulten van $S P^{\prime}$ s in de patiëntenbestanden van praktijken. Daar kan aan toegevoegd worden, dat slechts in een minderheid van de gevallen onderwijsprogramma's op hun effectiviteit ten aanzien wan feitenkennis (competence) en reitelijk handelen (performance) worden getoetst in een voor-/nameting design. De door ons gevonden effecten in de experiment groep mogen als bemoedigend op het niveau van competence en opmerkelijk op performance niveau worden aangemerkt. Onze performance test had betrekking op het uiteindelijk resultat van het hele scala van kennis, vaardigheden en inzichten van haio's op het gebied van voeding. We hebben systeem- of persoonsgebonden invloeden op performance niet apart benoemd, en van het toetsen wan wardigheden op het gebied van communicatie en verandering van leefstijl hebben we met opzet afgezien. We bespreken de (als gunstig aan te merken afwezigheid van casusspecificiteit en de te verwachten specificiteit ten aanzien wan het voedingsdomein. We betogen dat het COO over voeding een idiosyncratische manier van oplossen van patiëntproblemen toelaat.

De belangrijkste onderwerpen woor verder onderzoek ornvatten het beklijven van het effect van het COO programma en de effectiviteit van het programma bij gebruik door praktiserende huisartsen. 
120 
APPENDIX

MAASTRICHT VERSION OF THE WAGENINGEN GPS NUTRITION PRACTICES QUESTIONNAIRE

(IN DUTCH) 


\section{Universiteit Maastricht}

Vakgroep Plisartsgeneeslande

\section{Haio en voeding}

Vragenlijst in het kader wan het NECTAR-onderzoek

Afdeling huisartsopleiding Maastricht

drs H.J.S. Maiburg, huisarts-onderzoeker

Nutrition

Education by

Computerized

Training

And

Research 


\section{Aanwijzingen voor het invullen van de vragenlijst}

\section{S.v.p. goed doorlezen}

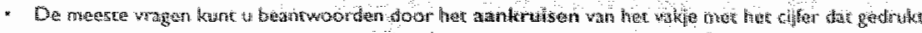

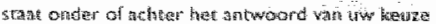

Voourtweld:

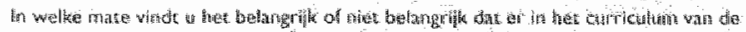

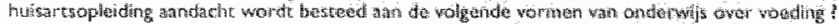

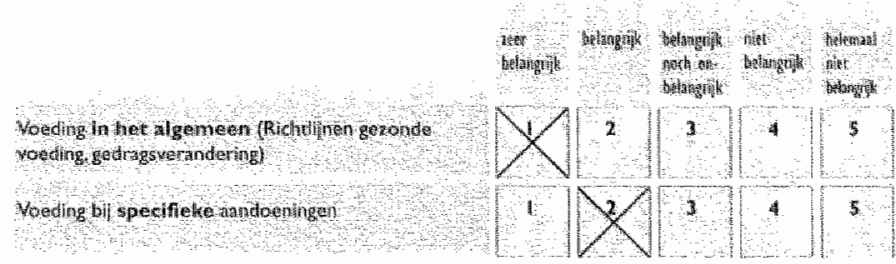

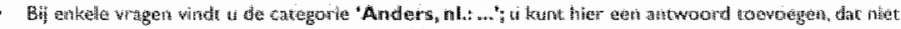

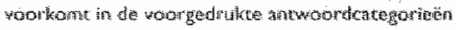

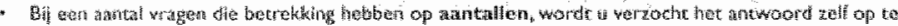

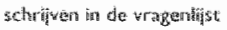

Met dank voor het invullen wan deze vragenlijst; veel succes! 


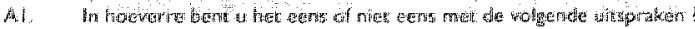

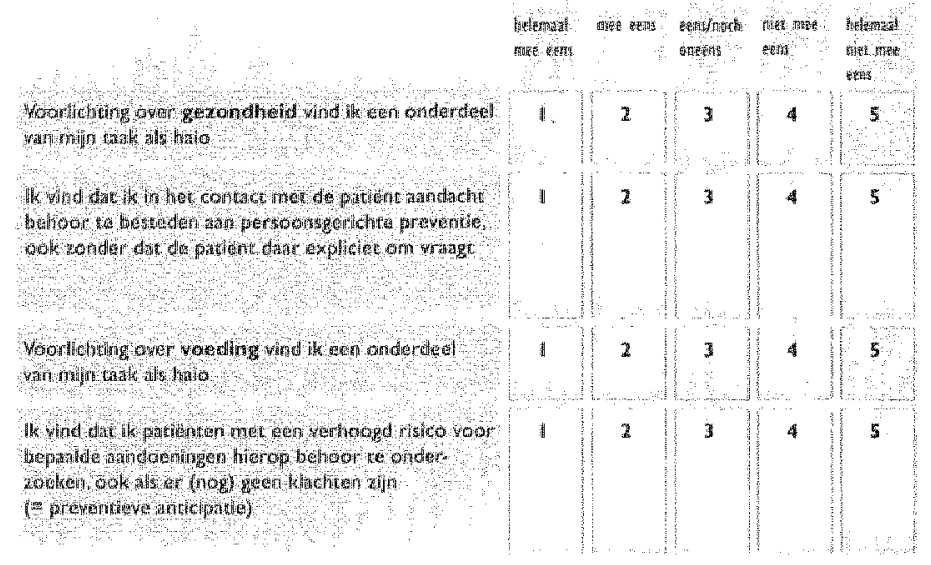

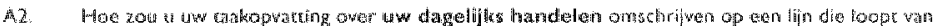

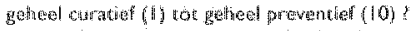

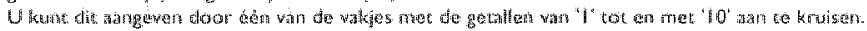

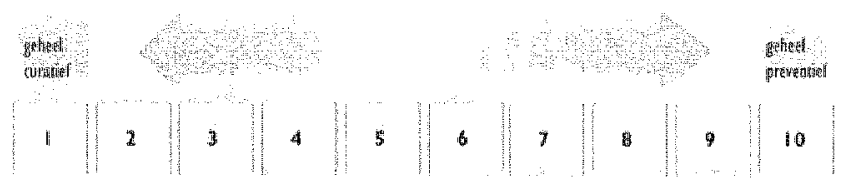

9. 10

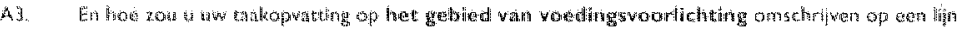

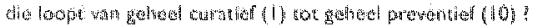

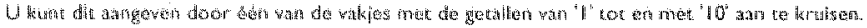

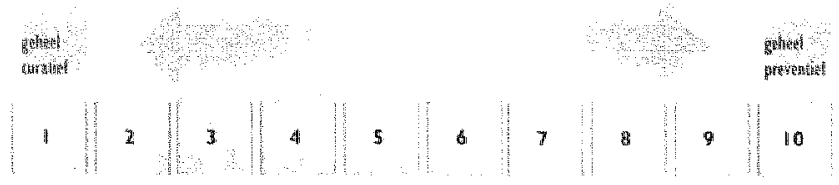



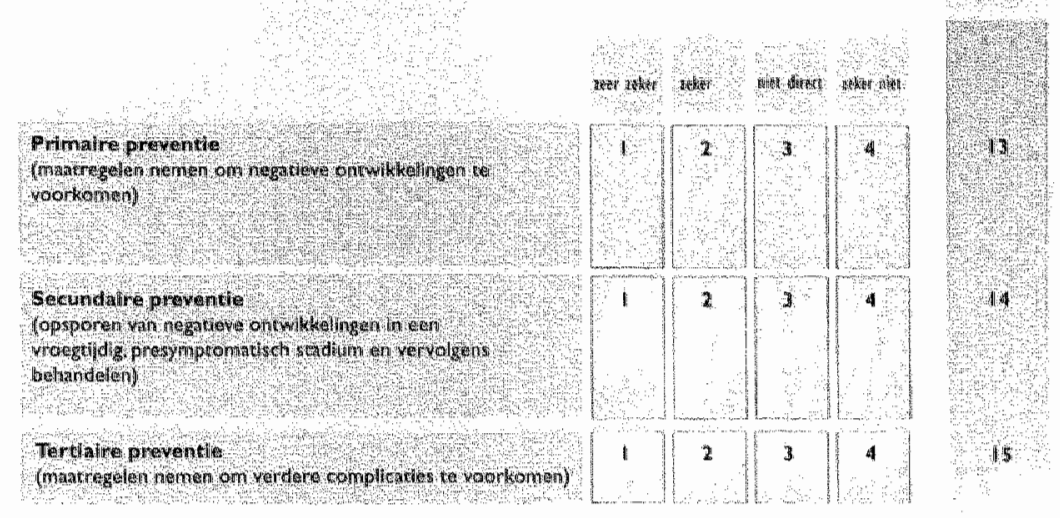

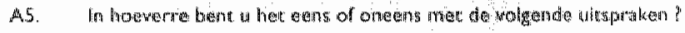

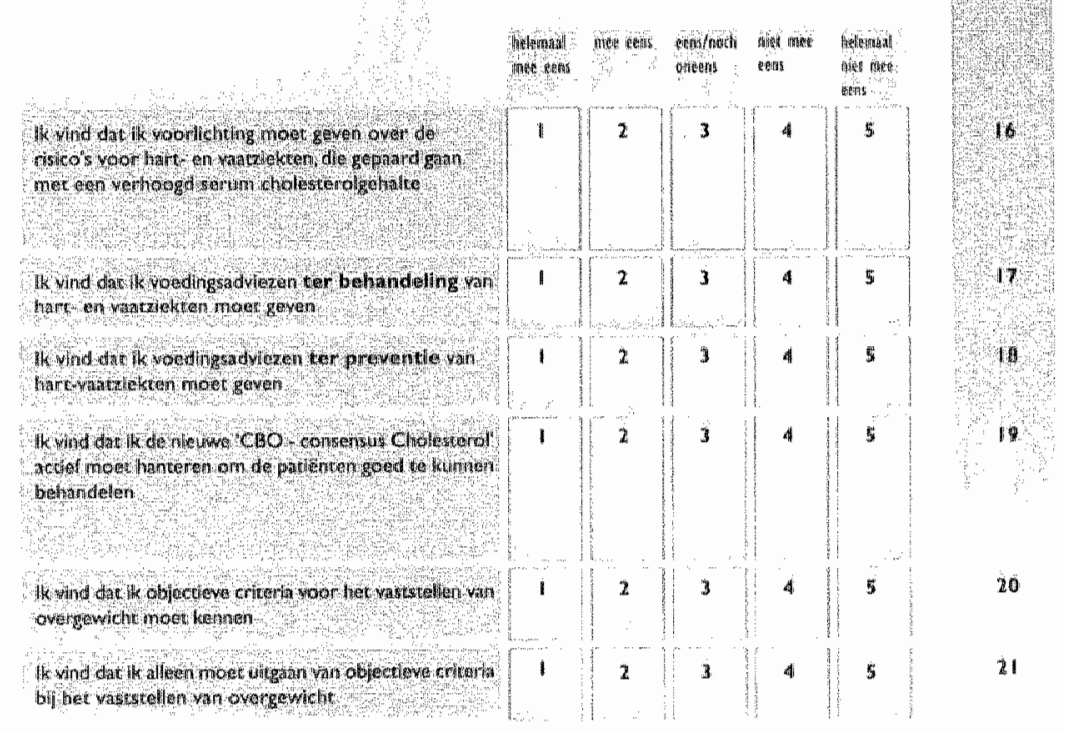




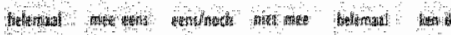

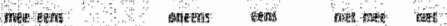

紋新
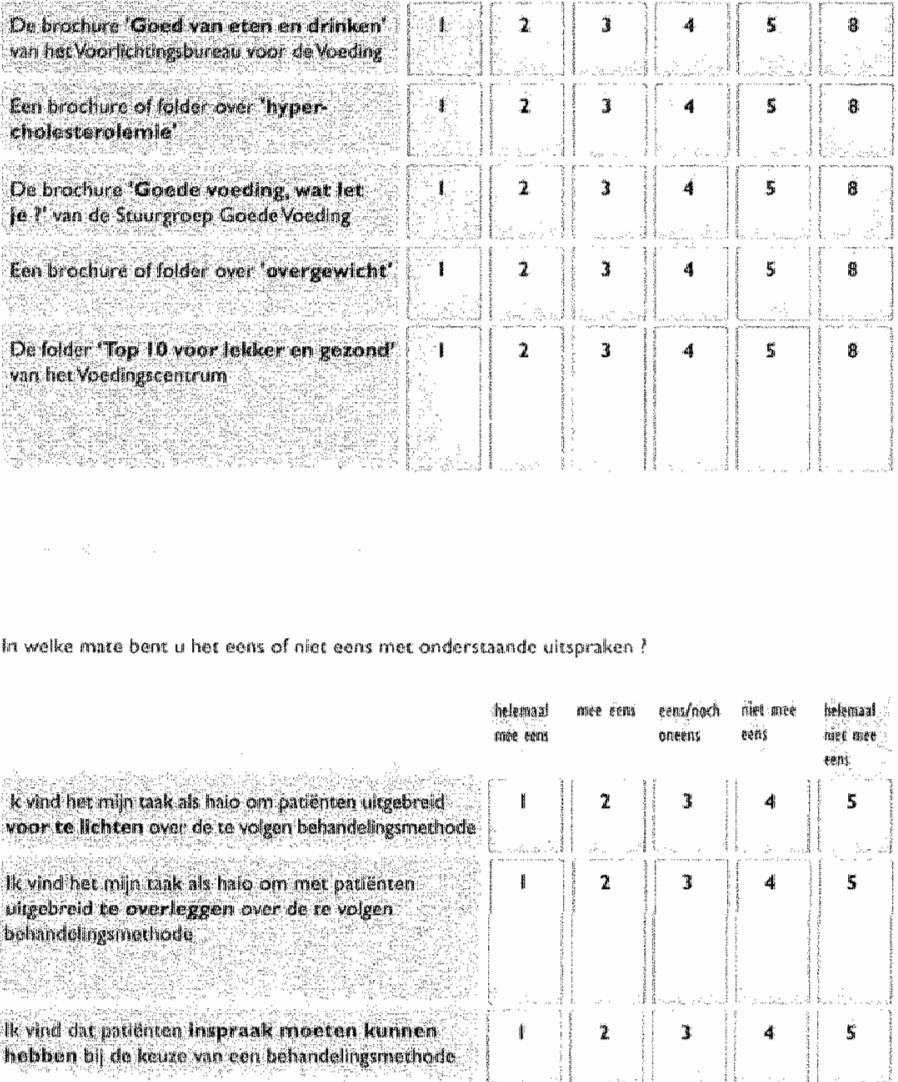

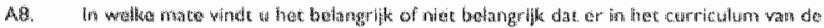

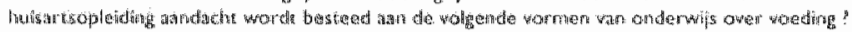

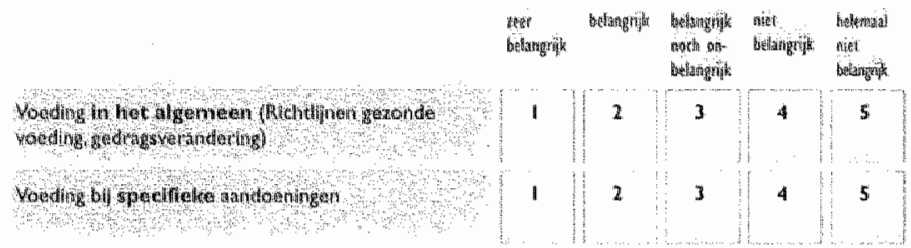



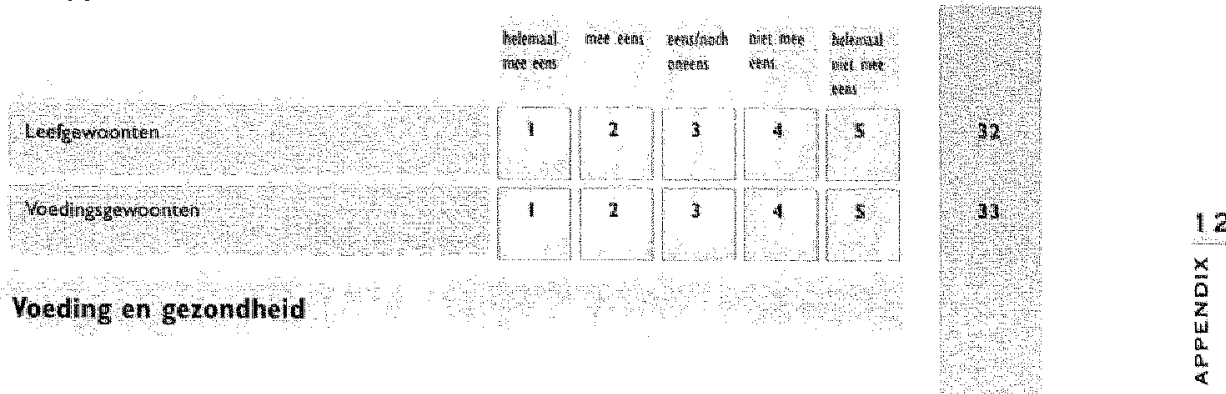

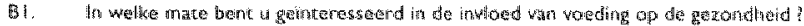

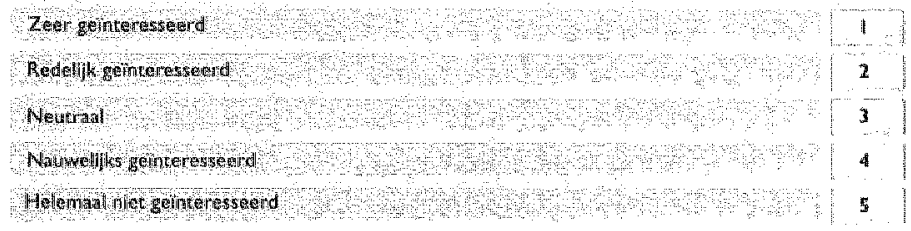

B Voeding en gezondheid

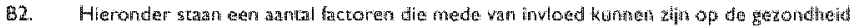

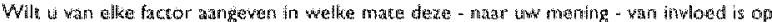

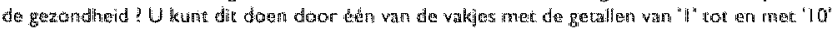
a ath te kritigen

\begin{tabular}{|c|c|c|c|c|c|c|c|c|c|c|c|}
\hline & 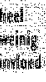 & & & & & & & & & beflots & \\
\hline How & 1 & 2 & 3 & 4 & 5 & 6 & 7 & 8 & 9 & 10 & 35.36 \\
\hline molaninger & 1 & 2 & 3 & 4 & 5 & 6 & $\pi$ & t & 9 & 10 & 178 \\
\hline 486 & 1 & 2 & 3 & 베 & 5 & 6 & $r$ & 8 & 9 & 10 & $39=40$ \\
\hline how & 1 & 2 & 3 & 4 & s & 6 & $\pi$ & 18 & 9 & 10 & 4142 \\
\hline Motate & 1 & 2 & 3 & 4 & 5 & 4 & $\pi$ & B & 9 & 10 & $43-44$ \\
\hline gakgas & I & 2 & 3 & 4 & 5 & 6 & $\pi$ & 0 & 9 & 10 & $45 \times 4$ \\
\hline Gediter & 1 & 2 & 3 & 4 & 穷 & 6 & 7 & 8 & 9 & 10 & A7 \\
\hline
\end{tabular}




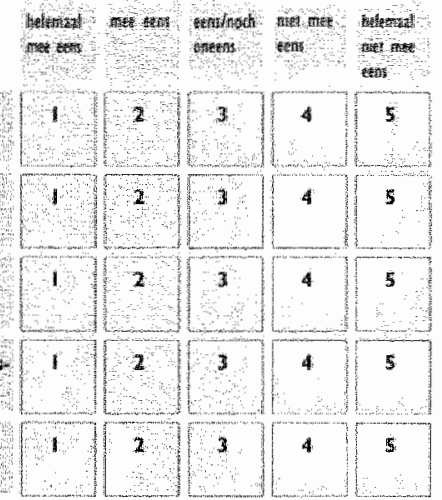

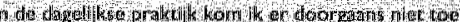

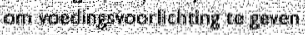

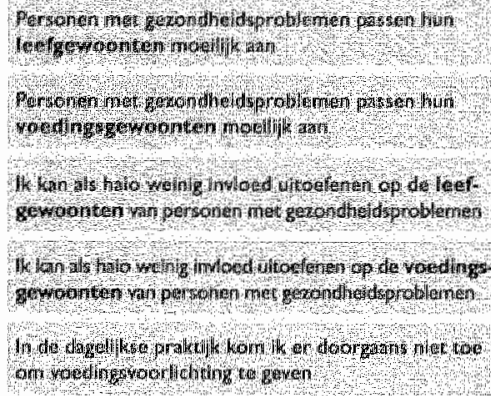

Bis.

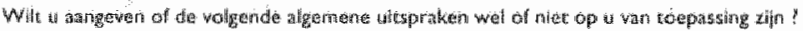
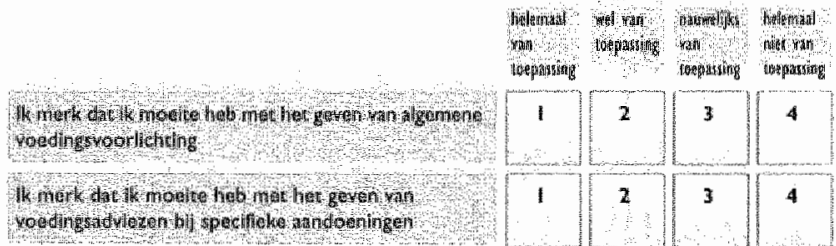

\begin{tabular}{|c|c|c|c|}
\hline I & 2 & 3 & 4 \\
\hline 1 & 2 & 3 & .4 \\
\hline
\end{tabular}

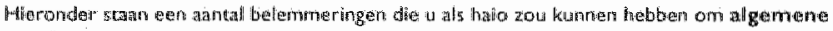
voedingsvoow it thithg the geven.

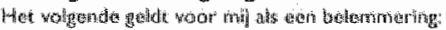

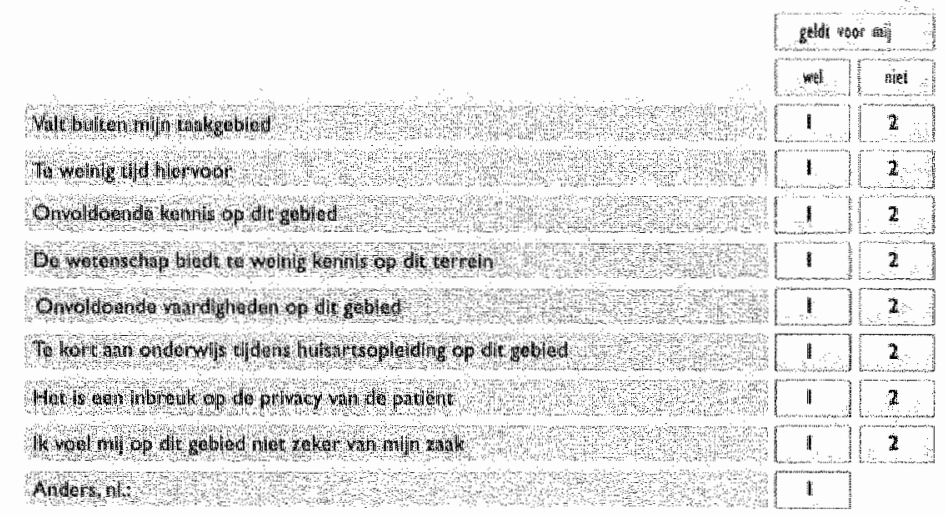




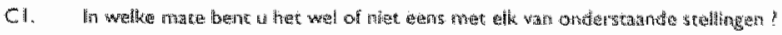

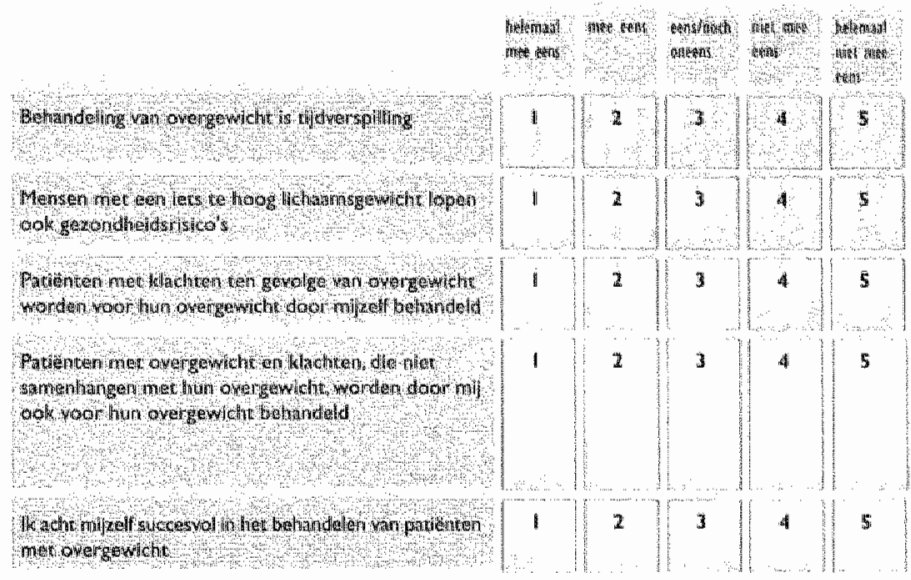

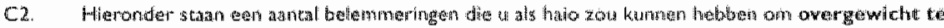

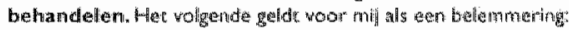

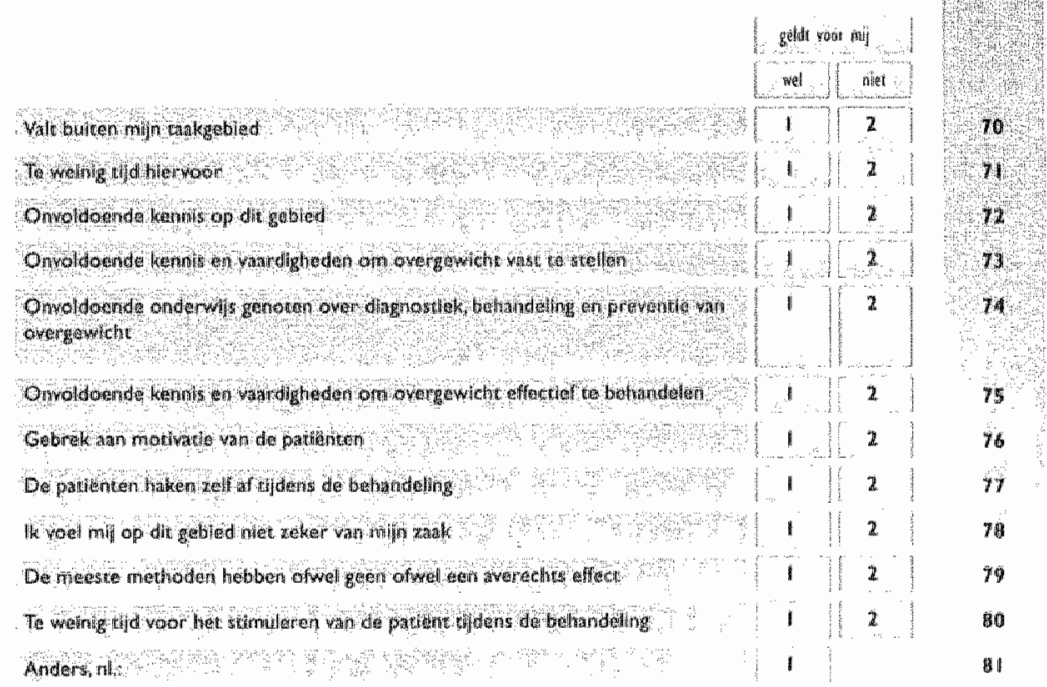




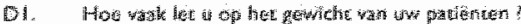
(act) antwoond

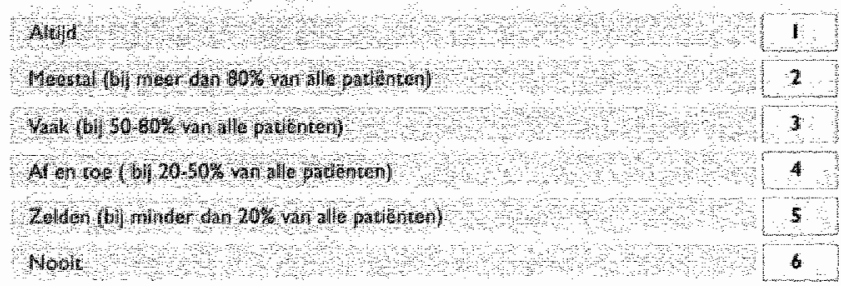

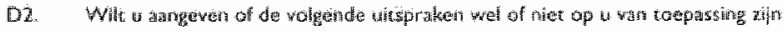
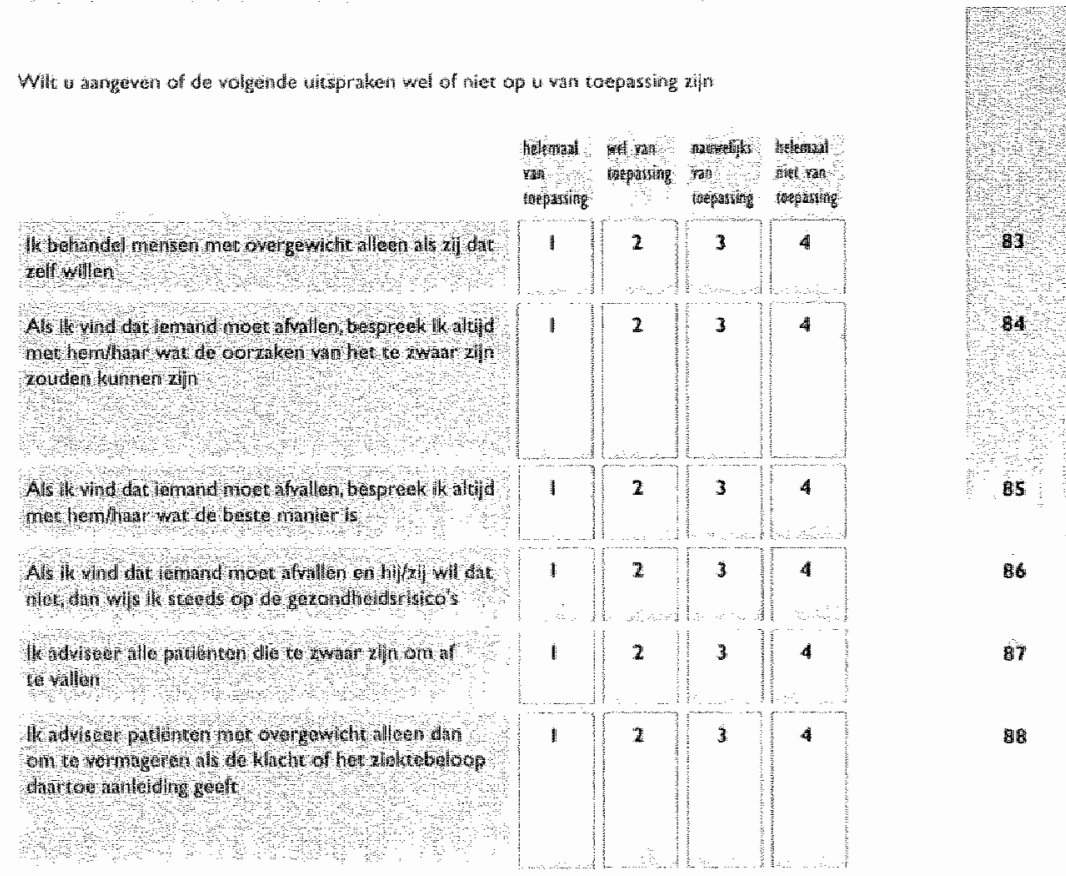


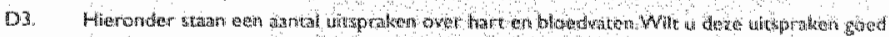

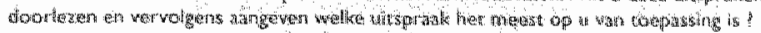

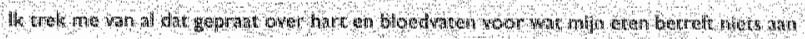

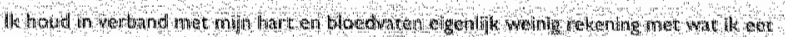

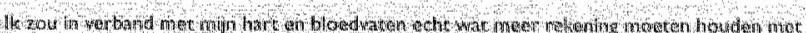

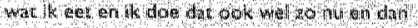

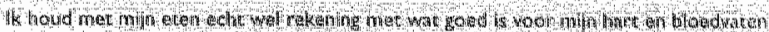

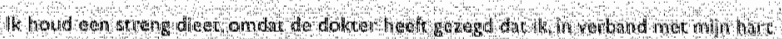

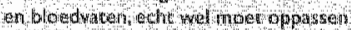

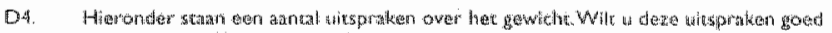

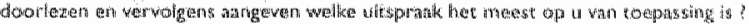

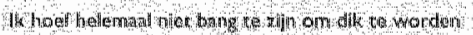

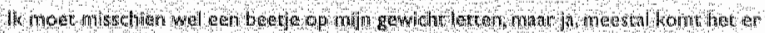
isterth

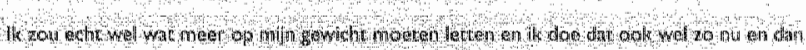

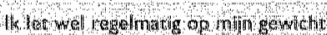

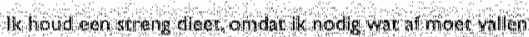

\section{E Behandeling en preventie wan hart- en vaatziekten in die} opleidingspraktijk

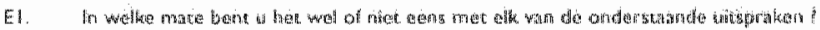

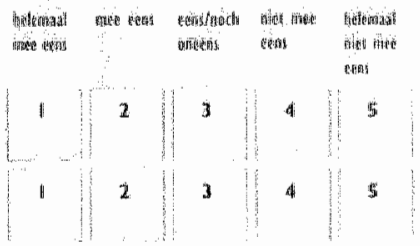

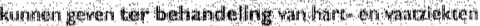

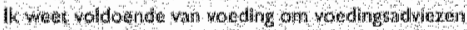

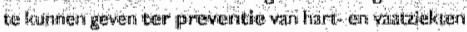




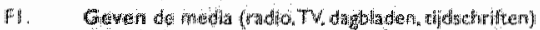

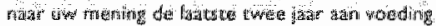

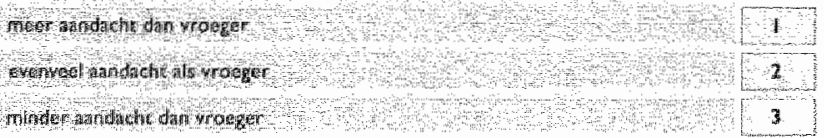

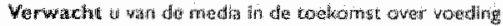

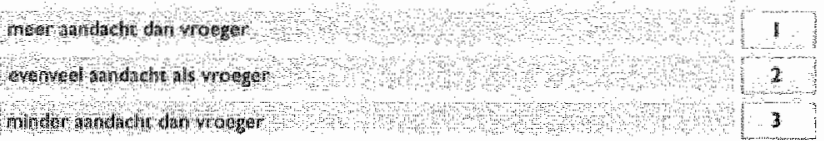

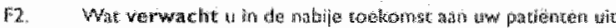

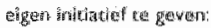

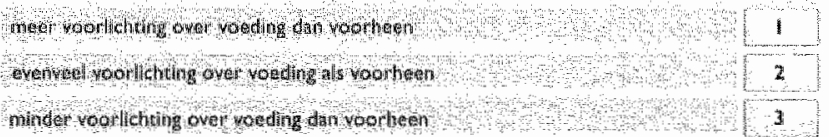

G. De dagelijksie gang van zaken in de opleidingspraktijlk betreffende voedingsvoorlichting

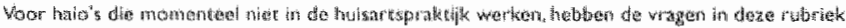

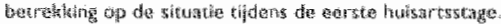

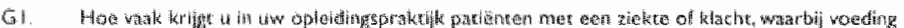

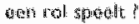

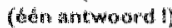

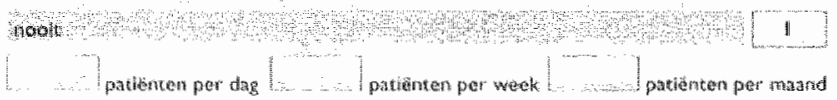




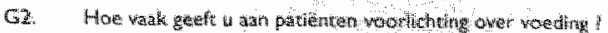

(écer an aroword)

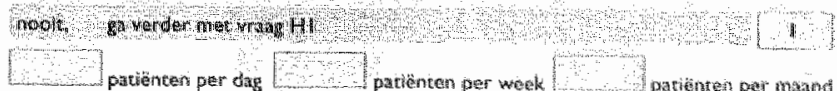

G. Is uw worlichtrige ower woieding im hac algemed

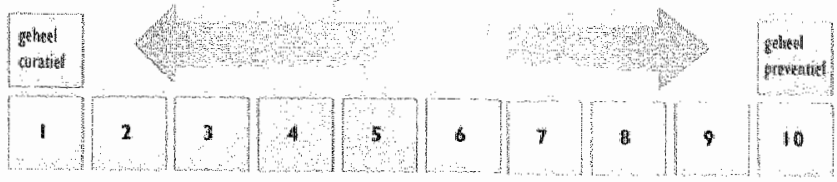

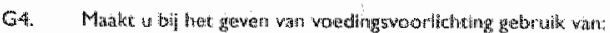

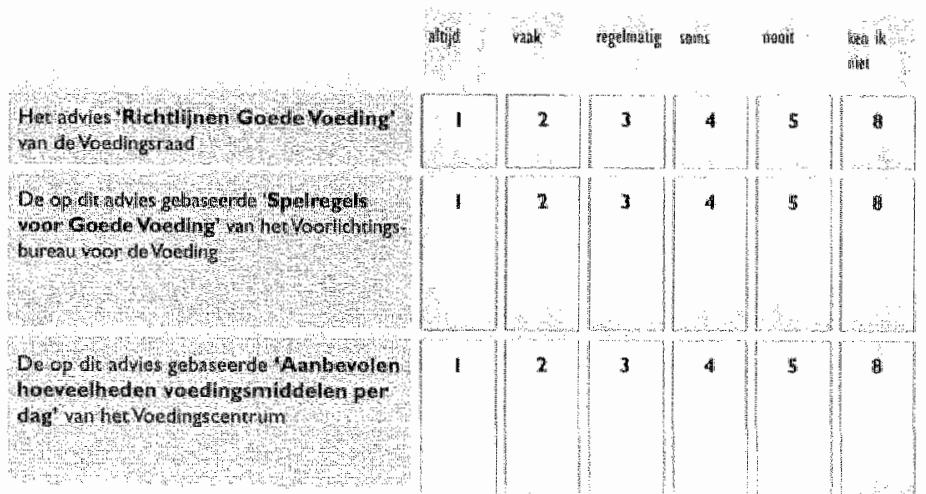

110.11

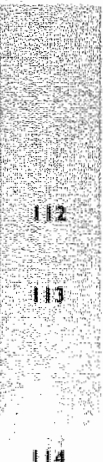

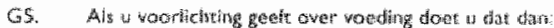

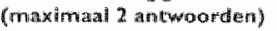

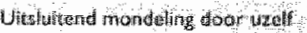

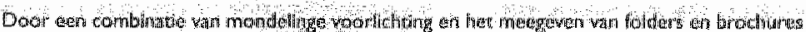

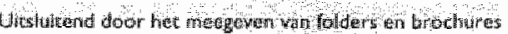

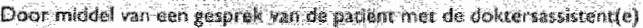

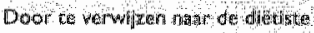




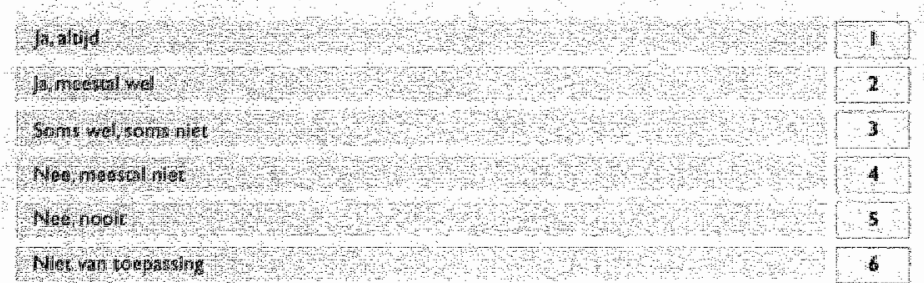

H. Persoonlike en opleidingspraktijk kenmerken

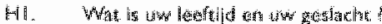
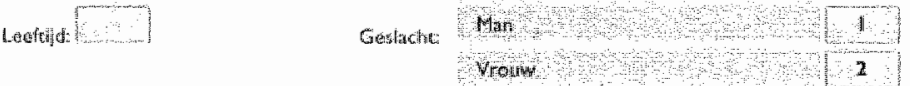

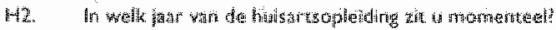

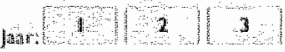

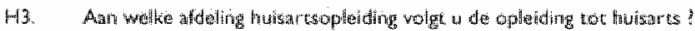

\begin{tabular}{|c|c|c|c|}
\hline 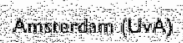 & 1 & Messtrehs & 5 \\
\hline 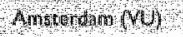 & 2 & Nomergen & 6 \\
\hline Conthingers & 3 & Aorradsm & 7 \\
\hline
\end{tabular}

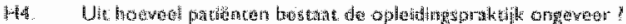

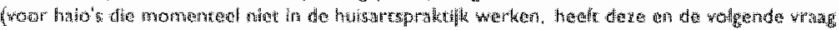

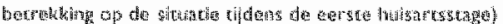

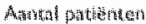

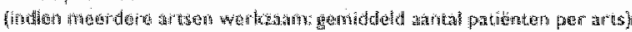

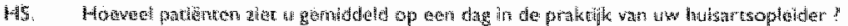

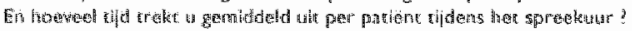

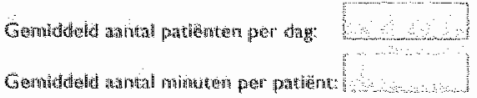

\section{Harrtelijk dank voor wiw medlewerking!}


DELPHI QUESTIONNAIRE ROUND ONE

(IN DUTCH) 

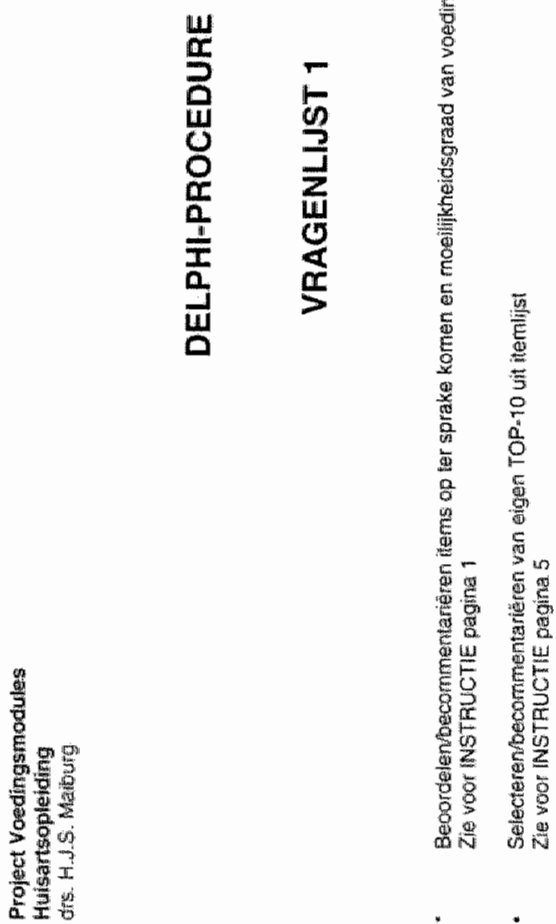


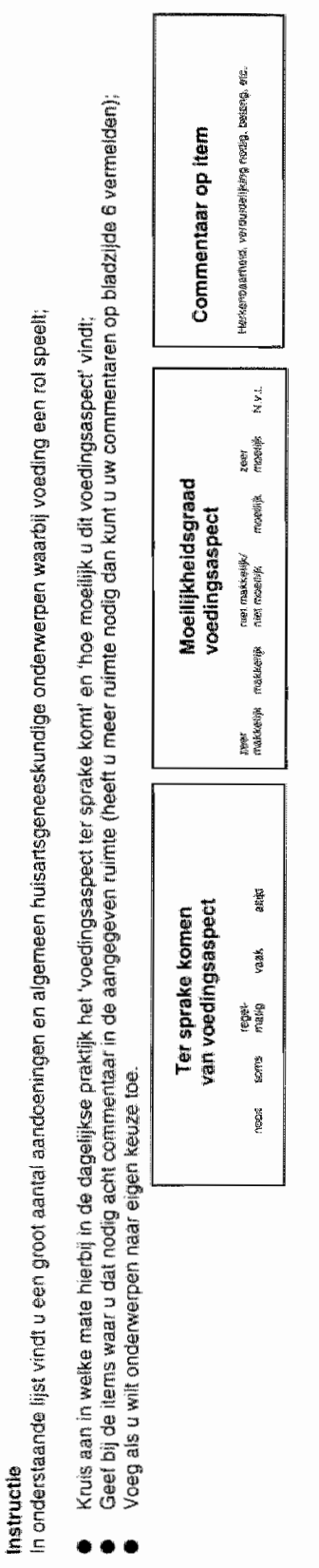

ロロロロコロ ロロロロロコロロロロロ

ロロコロコロ ロロロロロロロロロロロ

ロロロロロロ ロロロロロロロロロロロ

ロロロロロロ ロロロロロロロロロロロ

ロロコロロ ロロロロロロロロロコロ

ロコロロロコ ロロロコロロロロロロロ

ロロロロロロ ロロロロロロロロコロ

ロロロロロロ ロロロロコロロロコロ ロロロロロロ ロロコロロロロロロロa ロロロロロコ ロロロロロロロロロロロ ロロロロロロ ロロロロロロコロロロa

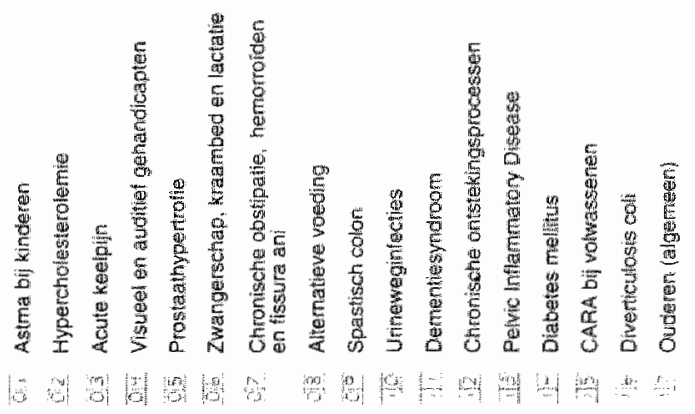



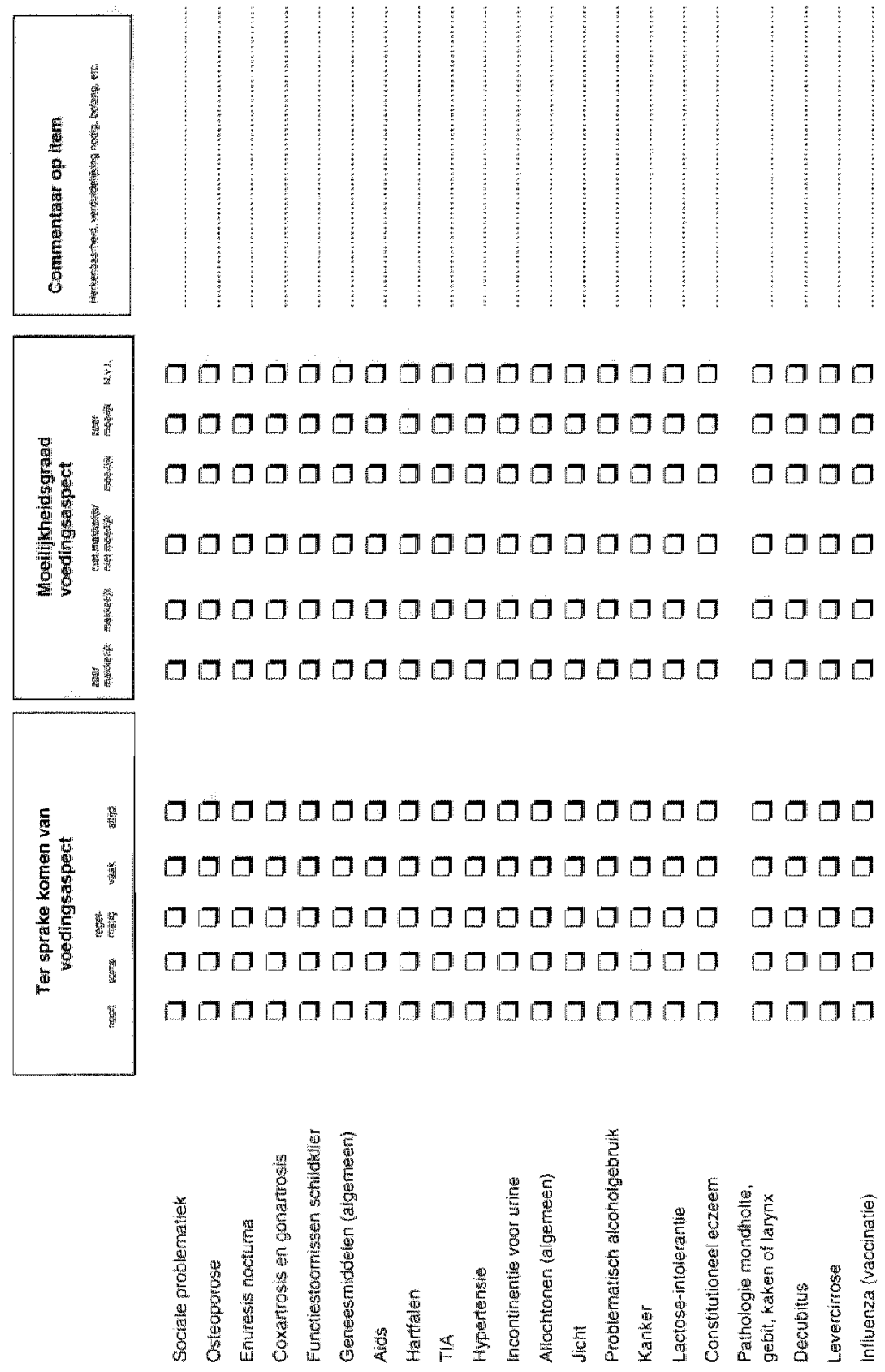

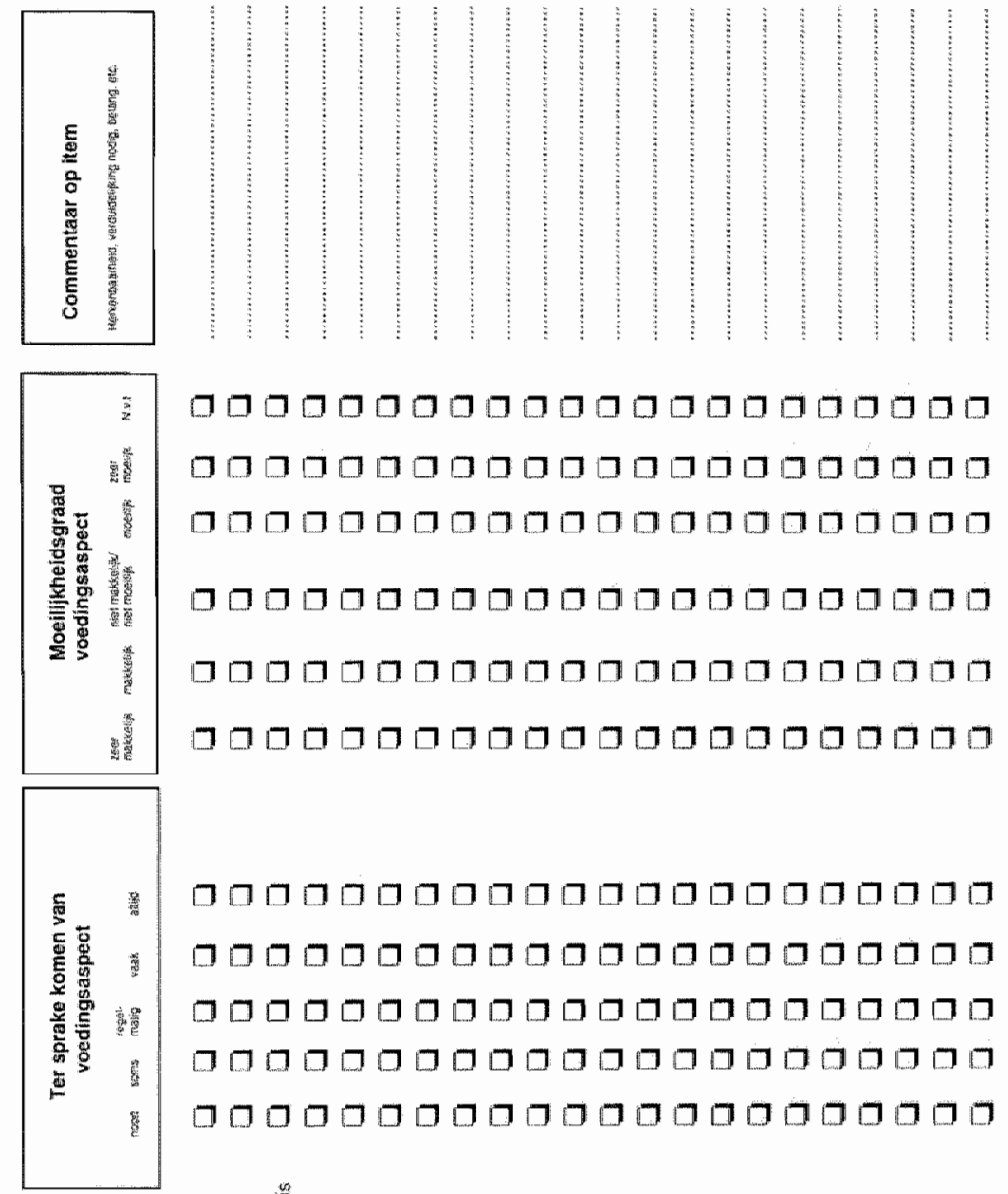

ロロコロロロロロコロロロロロロロコロロロコ コロロロロロロロコロロロロロロロロロロロロ ロロロロロロロロロロロロロロロロロロロロロ

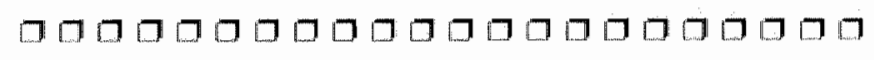

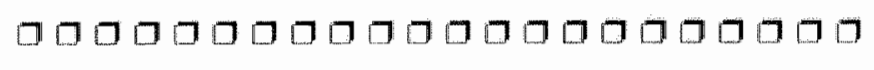

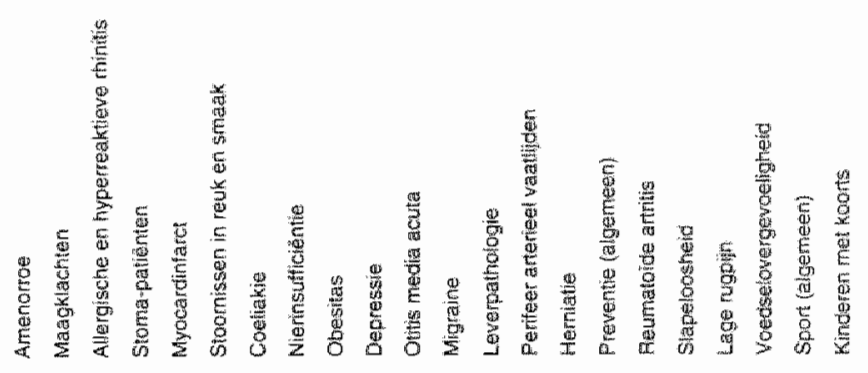



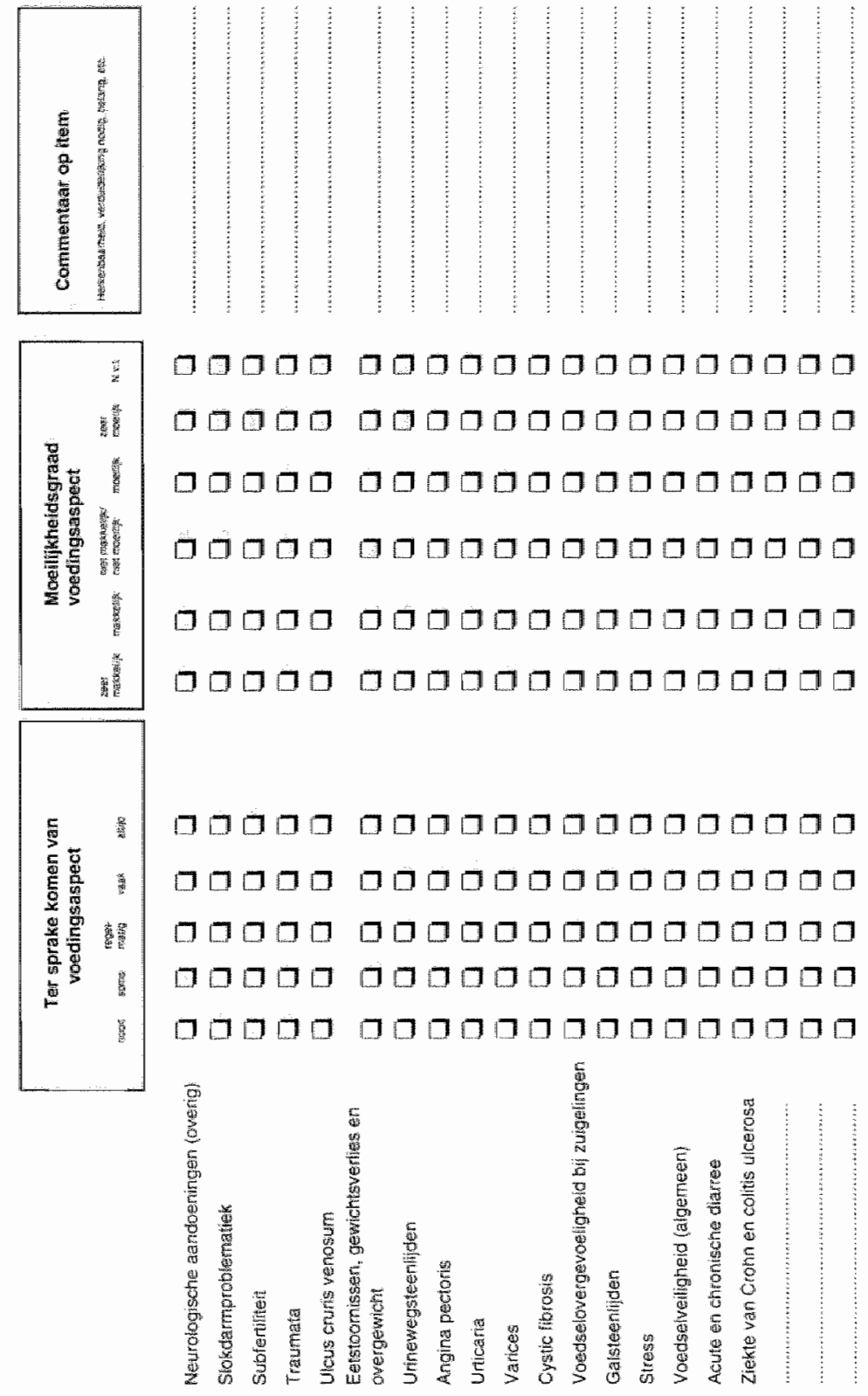


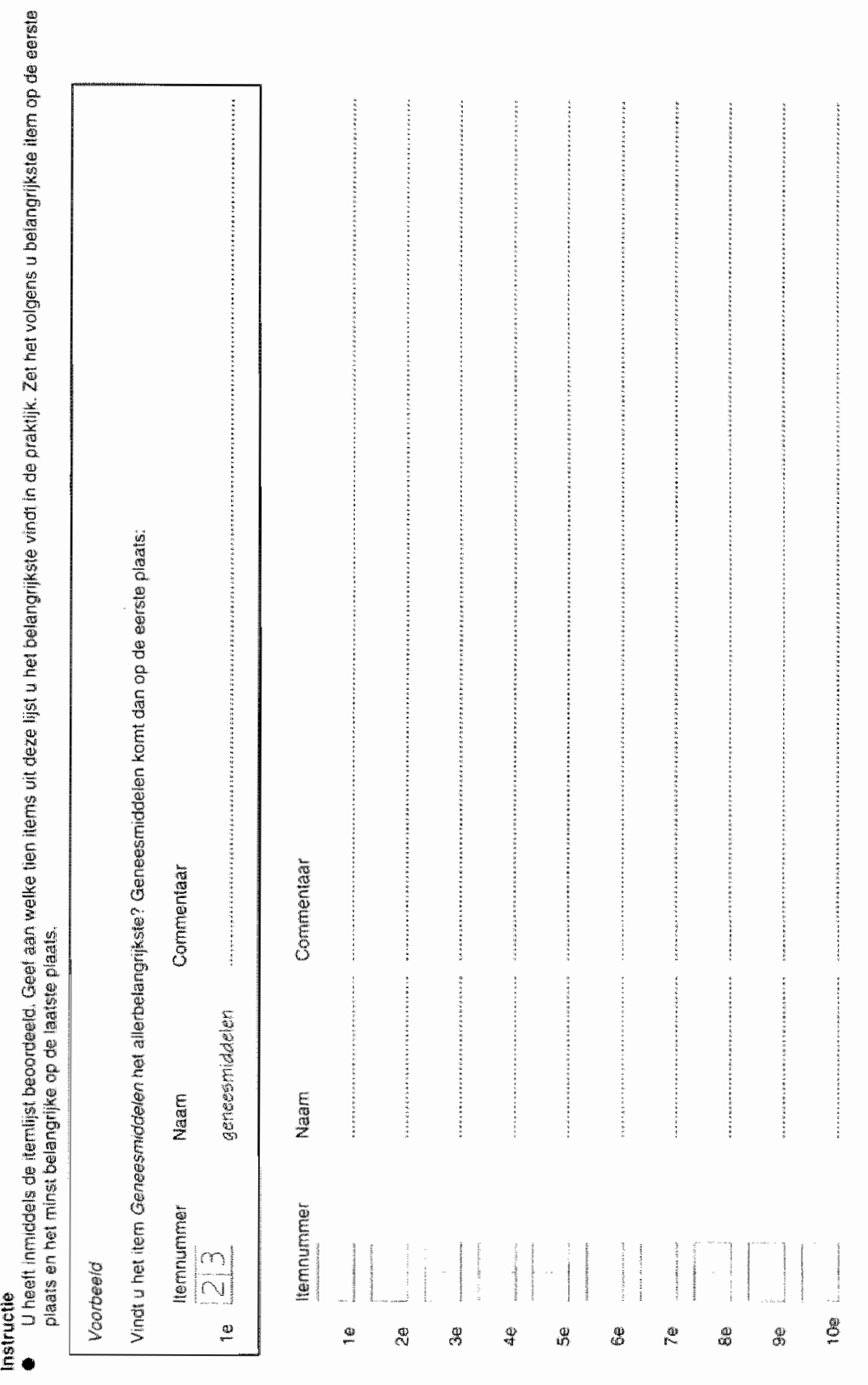

$\frac{141}{x}$ 
142

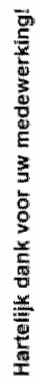




\section{DANKWOORD}

143
0
0
0
3
$\frac{3}{2}$
$\frac{1}{0}$
$\frac{1}{0}$ 
Aan de ontwikkeling van het computerondersteund onderwijsprogramma over woeding en het vaststellen wan de effecten ervan hebben velen bijgedragen. De kwalificatie van hat NECTAR project als "a strong, exciting piece of research" door een gastredacteur van het American Joumal of Climical Nutrition is de gezamenlijke verdienste van al deze personen. ledereen die meegewerkt heeft aan het project wil ik dan ook hartelijk bedanken!

Eric van Wylick ondersteunde het Delphi-onderzaek door zijn aandeel in de dataverwerking en het vormgeven van de vragenlijsten voor de huisartsen. Vanzelfsprekend was de Delphi niet mogelijk geweest zonder de deelname van een veertigtal huisartsen verspreid over Nederland.

Bijna zeshonderd huisartsen-in-opleiding (haio's) hebben de enquête over het handelen rond voedingsvragen van patiënten ingevuld en teruggestuurd. Dit was niet mogelijk geweest zonder de onbaatzuchtige medewerking van vele huisartsbegeleiders, gedragswetenschappers en secretariaatsmedewerkers van alle acht opleidingsinstituten.

Bij de dataverwerking van de enquête hebben de dames van het Memic, onder leiding van Gertie Wijnands, fraai werk afgeleverd. De data-analyse werd voortvarend door Martin van 't Hof, statisticus, ter hand genomen.

Het ontmoeten van André Koehorst, onderwijs-technoloog, op een onderwijsmiddag van de Universiteit Maastricht heeft uiteindelijk geleid tot het computerondersteund onderwijsprogramma over voeding. Het eind van de samenwerking is overigens nog niet in zicht. Zonder hem had dit proefschrift er anders uit gezien.

Met een goed programma is het prettig werken. Los van de gemeten effecten kan gesteld worden dat alle 49 haio's die als proefpersonen fungeerden op een geweldige manier meegewerkt hebben.

Evenveel dank gaat natuurlijk uit naar de 50 huisartsopleiders en hun assistentes waar bovenstaande haio's in opleiding waren. Zij zaten niet alleen in het complot van de simulatiepatiënten, maar stelden hun praktijk ook beschikbaar voor het experiment.

De voorbereiding van het veldwerk voor de praktijkmeting komt voor het leeuwendeel op het conto van Ingrid van Erk. Gekomen als derdejaars student geneeskunde en bijna wee jaar gebleven.

Niet te vergeten zijn de 14 simulatiepatiënten die door Limburg en omstreken trokken om op het spreekuur van haio's te verschijnen. Van leek tot simulatiepatiènt in twee dagen. De spreekuubezoeken leverden mooie verhalen op, maar in de voorbereiding (afspraken maken) en uitvoering (reizen, wachten in praktijk, consulten uitvoeren, checklists invullen) gingen heel wat zweetdruppels en uren zitten.

Voor het verwerken van de lijsten van de simulatiepatiënten kon ik weer een beroep doen op het Memic: naast een perfecte invoer, zorgde Gregor Franssen in een handomdraai voor een bewerkbaar databestand. Op Arnold Kester kon ik altijd een beroep doen bij voor mij onoplosbare analyse- en statistiekvraagstukken.

Het omzetten van data in Engelse tekst was geen sinecure. Daarbij heeft Carol Herman mij over de eerste drempels van artikelen en presentaties in het Engels heen geholpen. 
Jan Klerkx heeft uiteindelijk gezorgd voor zowel perfecte Engelse als Amerikaanse teksten in het proefschrift.

De aanwezigheid van Lambert Schuwirth zorgde niet alleen voor pittige, inhoudelijke discussies in de projectgroep. Zijn (individuele) mini-colleges waren voor mij witerst leerzaam. Jan-Joost Rethans heeft het overgrote deel van mijn begeleiding op zich genomen. Hij heeft ervooir gezorgd dat ik niet geheel de solotoer op ging. Naast een creatief deskundige was hij (o.a. tijdens een weetal internationale congressen) een zeer prettige reispartner. Hij heeft het begeleiderstokje overgenomen van Yvonne van Leeuwen. Zij moedigde mij aan bij de eerste wankele schreden op het onderzoekspad en heeft mij met vernieuwende ideeën op (de) weg (van computerondersteund onderwijs) gestuurd.

Het project werd aangestuurd door de landelijke stuurgroep onder voorzitterschap van Arnold Balfoort. Hij was het die het project, samen met lan wan Ree in gang gezet heeft. Hij wist een prima groep om zich heen te verzamelen. Zo heeft Lara van Aalst uitgebreid meegedacht over de ontwikkeling van het computerprogramma. Jaap van Binsbergen was de echte generalist binnen de groep: van deskundige op voedingsgebied tot begaafd acteur in de video's van het programma. Een van de belangrijkste motoren achter het project was Gert-Jan Hiddink: een belangrijk meedenker bij opzet en analyse en ook steeds vooruitdenkend.

Theo Ockhuizen maakte het mogelijk dat het project op adequate wijze kon worden afgewerkt en Janine Messing-Verheesen maktte het karwei van Arnold Balfoort af.

De steun van mijn collegae bij de Huisartsopleiding was onontbeerlijk om binnen deze steeds groeiende groep het project te kunnen uitvoeren.

Een bijzonder woord van dank is op zijn plaats voor Jan van Ree als mijn promotor. Hij heeft het project promotie-waardig gemakkt en mij aan het eind de juiste zetjes in de goede richting gegeven.

Lisbeth Mathus-Vliegen, promotor op afstand, leerde mij wat voedingsonderwijs inhoudt en oefende door haar opbouwende kritiek op de diverse versies van arlikelen een grote invloed op de uiteindelijke inhoud van dit proefschrift uit.

Onze kinderen Merel, Joost en Carlijn hebben niet alleen in uitvoerende zin bijge. dragen alan mijn onderzoek, maar hebben ook de consequenties weten te verduren van mijn beginnende kennis op voedingsgebied. Petra heeft met har vermogen lot relativeren gedurende het hele project mijn plannen, ambities en werkzamheden (met uitzondering van het laatste half jaar) binnen de perken weten te houden. 
1.46 


\section{CURRICULUM VITAE}

Bas Maiburg was born in Utrecht, the Netherlands; on October $6^{\text {th }}$, 1954. He completed secondary school at the Sint-Janslyceum in 's-Hertogenbosch in 1973. In the same year, he entered medical school at the Catholic University of Leuven, Belgium, were he graduated in 1980. He started training as a general practitioner at the Department of General Practice of Erasmus University Rotterdam in 1981. From 1983 until 1988, he worked as a general practitioner in Eind hoven. He then moved to Maastricht University, where he first worked as a trainer at the Skillslab Department. In 1991, he started work as general practitioner trainer at the Department of General Practice in Maastricht and as a general practitioner in Heerlen. He left the practice in 1997, and attended a two-year research training course for general practitioners in Flanders and the Netherlands. At the same time, he conducted the studies presented in this thesis. He now works as a coordinator of vocational training at the Department of General Practice in Maastricht. 